National

\title{
NAS-NS
}

3115

Academy

of

Sciences

National Research Council

D

NUCLEAR SCIENCE SERIES

Radiochemical Techniques

\section{Users' Guides for \\ Radioactivity Standards}

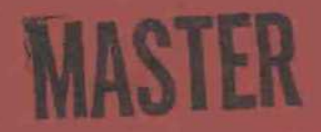

Published by

Technical Information Center, Office of Information Services

UNITED STATES ATOMIC ENERGY COMMISSION 


\section{COMMITTEE ON NUCLEAR SCIENCE}

D. A. Bromley, Chairman, Yale University

C. K. Reed, Executive Secretary, National Academy of Sciences

Victor P. Bond, Brookhaven National Laboratory

Gregory R. Choppin, Florida State University

Herman Feshbach, Massachusetts Institute of Technoiogy

Russell L. Heath, Aerojet Nuclear Co., Inc.

Bernd Kahn, National Environmental Research Center, EPA

Joseph Weneser, Brookhaven National Laboratory

Sheldon Wolff, University of California Medical Center

\section{Members-at-Large}

John R. Huizenga, University of Rochester

G. C. Phillips, Rice University

Alexander Zucker, Oak Ridge National Laboratory

\section{Liaison Members}

John McElhinney. Naval Research Laboratory

William S. Rodiney, National Science Foundation

George Rogosa, U.S. Atomic Energy Commission

\section{Subcommittee on Radiochemistry}

Gregory R. Choppin, Chairman, Florida State University Raymond Davis, Jr., Brookhaven National Laboratory

Glen E. Gordon, University of Maryland

Rolfe Herber, Rutgers University

John A. Miskel, Lawrence Radiation Laboratory

G. D. O'Kelley, Oak Ridge National Laboratory

Fichard W. Perkins, Pacific Northwest Laboratory

Andrew F. Stehney, Argonne National Laboratory

Kurt Wolfsberg. Los Alamos Scientific Laboratory

\section{Subcommittee on the Use of Radioactivity Standards}

Bernd Kahn, Chairman, National Environmental Research Center, EPA A. P. Baerg, National Research Council, Ottawa, Ontario, Canada

J. Calvin Brantley, New England Nuclear Corp., Boston, Mass.

Gregory R. Choppin, Florida State University

James S. Eldridge, Oak Ridge National Laboratory

Kevin F. Flynn, Argonne National Laboratory

Robert C. Koch, International Chemical and Nuciear Corp., Irvine, Calif.

Wilfred B. Mann, National Bureau of Standards

Samuel A. Reynolds, Oak Ridge National Laboratory 


\section{DISCLAIMER}

This report was prepared as an account of work sponsored by an agency of the United States Government. Neither the United States Government nor any agency Thereof, nor any of their employees, makes any warranty, express or implied, or assumes any legal liability or responsibility for the accuracy, completeness, or usefulness of any information, apparatus, product, or process disclosed, or represents that its use would not infringe privately owned rights. Reference herein to any specific commercial product, process, or service by trade name, trademark, manufacturer, or otherwise does not necessarily constitute or imply its endorsement, recommendation, or favoring by the United States Government or any agency thereof. The views and opinions of authors expressed herein do not necessarily state or reflect those of the United States Government or any agency thereof. 


\section{DISCLAIMER}

Portions of this document may be illegible in electronic image products. Images are produced from the best available original document. 


\title{
Users' Guides for Radioactivity Standards
}

\author{
Prepared by the Subcommittee on Radiochemistry \\ and the Subcommittee on the Use of Radioactivity Standards
}

\author{
Committee on Nuclear Science \\ National Academy of Sciences-National Research Council
}

NOTICE

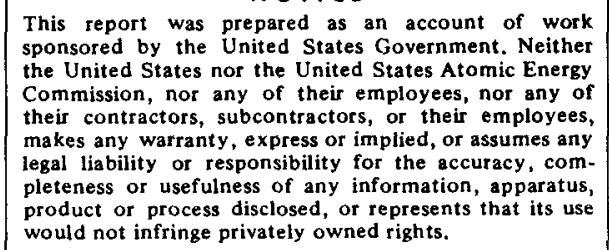

Issuance Date: February 1974

Published by

Technical Information Center, Office of Information Services UNITED STATES ATOMIC ENERGY COMMISSION 


\section{NOTE ON THE REVISED EDITION}

Thıs compilation was origınally written by B. Kahn, G. R. Choppın, and J. G. V. Taylor and published in October 1967 by The Natıonal Academy of Sciences-National Research Council. The present revised edition was compiled by the Members of the Subcommittee on Radiochemistry of The Committee on Nuclear Science. The assistance of the Subcommittee on Use of Radioactivity Standards, B. Kahn, Chaırman, and of S. A. Reynolds, Oak Ridge Natıonal Laboratory, is gratefully acknowledged.

\section{R. H. Herber \\ Editor, revisıon}

Price $\$ 300$, which is the minimum order price for either one, two, or three randomly selected publications in the NAS NS series Additional individual copies will be sold in increments of three for $\$ 300$ Avallable from

National Technical Information Service

U S Department of Commerce

Sprıngfıeld, Vırgınıa 22151

Printed in the United States of America 


\section{Foreword}

The Subcommittee on Radiochemistry is one of a number of subcommittees working under the Committee on Nuclear Science within the National Academy of Sciences-National Research Council. Its members represent government, industrial, and university laboratories in the areas of nuclear chemistry and analytical chemistry.

The Subcommittee has concerned itself with those areas of nuclear science which involve the chemist, such as the collection and distribution of radiochemical procedures, the radiochemical purity of reagents, the place of radiochemistry in college and university programs, and radiochemistry in environmental science.

This series of monographs has grown out of the need for compilations of radiochemical information, procedures, and techniques. The Subcommittee has endeavored to present a series that will be of maximum use to the working scientist. Each monograph presents pertinent information required for radiochemical work with an individual element or with a specialized technique.

Experts in the particular radiochemical technique have written the monographs. The Atomic Energy Commission has sponsored the printing of the series.

The Subcommittee is confident these publications will be useful not only to radiochemists but also to research workers in other fields such as physics, biochemistry, or medicine who wish to use radiochemical techniques to solve specific problems.

Gregory R. Choppin, Chairman

Subcommittee on Radiochemistry 


\section{Users' Guides for Radioactivity Standards}

Radioactive tracers have shown themselves to be so convenient for solving problems in the physical sciences, biology, medicine and industry that they are often used by experimenters who are unfamiliar with the chemical behavior or nuclear decay characteristics of the substance. Moreover, even specialization in the field does not prevent occasional circumstances that lead to losses of the radionuclides during storage, dilution, chemical separation, and deposition, or to erroneous radioactivity measurements. To aid users of radioactive materials, to whom such errors would be especially unwelcome, we have prepared these short guides to chemical and counting problems for standards that are in common use or are expected to be available.

The Users' Guides are prepared separately for every element, so that the user need only consult a few paragraphs. It is hoped that this presentation will make each set of problems immediately evident. The discussions are, of course, far too brief to provide adequate information on the chemical and nuclear decay properties of the substances; and the monographs ${ }^{2}$ prepared by the Radiochemistry Subcommittee, NAS-NRC, and Nuclear Data Sheets ${ }^{2}$ should be consulted for this purpose. Brief summaries of chemical properties are also available. ${ }^{3}$

A radioactivity standard, or standard reference material (SRM) for radioactivity, is a preparation containing a known activity of a particular radiation. Techniques for preparting standards have been described elsewhere, $4^{-6}$ and will not be included here. A SRM may be in the form of a solution, point source, or solid (or gas, e.g., ${ }^{85} \mathrm{Kr}$ ). Solutions are generally preferable, and will be emphasized. Chemical considerations may be important except for point sources, and physical items such as decay schemes and counter performance are important for all types.

Many users require calibrations for only a few common nuclides, and need standards for all. Others who must measure many gamma emitters, for example, may find it necessary to establish energy-response curves for their instruments, and calculate efficiencies for nuclides for which SRMs are not available. Some ionization-chamber ${ }^{4} 7$ and scintillation ${ }^{8,9}$ devices are sufficiently uniform in manufacture to permit use of common "factors" or curves, with confirmation by only a few SRMs.

The National Bureau of Standards (NBS) is the only supplier of SRMs ${ }^{10}$ and calibration services ${ }^{11}$ in the United States established by statute, but other suppliers exist, both good and bad. ${ }^{12}$ A certificate must be supplied with a standard, and should meet the requirements of the National Research Council. ${ }^{13}$ A U.S. supplier should give evidence of traceability of his measurement to a standard or calibration by NBS.

It is assumed that many significant chemical problems have been omitted because the authors have not encountered them directly or in the literature. For example, radiocolloidal problems-deposition of radionuclides on surfaces and dust particles, nonhomogeneous distribution in solution, etc. ${ }^{14}$ undoubtedly occur under conditions that have not been discussed. Impurities are a function of radionuclide preparation. The user should convince himself in each case that the system he is using is sufficiently well understood that these problems (i.e.: chemical behavior at carrier free levels, colloid formation, etc.) can be appropriately dealt with.

Since these guides are intended for users of radioactivity standards, it 
is assumed that the reader is interested in exploiting the full accuracy of the available standards. Neglect of some of the suggested precautions might lead to errors of only a few percent or less while the neglect of others (particularly warnings about adsorption, volatility, hydrolysis, etc.) could be much more serious.

Radioactivity standards are usually supplied in flame-sealed ampoules. Before opening, the ampoule should be inverted for a moment and then tapped until no liquid remains in the tip. On opening, the contents should be transferred immediately to a dry flask or vial fitted with a greased or Teflon sleeve covered ground-glass stopper. The size of flask should be chosen so the standard will more than half fill it. These precautions will help to avoid diluting or concentrating the solution unknowingly.

As a rule, standards are prepared in media and at carrier concentrations which the supplier believes will give optimum stability. In preparing a dilution, the diluent should therefore have the same carrier concentration and composition as the original solution. Note also that if dilutions are prepared gravimetrically and aliquots taken volumetrically (or vice versa) and if the density of the diluent differs from that of the original solutions, then the dilution factor involves the density ratio. If the density of a solution is not known, the same method should be used for diluting and aliquoting.

Long-lived standards may be conserved by using them to prepare secondary or reference solutions. Then the original standard need be opened only occasionally, and the concentration of the standard solution will not increase appreciably even over a period of a year. Calibrations with short-lived standards can be preserved by normalization to the response of a long-lived source.

Sample position, volume, absorption, etc. must be duplicated by the standard. Thus when thick sources of low specific activity are being measured, aliquots of the standard should be added to some of the sources and the same amount of inactive solution of the same composition to others as they are being prepared. The counting efficiency is then found from the known activity of the standard and the observed difference in counting rate. This spiking procedure ensures that the standard and unknown have been counted under identical conditions.

The NaI(TI) scintillation spectrometer method widely used for measuring gamma-emitting isotopes has been described. ${ }^{8} 9$ Users are referred to these reports, especially to the sections on summation effects. Publications are available for the $\mathrm{Ge}(\mathrm{Li})$ spectrometer which has come into common use as a highresolution instrument for identifying gamma-emitting radionuclides.

Summation effects involving conversion electrons should not be overlooked in beta particle counting. The relative number of conversion electrons in coincidence with detected beta particles which will not be recorded as separate events increases with increasing counting efficiency. For example, for thin ${ }^{141} r_{e}$ sources counted at $50 \%$ and $10 \%$ efficiency, events will be recorded for $\sim 55 \%$ and $\sim 12 \%$ of the decays; thus the observed ratio of the counting rates differs from the ratio of the actual counting efficiencies by $\sim 7 \%$. With positron emitters the annihilation radiation can be used for accurate measurement only if the positrons are stopped in a well-defined "geometry," e.g., by sandwiching the source between absorbers, or counting liquid samples in a well-type detector.

The importance of information on decay schemes is exemplified by the fact that a user could make a 26 -fold error in $109 \mathrm{Cd}$ measurement by assuming that the percentage of the $88-\mathrm{key}$ gamma is $100 \%$, rather than the actual $3.8 \%$. A brief listing of the more important components of the decay mode (or modes) is 
given on the data sheet for each nuclide. For a more detailed discussion the user is referred to the information on decay schemes compiled in the Nuclear Data journals, and attention is particularly directed to a compilation of data on 105 common radionuclides. ${ }^{25}$

"The most recent compilation of data for some nuclides is found in the Table of Isotopes. ${ }^{16}$ A user should check values of critical decay-scheme parameters in two or more compilations, as well as recent papers. Nuclear Science Abstracts is convenient for finding the latter."

The authors would like to thank the members of the Subcommittees on Radiochemistry and on the Use of Radioactivity Standards for their reviews and contributions. 


\section{REFERENCES}

1. National Research Council Subcomnittee on Radiochemistry monographs on the radiochemistry of the elements, NAS-NS-3001 et seq., and radiochemical techniques, NAS-NS-3101 et seq. (1960--).

2. Nuclear Data Sheets, Academic Press, New York (1965), being supplanted by issues of journal of same title; also Nuclear Data Tables.

3. M. Haissinsky and J. P. Adloff, Radiochemical Survey of the Elements, Elsevier, New York (1965).

4. A Manual of Radioactivity Procedures, Report 28, NCRP, Washington, D. C. (1961); NBS Handbook 80 (revision in preparation).

5. Standardization of Radionuclides, IAFA, Vienna (1967).

6. W. B. Mann and S. B. Garfinkel, eds., Radioactivity Calibration Standards, NBS Spec. Publ. 331, Govt. Printing of fice, Washington, D. C. (1970).

7. G. D. O'Kelley, Detection and Measurement of Nuclear Radiation, NAS-NS3105, National Research Council, Washington, D. C. (1962).

8. F. Adams and R. Dams, Applied Gamma-Ray Spectrometry, 2nd ed., Pergamon, New York (1970).

9. R. L. Heath, Scintillation Spectrometry, Gamma-Ray Spectrum Catalog, AEC Report IDO-16880 (1964).

10. Catalog of Standard Reference Materials, NBS Spec. Publ. 260, Govt. Printing Office, Washington, D. C. (annualiy).

11. Calibration and Test Services of the National Bureau of Standards, NBS Spec. Publ. 250, Govt. Printing Office, Washington, D. C. (1970) (revised pages and new editions as needed).

12. National Uses and Needs for Standard Radioactive Materials, National Academy of Sciences, Washington, D. C. (1970).

13. S. B. Garfinkel, et al., Certificates of Radioactivity Standards, National Academy of Sciences, Washington, D. C. (1966).

14. I. M. Korenman, Analytical Chemistry of Low Concentrations, Israel Program for Scientific Translations, Jerusalem (1968).

15. M. J. Martin and P. H. Blichert-Toft, Nuclear Data Tables, A8: 1-198 (1970).

16. C. M. Lederer, J. M. Hollander and I. Perlman, Table of Isotopes, 6th Ed., Wiley, New York (1967) (A new edition of this work is in preparation). 


\section{A Note on Units and Abbreviations}

In the section on counting in the body of the present Guide under each nuclide, the following conventions relative to quantities and units have been used:
(a) $s=$ second
$\mathrm{m}=$ minute
$\mathrm{h}=$ hour
$\mathrm{d}=$ day
$\mathrm{y}=$ year
e.c. = electron capture
$\alpha=$ alpha decay
$\beta^{-}=$negatron decay
$\beta^{+}=$positron decay
$\gamma=$ gamma decay
I.T. = isomeric transition
$\mathrm{X}=\mathrm{X}$ ray

(b) All energies are in MeV (e.g.: B-0.0185 signifies a negatron decay energy of $0.0185 \mathrm{MeV}$ or $18.5 \mathrm{keV})$.

(c) The figures preceeding the percent symbol (\%) refer to the relative abundance or intensity of a given decay mode.

(d) Under the information concerning shielding, mCi refers to one millicurie of activity of the stated nuclide. The thickness in inches refers to lead shielding material (see below).

\section{A Note on Shielding}

The safe storage of radioisotopes demands that SOME CONSIDERATION BE GIVEN TO THE PROTECTION OF PERSONNEL from ionizing radiation. For a number of the nuclides included in the present compilation a recommended lead shield thickness is indicated for various levels of activity. These shield values are in addition to the standard 5/8" lead shipping container normally provided, and are so indicated. For further information concerning the safe shipping and storage of radioisotopes, the reader is referred to the following:

"Regulations for the Safe Transport of Radioactive Materials" 1967 Edition, International Atomic Energy Agency, Vienna, 1967.

"Hazardous Materials Regulations, Part 170/179 of the Code of Federal Regulation" U. S. Govt. Printing Office, Washington, D. C.

The authors are indebted to Dr. R. D. Seagren, Isotopes Division, Oak Ridge National Laboratories for generously making this information available to us. 
Significant isotopic effects may be expected in any processes involving changes in physical or chemical states because of the relatively large mass difference between $3 \mathrm{H}$ and $1_{\mathrm{H}}$. Cognizance of these effects, especially in low molecular weight forms such as hydrogen gas or water, is important. Also, care should be exercised to prevent or minimize isotopic exchange with the experimental environment. For further details concerning the chemistry of tritium, see F. S. Rowland in "Inorganic Isotopic Syntheses" Benjamin, New York (1962).

$$
\text { Tritium - Counting }
$$

Tritium standards are normally supplied as tritiated water or hydrocarbons. Reliable measurements of the radioactivity of $3 \mathrm{H}\left(12.3\right.$ - years, $0.0185 \mathrm{MeV}^{15} \mathrm{~B}^{-}$ $\max$ ) require methods employing internal counting of condensed or gas phase samples.

Where tritium levels are greater than a few hundred tritium units, * assays are most readily conducted by liquid scintillation counting. Detailed procedures are available in the literature or from manufacturers of liquid scintillation counting equipment.

After conversion to a suitable gaseous form ( $\mathrm{H}_{2}$ gas or gaseous hydrocarbon) tritium may be counted by introduction into a $\mathrm{G}-\mathrm{M}$ tube, ionization chamber, or proportional counter. In general, gas proportional counting is at least an order of magnitude more sensitive than liquid scintillation counting and is the preferred assay method for low-activity samples.

$3_{\mathrm{H}} \quad 12.3$ y $\beta^{-} 0.0185$

\footnotetext{
${ }^{*} 1$ tritium unit $=1$ tritium atom $/ 10^{18}$ protium atoms $-0.0072 \mathrm{dpm} / \mathrm{g}-\mathrm{H}_{2}$ )

$=3.24 \times 10^{-15}$ curies $/ \mathrm{g}-\mathrm{H}_{2} \mathrm{O}$.
} 
The severe chemical toxicity of beryllium should be kept in mind at all times when chemical separations are made with this element. Care should be exercised to avoid ingestion of the element orally, by inhalation of dust, or through the skin.

Carrier exchange with tracer species of beryllium presents no special problem as long as the sample containing them is homogeneous. Hydrolytic species and radiocolloidal behavior may be avoided by making carrier-tracer exchanges in fairly acid solutions. In aqueous solution beryllium exhibits only one stable valence, +2 .

For further details consult "The Radiochenistry of Beryllium" by A. W. Fairhal1, USAEC Report NAS-NS-3013 (1960).

Beryllium - Counting

Beryliium-7, the most important tracer of this element, decays by electron capture with a half-life of 53.6 days. Commercial suppliers of the tracer material produce the product by proton bombardment of ${ }^{7} \mathrm{Li}$ via a $(p, n)$ reaction. It is usually supplied carrier-free in $0.5 \mathrm{~N} \mathrm{HCl}$ solution with a radiochemical purity $>99.9 \%$. As an unsealed source, $50 \mu^{-} \mathrm{Ci}$ of this nuclide may be Generally Licensed.

The emission of $0.054 \mathrm{-keV}$ Auger electrons is the prominent particulate radiation in $288 \%$ of the decays. Note that essentially no $\mathrm{K} x$-rays are emitted. For radiochemical work the $477.56 \mathrm{keV}$ gamma-ray, with an intensity of $10.3 \%$ of the disintegration, is the preferred radiation for measurement.

In the presence of other radionuclides, caution should be exercised with low-resolution spectrometers to ensure that there is no interference from the $511 \mathrm{keV}$ annhilation radiation from light-element positron emitters.

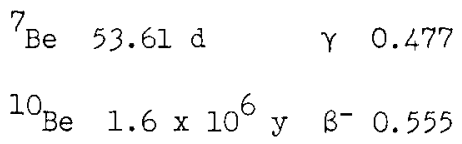


Standardized solutions of compounds labelled with carbon-14 include carbonate in water, benzoic acid in toluene and toluene-C14 in toluene. Toluene-CI4 solutions and standardized n-hexadecane-1-C14 are commonly used for internal standardization for liquid scintillation counting of carbon-14.

The activity of the standard is usually expressed in terms of $\mu \mathrm{Ci} / \mathrm{g}$ of carbon. In the case of toluene-Cl4 solution, precautions must be taken to avoid loss by volatilization during aliquoting by weight or volume. Labeled n-hexadecane is comparatively non-volatile at room temperature.

Labelled carbonate may lose carbon-14 rapidly through exchange with carbon dioxide in the presence of water. For example, dilution of sodium carbonateCl4 solution with distilled water having a pH of 5 and containing dissolved carbon dioxide can lead to the loss of most of the activity upon evaporation of the solution. Dilution with dilute, e.g., 0.1\%, sodium hydroxide solution reduces the loss. Solid carbonate sources such as barium carbonate should be stored in dry air or in vacuum to prevent exchange with carbon dioxide in the laboratory air.

For carbon-14 labelled organic material of very high specific activity, it is important to take precautions against self-decomposition during storage and to check the purity periodically.

For further details see "The Radiochemistry of Carbon, Nitrogen and Oxygen" NAS-NS-3019 (1960).

Carbon - Counting

Carbon-14 emits only beta radiation having an $E_{\text {max }}$ of $156 \mathrm{keV}$. Efficient measurement requires the use of methods in which self-absorption of the "soft" beta radiation is avoided or reduced to a negligible effect.

Liquid scintillation counting is used for routine measurement of carbon-14. In this method, lowering of the counting efficiency can result from quenching and from self-absorption in the case of suspended solid samples. Self-absorption and quenching can be avoided by internal gas counting as carbon dioxide, for example, in a proportional counter or in an ionization chamber. If counting efficiency is not important, solid sources, e.g., barium carbonate, can be measured by means of a very-thin-window or windowless proportional counter or Geiger-Müller counter.

The nuclear radiations of the carbon isotopes are described in Nuclear Data Sheets (National Academy of Sciences - National Research Council), see also refs. 15 and 16.

AlI beta-emitters are also emitters of X-rays (bremsstrahlung). Although bremsstrahlung production becomes more important with increasing $E_{\max }$ of the beta-radiation, the X-radiation is measurable for carbon-14 and may be significant for samples containing more than a few millicuries.

$\begin{array}{llll}{ }^{11_{C}} & 20.4 \mathrm{~m} & \beta^{+} & 0.959 \\ { }^{14} \mathrm{C} & 5730 \mathrm{y} & B^{-} & 0.1561(100 \%)\end{array}$


Solutions of ${ }^{22} \mathrm{Na}$ or ${ }^{24} \mathrm{Na}$ present no unusual radiochemical problems. Since $\mathrm{NaCl}$ is deliquescent, care should be taken to ensure that samples for beta counting are dry. At tracer concentrations, radiosodium exchanges with sodium in glassware and on other surfaces.

The chemical behavior of radioactive sodium is discussed in "The Radiochemistry of Sodium" by W. T. Mullins and G. W. Leddicotte, USAEC Report NASNS-3055 (1962).

Sodium - Counting

The radioactivity of ${ }^{22} \mathrm{Na}\left(2.6\right.$-year) or ${ }^{24} \mathrm{Na}$ (15-hour) can be measured by G-M, proportional, or scintillation counting since both nuclides emit beta particles and gamma rays. The $100 \%$ abundant gamma rays of 1.37 and $2.75 \mathrm{MeV}$ for $24 \mathrm{Na}$ and $1.28 \mathrm{MeV}$ for $22 \mathrm{Na}$ makes these nuclides well suited to gamna-ray spectrometry, which reduces considerably the problems of radiochemical purity and sample preparation.

As with all positron emitters, the annihilation radiation $(0.51 \mathrm{MeV})$ from $22 \mathrm{Na}$ sources can be used for high accuracy measurements only if care is taken to stop all the positrons in a well defined geometry, e.g., by sandwiching the sources between $2 \mathrm{~mm}$ thick plastic absorbers or by counting liquid samples in a $\mathrm{NaI}(\mathrm{Tl})$ well-crystal detector. If thin sources are counted very close to a large NaI(TI) detector, the fate of the positrons can also affect the count rate in the $1.28 \mathrm{MeV}$ peak since the efficiency for detecting annihilation radiation determines how many events are shifted from the $1.28 \mathrm{MeV}$ peak into the 1.8 $\mathrm{MeV}$ coincidence sum peak.

The nuclear radiations of the sodium isotopes are described in Nuclear Data Sheets (National Academy of Sciences - National Research Council), see also ref. 16.

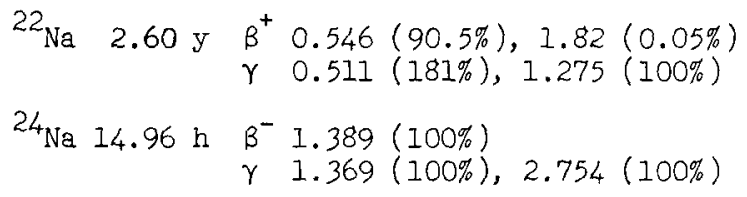

Shielding:

10mci require $3.75^{\prime \prime}$ of $\mathrm{Pb}$ to give $<0.5 \mathrm{mrem}$ at $3^{\prime}$

$0-\operatorname{lmCi} 5 / 8^{\prime \prime}+1 / 2^{\prime \prime}$

1 - $10 \mathrm{mCi} 5 / 8^{\prime \prime}+1-1 / 2^{\prime \prime}$

$10-50 m C i 5 / 8^{\prime \prime}+3^{\prime \prime}$ 
Magnesium is divalent in solution and presents no problem in exchange between tracer and carrier. At high pH, magnesium behaves radiocolloidally. Magnesium-28 decays to $2.3 \mathrm{~min}$. $28 \mathrm{Al}$, but it is not necessary to be concerned about the chemical behavior of the daughter unless counting must be done before equilibrium is reached ( $20 \mathrm{~min}$.).

For chemical details see "The Radiochemistry of Magnesium" by A. W. Fairhal1, USAEC Report NAS-NS-3024 (1961).

$$
\text { Magnesium - Counting }
$$

Use of thin uniform sources will give more reproducible results when beta counting $28_{\mathrm{Mg}}+28 \mathrm{Al}$. If thick sources must be beta counted, it may be advantageous to absorb the $0.45 \mathrm{MeV} 28_{\mathrm{Mg}}$ betas and count oniy the $2.9 \mathrm{MeV}$ betas from $28 \mathrm{Al}$. Magnesium-28 more often is measured by gamma-ray counting. The $1.8 \mathrm{MeV} 28 \mathrm{Al}$ ganma ray is $100 \%$ abundant.

Some ${ }^{2} 8 \mathrm{Mg}$ is produced by

$$
\mathrm{n}+\mathrm{Li} \rightarrow{ }^{3} \mathrm{H}+{ }^{26} \mathrm{Mg} \rightarrow 28_{\mathrm{Mg}}+\mathrm{p}
$$

and is therefore contaminated with ${ }^{3} \mathrm{H}$.

The nuclear radiations of the magnesium isotopes are described in Nuclear Data Sheets (National Acaderny of Sciences - National Research Council). See also ref. 16.

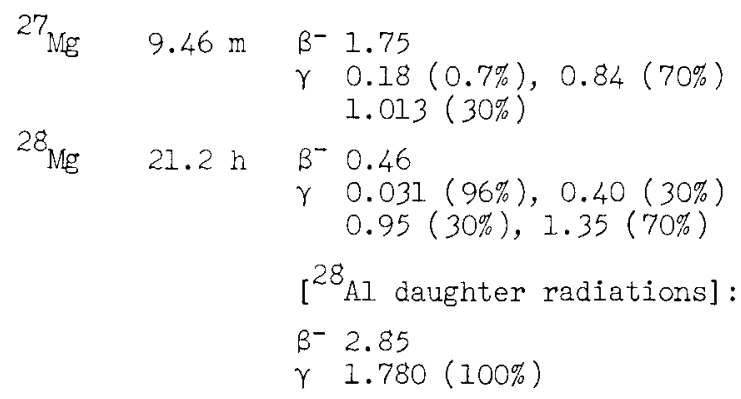


Aluminum is an amphoteric element, behaving as a metal in acid and as a nonmetal in alkaline media. Pure aluminum is soluble in dilute mineral acids, except in nitric acid in which the metal remains relatively passive. Caustic solutions dissolve aluminum readily.

Ammonium and alkali hydroxides of aluminum precipitate upon neutralizing acid solutions of the trivalent salts, but high concentrations of alkali hydroxides dissolve the precipitate. Gravimetric procedures involve the sesquioxide, $\mathrm{Al}_{2} \mathrm{O}_{3}$, resulting from the ignition of hydroxides or organic precipitates such as cupferrates and quinolates. Chloride solutions of $26 \mathrm{Al}$ should present no unusual radiochemical problems.

For further details, see J. E. Lewis, "The Radiochemistry of Aluminum and Gallium," USAEC Report NAS-NS-3032 (1961).

\section{Aluminum - Counting}

The radioactivity of the only long-lived aluminum isotope, ${ }^{26} \mathrm{Al}\left(\mathrm{T}_{\frac{1}{2}}=7.4 \mathrm{x} 10^{5} \mathrm{y}\right)$, can be measured with G. M., proportional, scintillation, and semi-conductor counters since the nuclide emits beta particles and gamma rays. The high energy (1.8 MeV) gamma ray that accompanies almost every disintegration makes this nuclide well suited to gamma-ray spectrometry, which reduces considerably the problems of radiochemical properties and sample preparation.

As with all positron emitters, the annihilation radiation $(0.511 \mathrm{MeV})$ from $26_{\mathrm{Al}}$ sources can be used for high accuracy measurements if care is taken to stop all the positrons in a well defined geometry.

The nuclear radiations of the aluminum isotopes are described in the Nuclear Data Sheets (National Academy of Science - National Research Council). See also ref. 16.

\begin{tabular}{|c|c|c|}
\hline \multirow[t]{3}{*}{${ }^{26} \mathrm{Al} \quad 7.4 \times 10^{5} \mathrm{y}$} & $\beta^{+}$ & $1.16 \mathrm{MeV}(85 \%)$ \\
\hline & e.c. & $(15 \%)$ \\
\hline & Y & $\begin{array}{l}0.511(170 \%), 1.12(3.7 \%), 1.809(99.6 \%) \\
2.96(0.3 \%)\end{array}$ \\
\hline
\end{tabular}


Radioactive phosphorus is usually present in the +5 oxidation state as $\mathrm{PO}_{4}^{-3}$. Strongly reducing conditions should be avoided because phosphorus may be lost as $\mathrm{PH}_{3}$. If $32 \mathrm{P}$ is present as phosphoric acid it is difficult to make dry sources for beta counting by simple evaporation. Thin sources are sometimes prepared as $\mathrm{NaH}_{2} \mathrm{PO}_{4}$ but precipitation as $\mathrm{MgNH}_{4} \mathrm{PO}_{4} \cdot 6 \mathrm{H}_{2} \mathrm{O}$ or $\left(\mathrm{NH}_{4}\right)_{3}\left(\mathrm{MoO}_{3}\right)_{12} \mathrm{PO}_{4}$ is more usual when appreciable amounts of carrier are present. A few parts per million of dichromate ion or 0.5 percent of formaldehyde or phenol should be added to solutions of $32 \mathrm{p}$ to prevent the growth of micro-organisms which can concentrate phosphorus by factors of $10^{6}$ or more. Phosphorus chemistry is outlined in "The Radiochemistry of Phosphorus" by W. T. Mullins and G. W.

Leddicotte, USAEC Report NAS-NS-3056 (1962). See also L. Lindner in "Inorganic Isotopic Syntheses," Benjamin, New York, 1962.

$$
\text { Phosphorus - Counting }
$$

Phosphorus -33 ( 25 days, $0.25 \mathrm{MeV} \beta_{\max }$ ) is always associated with $32 \mathrm{p}$ ( 14.3 days, $1.7 \mathrm{MeV} \beta_{\text {max }}^{-}$) produced by neutron irradiation of sulfur and complicates accurate assays of $32 \mathrm{P}$. Typically, $33 \mathrm{P}$ is about $1 \%$ of $32 \mathrm{P}$ in freshly processed $32 \mathrm{P}$ and the relative concentration approximately doubles for every month's decay. Interference from $33 \mathrm{P}$ can be eliminated by counting $32 \mathrm{P}$ beta particles through $0.3 \mathrm{~mm}$ of aluminum, but some particles from $32 \mathrm{p}$ will also be absorbed. The $33 \mathrm{p}$ content of a $32 \mathrm{P}$ solution can be estimated by comparing the apparent half-life of a very thin uniform source counted in a windowless or thin-window counter with its half-life measured by counting through the absorber.

The nuclear radiations of the phosphorus isotopes are described in Nuclear Data Sheets (National Academy of Sciences - National Research Council) and in ref. 16.

$$
\begin{aligned}
& { }^{32} \mathrm{P} \quad 14.28 \mathrm{~d} \quad \mathrm{~B}^{-} \quad 1.710 \\
& { }^{33} \mathrm{P} \quad 25 \text { d } B^{-} \quad 0.248
\end{aligned}
$$


Radioactive sulfur is usually in solution as $\mathrm{SO}_{4}^{-2}$. If sulfides are present, care should be taken to avoid losing sulfur as ${ }^{4} \mathrm{H}_{2} \mathrm{~S}$ or precipitating it as elemental sulfur. If $35 \mathrm{~s}$ is present as sulfuric acid it is difficult to make dry sources for beta counting by simple evaporation. Very thin, low-weight sources are sometimes prepared as $\mathrm{Li}_{2} \mathrm{SO}_{4}$; precipitation as barium or benzidine sulfates is common when appreciable amounts of carrier are present. A few parts per million of dichromate ion or a few tenths of a percent of formaldehyde should be added to solutions of $35 \mathrm{~S}$ to prevent the growth of micro-organisms which concentrate the sulfur and attach it to the container walls.

For chemical information consult "The Radiochemistry of Sulfur" by G. W. Leddicotte, USAEC Report NAS-NS-3054 (1962). See also R. H. Herber in "Inorganic Isotopic Syntheses," Benjamin, New York, 1962.

\section{Sulfur - Counting}

The low beta energy of ${ }^{35} \mathrm{~S}\left(\beta_{\mathrm{max}}^{-} 0.167 \mathrm{MeV}\right.$ ) requires extremely thin and uniform sources to obtain reproducible beta-counting results. For this reason liquid scintillation counting should be considered whenever possible. Manufacturers of liquid scintillation counting equipment should be consulted for detailed procedures. At low specific activity, it may be possible to achieve reproducible counting conditions by using "infinitely" thick sources of $\mathrm{BaSO}_{4}$.

The nuclear radiations of the sulfur isotopes are described in Nuclear Data Sheets (National Academy of Sciences - National Research Council), and ref. 16.

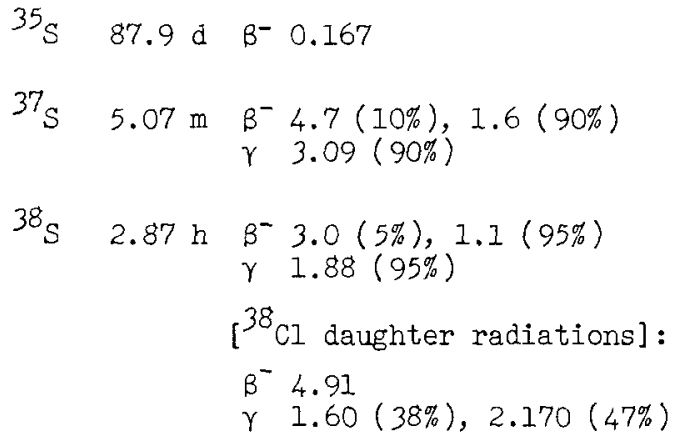


Chlorine presents no unusual radiochemical problems. It can exist in six oxidation states but only as chloride ion is it stable in the presence of even the mildest of reducing agents. In acidic solution the higher oxidation states are all good oxidizing agents. Chlorine may be easily separated from bromine and iodine by selective oxidation of the latter halogens to the elemental state, which can subsequently be extracted or distilled.

Chlorine-36 is of ten precipitated for counting as silver chloride, which tends to agglomerate into a rather lumpy form. Precipitation of mercurous chloride $\left(\mathrm{Hg}_{2} \mathrm{Cl}_{2}\right)$ avoids this difficulty. The silver salt is sensitive to light and needs protection to prevent conversion to the elements. Samples have been plated by evaporating solution containing chloride ions, but acid solutions so treated can lose activity as $\mathrm{HCl}$ or other volatile salts upon heating to dryness. Evaporation of aliquots of a solution made by dissolving silver chloride in concentrated ammonium hydroxide avoids this difficulty.

For further details consult "The Radiochemistry of Fluorine, Chlorine, Bromine, and Iodine" by Jacob Kleinberg and G. H. Cowan, USAEC Report NAS-NS-3005 (1960). See also B. J. Masters in "Inorganic Isotopic Syntheses," Benjamin, New York, 1962.

Chlorine - Counting

In assaying ${ }^{36} \mathrm{Cl}$, the $\sim 1.9 \%$ decaying by electron capture and the $20.002 \%$ positron branch are usually ignored. The low $\mathrm{K} \mathrm{X}$-ray energy $(\sim 2.3 \mathrm{keV})$ and low $\mathrm{K}-$ fluorescence yield ( $5 \%$ ) make very unlikely the detection of electron capture events in any beta counting arrangement. Self-absorption problems are not too severe for the beta energy ( $\beta_{\max }^{-} 0.7 \mathrm{MeV}$ ) of $36 \mathrm{Cl}$ but the use of thin uniform sources will give the most reproducible results. Chlorine-36 radioactivity standards are commonly certified for beta emission only rather than for disintegration rate.

The nuclear radiations of the chlorine isotopes are described in Nuclear Data Sheets (National Academy of Sciences - National Research Council), and ref. 16.

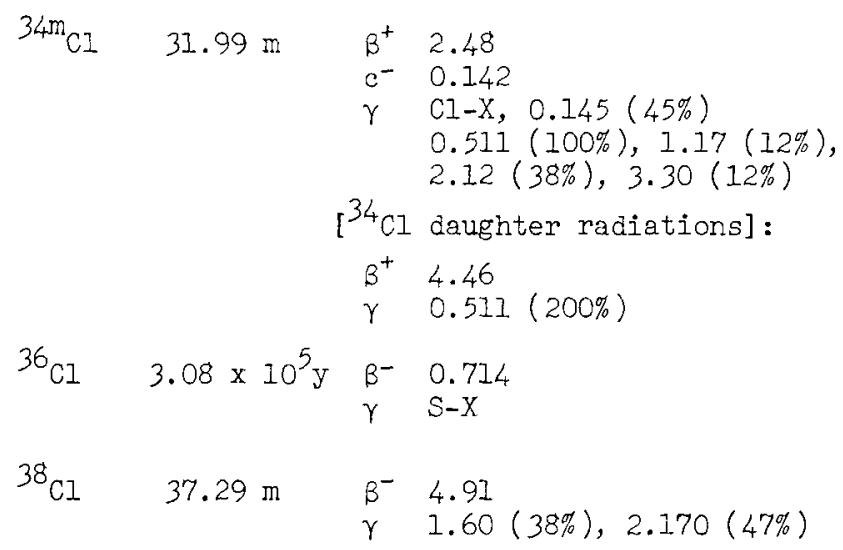


Argon behaves as an inert noble gas. Its adsorption properties on activated charcoal and molecular sieves are used for collecting the gas and separating it from other rare gases. Reactive gases are removed from argon by heating the gas over titanium metal at $900^{\circ} \mathrm{C}$. For further details see F. F. Momyer, Jr., "The Radiochemistry of the Rare Gases," USAEC Report NAS-NS-3025 (1960). A typical gas handling system is described by R. W. Stoenner et al, Proc. of the Apollo 11 Lunar Science Conference, Vo1. 2, p. 1583 (1970).

\section{Argon - Counting}

Argon-37, half life 35.1 days, decays by electron capture, and is counted internally in a gas proportional counter with $10 \%$ methane, or in a G-M counter. The $2.8 \mathrm{keV}$ Auger electrons from $\mathrm{K}$ capture are observed. With pulse height analysis a 25-30 percent resolution is achieved for the K-capture events. L capture occurs in 10 percent of these decays resulting in a 280-eV Auger electron. Thus to observe all $37 \mathrm{Ar}$ decay events in a proportional counter, sufficient counter and amplifier gain must be used to include the L-capture events. The voltagecount rate plateau exhibits a step when sufficient voltage-gain is achieved. Argon-37 standards are made by counting the gas in a proportional or G-M counter of measured geometrical efficiency. Standardized samples of $37 \mathrm{Ar}$ are available from the National Bureau of Standards.

Argon-39 decays by beta-minus emission with a maximum energy of $0.565 \mathrm{MeV}$ with a half life of 269 years. Argon-41, half life 1.83 hours, decays also by beta-minus emission with 99.2 percent of the decays emitting a beta with maximum energy of $1.198 \mathrm{MeV}$ followed by a $1.293-\mathrm{MeV}$ gamma. These isotopes of argon can be counted internally in a proportional counter or G-M counter. Standards can be prepared by counting the gas in a counter of known geometrical efficiency. Since the beta radiation are energetic, their activities can be counted in windowed cells placed against an end window proportional counter. The Argon-4I gamma ray can be measured and standardized by a scintillation counter or a solid state counter.

Argon-42 decays by beta-minus emission $(E(\max )=0.60 \mathrm{MeV})$ with a half life of 33 years to $42 \mathrm{~K}$ (half life 12.4 hours--see potassium counting). See also ref. 16. Argon-42 activity is measured usually by observing the $42 \mathrm{~K}$ radiations. Standards can be prepared by separating the daughter $42 \mathrm{~K}$ from the walls of a flask and assaying the $42 \mathrm{~K}$ activity. For technique see $\mathrm{R}$. W. Stoenner et al, Science 148, 1325 (1965).

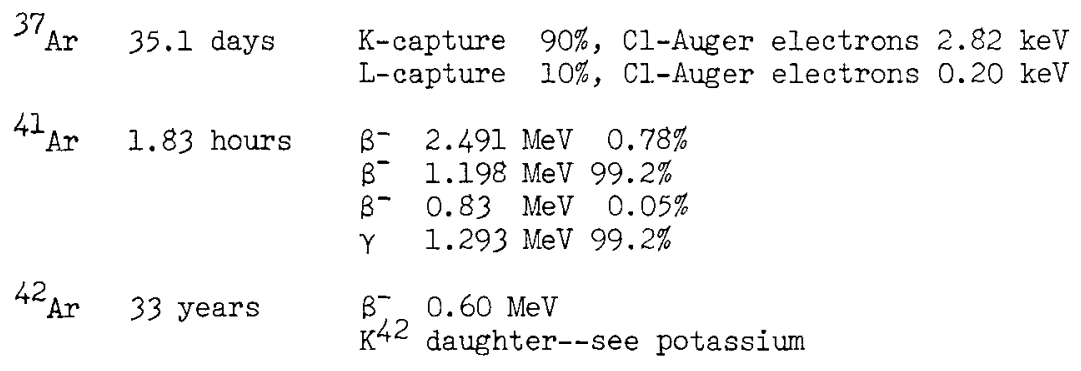


Potassium presents no unusual radiochemical problem. Radioactive potassium is isolated in final form most frequently as the perchlorate, $\mathrm{KClO}_{43}$ or the chloroplatinate, $\mathrm{K}_{2} \mathrm{PtCl}_{6} \cdot \mathrm{Ba}(\mathrm{II}), \mathrm{Sr}(\mathrm{II}), \mathrm{Mg}(\mathrm{II}), \mathrm{BO}_{2}^{-}, \mathrm{SO}_{4}^{2-}$, and $\mathrm{PO}_{4}^{4} 3$ - interfere in these precipitations. $\mathrm{Rb}(I), \mathrm{Cs}(I), \mathrm{NH}_{2}(I)$, and $\mathrm{TI}(I)$ also interfere in the perchlorate method while $\mathrm{Rb}(I)$ and $\mathrm{CS}$ (I) interfere in the chloroplatinate precipitation.

The chemical behavior of radioactive potassium is discussed in "The Radiochemistry of Potassium" by W. T. Mullins and G. W. Leddicotte, USAEC Report NASNS-3048 (1961).

\section{Potassium - Counting}

Geiger-Mueller, proportional, and scintillation counting are all useful for measuring $42 \mathrm{~K}$. The relatively high beta decay energy of $3.54 \mathrm{MeV}$ makes it possible to use aluminum absorbers to eliminate impurity activities of lower energy. Scintillation spectrometry is useful for the $1.53 \mathrm{MeV}$ gamma ray of $18 \%$ abundance. Potassium carrier contains $4 \mathrm{O}_{\mathrm{K}}$, which emits $\sim 3.5$ gamma rays $(1.46 \mathrm{MeV}$ ) and 28 beta particles per second per gram of natural potassium. Solutions of $12.4-\mathrm{hr} 42 \mathrm{~K}$ usually contain small amounts of $15-\mathrm{hr} 24 \mathrm{Na}$ as an impurity.

The nuclear radiations of the potassium isotopes are described in Nuclear Data Sheets (National Academy of Sciences - National Research Council), and ref. 16.

\begin{tabular}{|c|c|c|c|}
\hline $40_{K}$ & $1.26 \times 10^{9} \mathrm{y}$ & $\begin{array}{l}\beta^{-} \\
\beta^{+} \\
\gamma\end{array}$ & $\begin{array}{l}1.314 \\
0.483(0.001 \%) \\
\text { Ar-X, } 1.460(11 \%)\end{array}$ \\
\hline $42_{K}$ & $12.36 \mathrm{~h}$ & $\begin{array}{l}\beta^{-} \\
\gamma\end{array}$ & $\begin{array}{l}3.52 \\
0.31(0.2 \%), 1.524(18 \%)\end{array}$ \\
\hline & & & $\begin{array}{l}\text { Shielding: } \\
0-1 \mathrm{mCi} 5 / 8^{\prime \prime} \\
1-10 \mathrm{mCi} \quad 5 / 8^{\prime \prime}+1 / 8^{\prime \prime} \\
10-50 \mathrm{mCi} \quad 5 / 8^{\prime \prime}+1^{\prime \prime}\end{array}$ \\
\hline
\end{tabular}


Calcium - Chemistry

Calcium exists only as the +2 oxidation state in solution; hence there is no problem of exchange between carrier and tracer. Solutions of calcium that are to be stored for appreciable periods should be kept acidic to prevent precipitation of $\mathrm{CaCO}_{3}$ or radiocolloid formation produced by absorption of $\mathrm{CO}_{2}$ from air.

Calcium is usually precipitated for counting as the oxalate. Calcium- 47 is accompanied by its radioactive daughter, $47 \mathrm{Sc}$. Chemical separations and techniques of sample preparation may affect the relative quantities of the parentdaughter pair. Calcium chloride is hygroscopic; the water content of radio-calcium deposited by evaporation on a chloride solution therefore affects the degree of self-absorption, especially for $45 \mathrm{Ca}$.

For further details, see D. N. Sunderman and C. W. Townley, "The Radiochemistry of Barium, Calcium, and Strontium," USAEC Report NAS-NS-3010 (1960).

\section{Calcium - Counting}

Calcium-45 decays solely by beta emission with an end-point energy of $0.254 \mathrm{MeV}$ and an average energy of $0.076 \mathrm{MeV}$. There are no gamma rays emitted in the decay of this nuclide. Careful attention must be paid to self-absorption if solid samples are counted with Geiger-Mueller or proportional detectors because of the low energy associated with the decay. Liquid scintillation counting may be used to advantage with this nuclide.

Calcium-47 decays with a half-life of 4.5 days by the emission of two negatron groups ( $0.69 \mathrm{MeV} 82 \%$ and $1.98 \mathrm{MeV} 18 \%)$. Scandium-47 (3.4-d T $1 / 2$ ), the daughter of $47 \mathrm{Ca}$, decays by the emission of two negatron groups $\left(0 . \frac{1}{4} 4 \mathrm{MeV} 70 \%\right.$ and $0.60 \mathrm{MeV} 30 \%$ ). Consequently, ordinary methods of beta counting may be used for counting both these nuclides. Beta decay of the ${ }^{47} \mathrm{Ca}$ gives rise to a 1.3 $\mathrm{MeV}$ gamma ray in $71 \%$ of the disintegrations whereas the $0.16 \mathrm{MeV}$ ganma ray in $47 \mathrm{Sc}$ is produced in $66 \%$ of the $47 \mathrm{Sc}$ disintegrations. Therefore, scintillation counting and spectrometry may be used with these nuclides.

The nuclear radiations of the calcium isotopes are described in Nuclear Data Sheets (National Academy of Sciences - National Research Council). See also refs. 15 and 16.

$$
\begin{aligned}
& { }^{45} \mathrm{Ca} \quad 164 \text { a } \quad B^{-} \quad 0.257 \\
& { }^{47} \mathrm{Ca} \quad 4.535 \quad B^{-} \quad 1.98(18 \%), 0.687(82 \%) \\
& \gamma \quad 0.49(6.8 \%), 0.81(68 \%) \\
& 1.30(75 \%) \\
& \text { Shielding : } \\
& 0-1 \mathrm{mCi} 5 / 8^{\prime \prime} \\
& 1-10 \mathrm{mCi} 5 / 8^{\prime \prime}+1 / 2^{\prime \prime} \\
& {\left[{ }^{47} \mathrm{Se}\right. \text { daughter radiations]: }} \\
& B^{-} 0.600(30 \%), 0.441(70 \%) \\
& \gamma \quad 0.16(30 \%)
\end{aligned}
$$


Chromium is commonIy trivalent $\mathrm{Cr}^{+3}$ or hexavalent $\mathrm{CrO}_{4}=$ or $\mathrm{Cr}_{2} \mathrm{O}_{7}=$. Dilute acid solutions of both states are quite stable. For exchange, the trivalent state is readily oxidized by $\mathrm{H}_{2} \mathrm{O}_{2}$ in basic solution or $\mathrm{KBrO}_{3}$ in acid solution. At high $\mathrm{pH}$ and low concentrations, trivalent chromium forms a radiocolloid. It precipitates as hydroxide at higher concentrations.

Chromium in $\mathrm{HCl}$ can be distilled as $\mathrm{CrO}_{2} \mathrm{Cl}_{2}$ when $\mathrm{HClO}_{4}$ is present. The salts of the halides are deliquescent. When solid sources for counting are to be prepared from macro amounts of chromium, the ignited oxide or precipitates of lead or barium chromate should be used. As a rule, no significant radiochemical impurities are found in reactor-produced $5 I_{\mathrm{Cr}}$. The chemistry of chromium has been outlined by J. Pijck in "Radiochemistry of Chromium," USAEC Report NAS-NS3007 (Revised 1964).

Chromium - Counting

Chromium-51 is routinely measured by detecting its $0.320 \mathrm{MeV}$ gamma ray $(9.8 \%$ abundance) in NaI(TI) detectors or ion chambers. Since ${ }^{51} \mathrm{Cr}$ decays by electron capture only, it emits no beta particles. The $\sim 5 \mathrm{KeV} \mathrm{K} X$-rays of $\sim 22 \%$ abundance can be measured with Geiger-Mueller or proportional counters having argon as a filling constituent and thin beryllium or plastic windows, or with thin NaI(TI) detectors having beryllium windows. X-ray counting requires low-noise electronics and thin uniform sources to minimize X-ray self-absorption. Pijck's monograph cited above quotes several examples of special counting arrangements.

The nuclear radiations of the chromium isotopes are described in Nuclear Data Sheets (National Academy of Sciences - National Research Council), and in ref. 16.

$$
\begin{aligned}
& { }^{48} \mathrm{Cr} \quad 23 \mathrm{~h} \quad \mathrm{~V}-\mathrm{X}, 0.116(98 \%), 0.31(99 \%) \\
& {\left[{ }^{48} \mathrm{~V}\right. \text { daughter radiations] : }} \\
& \beta^{+} 0.696 \\
& \gamma \mathrm{Ti}-\mathrm{X}, 0.511(100 \%), 0.945(10 \%) \\
& 0.983(100 \%), 1.312(97 \%), 2.241(3 \%) \\
& { }^{49} \mathrm{Cr} \quad 41.9 \mathrm{~m} \\
& B^{+} \quad 1.54 \\
& \gamma \quad \mathrm{V}-\mathrm{X}, 0.063(14 \%), 0.091(28 \%) \\
& 0.153(13 \%), 0.511(186 \%) \\
& { }^{51} \mathrm{Cr} \quad 27.7 \text { d } \quad \mathrm{V}-\mathrm{X}, 0.320(9 \%) \\
& e^{-} \quad 0.315
\end{aligned}
$$


Standardized aqueous solutions of manganese-54 usually consist of manganous chloride in dilute hydrochloric acid (perhaps 0.1 to $0.5 \mathrm{Molar}$ ). The latter is present to provide a stable solution of manganous ions. Both $\mathrm{MnCl}_{2}$ and $\mathrm{MnCl}_{2} \cdot{ }_{4} \mathrm{H}_{2} \mathrm{O}$ are deliquescent.

Formation of manganous hydroxide radiocolloid can be expected in alkaline solutions of manganous ion at tracer concentrations. The hydroxide will undergo air oxidation.

Two compounds that can be used to form stable solid sources by ignition are $\mathrm{MnO}_{2}$ and $\mathrm{Mn}_{2} \mathrm{P}_{2} \mathrm{O}_{7}$. The chemistry of manganese has been outlined by $\mathrm{G}$. W. Leddicotte in "The Radiochemistry of Manganese," USAEC Report NASA-NS-3018 (1960). [Revision 1971].

Manganese - Counting

Manganese-54 decays entirely by electron capture followed by gamma-emission. It is routinely counted by detecting the $0.835 \mathrm{MeV}$ gamma-ray by gamma scintillation counting, e.g., with $\mathrm{NaI}(\mathrm{Tl})$, although it can be measured by means of proportional or Geiger-Muller counters. The gamma ray is converted to a negligible extent $(0.02 \%)$. The $\mathrm{K} \mathrm{X}$-rays from the chromium-54 decay product can be detected from thin sources by detectors with thin beryllium windows, e.g., proportional counters or thin $\mathrm{NaI}(\mathrm{Il}$ ) detectors. Both the X-rays and the very low-energy Auger electrons from chromium-54 can be detected from very thin sources placed inside a proportional counter.

The nuclear radiations of the manganese isotopes are described in Nuclear Data Sheets (National Academy of Sciences - National Research Council), and in refs. 15 and 16 .

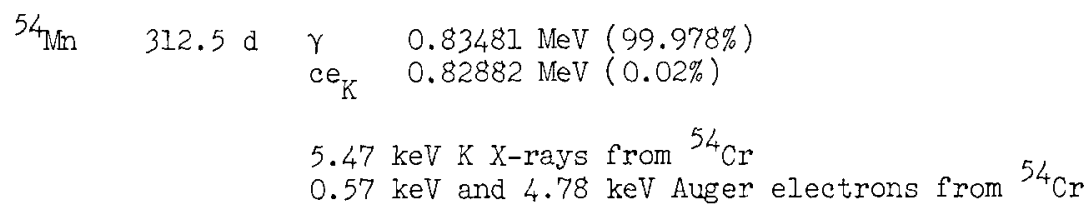

$\begin{array}{rlll}52 \mathrm{Mn} \quad 5.67 \mathrm{~d} \quad \mathrm{~B}^{+} & 0.57(28 \%) \\ & \gamma \quad 0.511(55 \%), 0.744(85 \%), 0.936(94 \%) \\ & 1.434(100 \%) \\ & \text { Shielding: } \\ & 0-1 \mathrm{mCi} 5 / 8^{\prime \prime} \\ & 1-10 \mathrm{mCi} 5 / 8^{\prime \prime}+1 / 2^{\prime \prime}\end{array}$


Standard solutions of radioiron are usually obtained in dilute hydrochloric acid and present no severe stability problems. Radioiron would be expected to be radiocolloidal above pH 5. Many of the iron salts, especially the halides, are deliquescent. With very thin solid sources this does not appear to present difficulties in counting. However, when macroscopic quantities of iron are to be used for preparing solid sources, the metal or ignited oxides are to be preferred. Thin, uniform sources of metallic iron can be prepared by electroplating or electrochemical deposition. For details see J. M. Nielsen, "The Radiochemistry of Iron," USAEC Report NAS-NS-3017 (1960).

$$
\text { Iron - Counting }
$$

$\mathrm{NaI}(\mathrm{TI})$ spectrometry is a convenient method of assaying $45-$ day ${ }^{59} \mathrm{Fe}$. Traces of $60 \mathrm{Co}$ in $59 \mathrm{Fe}$ are not easily detected except by coincidence measurements, but larger amounts are revealed by the sum coincidence peak at $2.5 \mathrm{MeV}$, especially if the latter is enhanced by counting with good geometry. Cobalt-60 and $59 \mathrm{Fe}$ are resolved easily with a $\mathrm{Ge}(\mathrm{Li})$ gamma-ray detector.

The relatively low-energy $59 \mathrm{Fe}$ beta groups dictate the usual precautions of keeping sources thin and uniform to obtain reproducible beta-counting results. Iron-59 nearly always contains 2.7 year $55 \mathrm{Fe}$ as an impurity. Iron-55 decays by electron capture, emitting only Mn X-rays or Auger electrons with an energy of $5.9 \mathrm{keV}$. Thus, even large amounts of $55 \mathrm{Fe}$ do not interfere with the assay of $59 \mathrm{Fe}$ by gamma-ray counting and easily could go undetected. Beta particles from $59 \mathrm{Fe}$ should be counted through absorbers to remove any $55 \mathrm{Fe}$ radiation. An adequate absorber for good beta transmission is $0.05 \mathrm{~mm}$ of titanium.

Iron-59 (45-d) is present in fresh, reactor-produced $55 \mathrm{Fe}$ but is usually negligible in material which has been allowed to decay for a year or more. As a rule, no other significant radiochemical impurities are found. The $\sim 5.9 \mathrm{keV}$, $28 \%$ abundant $\mathrm{X}$-rays of $55 \mathrm{Fe}$ can be detected with proportional counters filled with $90 \% \mathrm{Ar}+10 \% \mathrm{CH}_{4}$ having thin beryllium or plastic windows or with thin $\mathrm{NaI}$ (TI) detectors having thin Be windows. Good quality, low-noise, phototubes and electronics must be used with $\mathrm{NaI}(\mathrm{TI})$ detectors to obtain a good signal-tonoise ratio at this energy. If windowless counters are used, the sources should be covered with low $Z$ absorbers of uniform thickness $\left(\sim 200 \mu \mathrm{g} / \mathrm{cm}^{2}\right)$ to prevent Auger electrons from entering the counter. These sources should be comparable in thinness and uniformity to sources prepared for low energy beta counting so that $X$-ray self-absorption is minimized.

Nielsen's monograph, cited above, describes special counting arrangements for the simultaneous determination of $55 \mathrm{Fe}$ and $59 \mathrm{Fe}$.

The nuclear radiations of the iron isotopes are described in Nuclear Data Sheets (National Academy of Sciences - National Research Council), and ref's. 15 and 16 .

$$
\begin{array}{rlrl}
{ }^{55} \mathrm{Fe} \quad 2.7 \quad \text { y } & \gamma \mathrm{Mn}-\mathrm{X} \\
{ }^{59} \mathrm{Fe} \quad 44.6 \quad \mathrm{~d} \quad \beta^{-} & 1.57(0.3 \%), 0.467(53 \%), 0.274(46 \%) \\
& & \gamma & 0.143(0.8 \%), 0.192(2.8 \%) \\
& & & \\
& & \text { Shielding: } \\
& & 10 \mathrm{mCi} \text { require } 3.61 \mathrm{~Pb} \text { to reduce radiation to }
\end{array}
$$


$26^{\mathrm{Fe}}($ cont'd. $)$

$0.5 \mathrm{mrem}$ at $3^{\prime}$

$0-1 \mathrm{mCi} 5 / 8^{\prime \prime}$

$1-10 \mathrm{mCi} 5 / 8^{\prime \prime}+3 / 4^{\prime \prime}$

$10-50 \mathrm{mCi} 5 / 8^{\prime \prime}+1-1 / 2^{\prime \prime}$ 
Cobalt is comonly divalent and presents no problems in interchange unless stable cobalt complexes are present. Divalent cobalt is insoluble above pH 6.8 and would be expected to form a radiocolloid at tracer concentrations in $\mathrm{NaOH}$ solutions. Thin deposits are prepared by electrodeposition from ammoniacal solution.

The chemistry of radioactive cobalt is discussed by $L$. C. Bate and G. W. Leddicotte in "The Radiochemistry of Cobalt," USAEC Report NAS-NS-3041 (1961).

Cobalt - Counting

Cobalt-60 is routinely measured by detecting the $100 \%$-abundant 1.17 and 1.33 $\mathrm{MeV}$ gamna rays with NaI(T1) detectors or ion chambers. When beta counting ${ }^{60} \mathrm{Co}$, the relatively low energy $(0.314 \mathrm{MeV})$ beta-spectrum dictates the usual precautions of keeping sources thin and uniform to obtain reproducible results. For strong, e.g., teletherapy, sources the field determined by radiation dosimetry is more meaningfuI than the absolute source strength.

Since ${ }^{57}$ Co decays by electron capture, it enits no beta particles. It is usually measured by counting the 122 and $136 \mathrm{MeV}$ gamma rays. These are not resolved in a $\mathrm{NaI}(\mathrm{T} 1$ ) detector but together they are $~ 98 \%$ abundant. (The weak $14 \mathrm{keV}$ gamma ray is well known for its applications in Mössbauer effect studies.)

Cobalt-58 is usually measured by counting its $0.81 \mathrm{MeV}$ gamma rays (100\% abundance). As with all positron enitters, the annihilation radiation from the positron decay of $58 \mathrm{Co}(\sim 15 \%$ branch) can be used for accurate measurements only if all the positrons are stopped in a well-defined geometry. Summing of the coincident annihilation radiation and the gamma rays reduces the intensities of the photoelectric peaks in gamma spectrometry.

Traces of $45-d 59 \mathrm{Fe}$ might be present in very recently irradiated cobalt and go undetected because of the similarity of the gamma ray spectra of $60_{\mathrm{CO}}$ and $59 \mathrm{Fe}$.

The nuclear radiations of the cobalt isotopes are described in Nuclear Data Sheets (National Academy of Sciences - National Research Council), and ref. 16.

$$
\begin{aligned}
& \begin{array}{rrrr}
{ }^{55} \mathrm{CO} \quad 18.2 \mathrm{~h} & \mathrm{~B}^{+} & 1.50 \\
& & \gamma & \mathrm{Fe}-\mathrm{X}, 0.480(12 \%), 0.511(160 \%), \\
& & 0.930(80 \%), 1.41(13 \%)
\end{array} \\
& { }^{56} \mathrm{Co} 77.3 \text { d } \beta^{+} 1.49 \\
& \text { Y Fe-X, 0.511 (40\%), } 0.847(100 \%) \\
& 1.04(15 \%), 1.24(66 \%), 1.76(15 \%) \\
& 2.02(11 \%), 2.60(17 \%), 3.26(13 \%) \\
& { }^{57} \mathrm{Co} 270 \mathrm{~d} \quad \gamma \mathrm{Fe}-\mathrm{X}, 0.014(9 \%) 0.122(87 \%) \\
& 0.136(11 \%), 0.692(0.14 \%) \\
& \begin{aligned}
{ }^{58} \mathrm{Co} 71.3 \mathrm{~d} & \beta^{+} 0.474 \\
& \gamma \\
& \mathrm{Fe}-\mathrm{X}, 0.511(30 \%), 0.810(99 \%)
\end{aligned} \\
& 0.865(1.4 \%), 1.67(0.6 \%)
\end{aligned}
$$




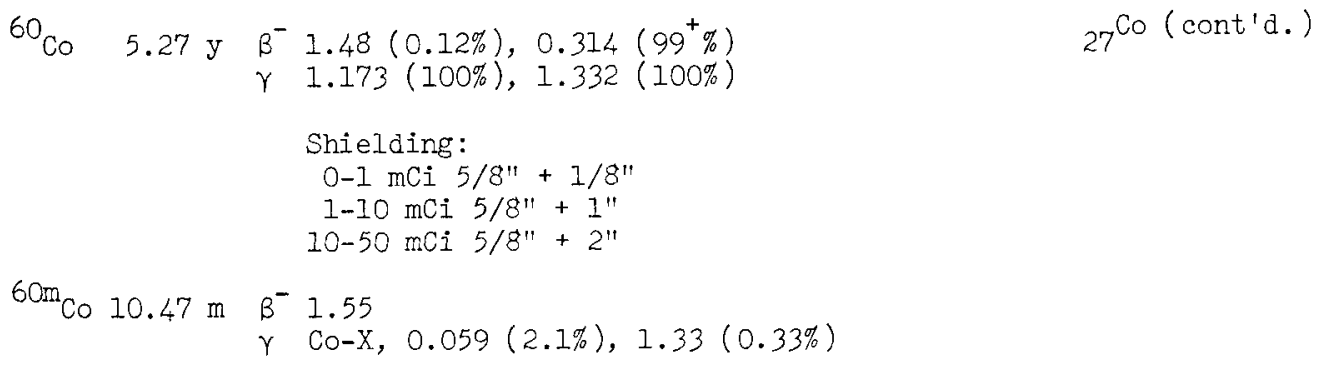


Copper, with an electron configuration of $3 \mathrm{~d}^{10} 4 \mathrm{~s}^{\prime}$ has two oxidation states, +1 and +2 . Since in aqueous solution the equilibrium constant $\left(\mathrm{Cu}^{++}\right) /\left(\mathrm{Cu}^{+}\right)^{2}$ is about $10^{6}$ at $20^{\circ} \mathrm{C}$, appreciable concentrations of the cuprous state cannot be maintained unless the metal is strongly complexed. Most of the solution chemistry of copper is that of the +2 state, and the salts of this ion, especially those which involve the anions of strong acids, are very soluble in water. Insoluble compounds of the cupric form of the metal include the oxide, hydroxide, sulfide, carbonate, iodate, arsenide, citrate, cyanide, hexacyanoferrate (II and III), and orthophosphate. $\mathrm{Cu}\left(\right.$ II ) forms a variety of complex cations with $\mathrm{NH}_{3}$, including $\mathrm{Cu}\left(\mathrm{NH}_{3}\right)^{++}, \mathrm{Cu}\left(\mathrm{NH}_{3}\right)_{2}^{++}, \mathrm{Cu}\left(\mathrm{NH}_{3}\right)_{3}{ }^{++}$and $\mathrm{Cu}\left(\mathrm{NH}_{3}\right)_{4}^{++}$. Complex anions are formed with thiocyanate. Copper can be separated from other metals by precipitation, solvent extraction, ion exchange, electrodeposition, ion transfer and vaporization procedures.

For further details see the summary in "The Radiochemistry of Copper" by F. F. Dyer and G. W. Leddicotte, NAS-NS-3027 (1961).

$$
\text { Copper - Counting }
$$

Copper-64 ( $12.7 \mathrm{hr}$ ) is the most important radionuclide of this element and can be produced readily in a reactor by the $63 \mathrm{Cu}(\mathrm{n}, \gamma) 64 \mathrm{Cu}$ process. This nuclide decays by electron capture ( $42 \%)$, negatron (39\%) and positron (19\%) emission and gives rise to a $1.34 \mathrm{MeV}$ gamma ray as well as the annihilation radiation of the positrons. It is readily counted using $3^{\prime \prime} \times 3^{\prime \prime} \mathrm{NaI}(\mathrm{Tl})$ scintillation techniques or by G.M. end window or internal flow counter methods. The most intense peak in the gamma pulse height spectrum is due to the $0.511 \mathrm{MeV}$ annihilation radiation, and absolute calibration can be effected using a differential pulse height spectrometer, a calibrated positron source and the known branching ratio for $\beta^{+}$ emission.

Copper-67 (61.7 hr) which can be produced by the deuteron bombardment of $67 \mathrm{Zn}$ or by a $(\gamma, \mathrm{p})$ process on the same target, decays by $\beta-$ emission and can be counted both by G.M. detection of the electrons or by scintillation counting of the gamna radiation $(0.093,0.184,0.388 \mathrm{MeV})$ of $67 \mathrm{Zn}$.

The nuclear radiation of copper isotopes are described in Nuclear Data Sheets (National Academy of Sciences-National Research Council), and ref. 16.

\begin{tabular}{|c|c|c|c|}
\hline${ }^{60} \mathrm{Cu}$ & $24 \min$ & $\begin{array}{l}\beta^{+}(93 \%) \\
\text { e.c. }(7 \%) \\
Y\end{array}$ & $\begin{array}{l}2.00,3.00,3.92 \\
0.85,1.33,1.76 \text {, others }\end{array}$ \\
\hline${ }^{61} \mathrm{Cu}$ & $3.3 \mathrm{hrs}$ & $\begin{array}{l}\beta^{+}(68 \%) \\
\text { e.c. }(32 \%) \\
\gamma\end{array}$ & $\begin{array}{l}1.22,0.94,0.56 \\
0.070,0.280,0.38,1.22, \text { others }\end{array}$ \\
\hline${ }^{62} \mathrm{Cu}$ & $9.7 \mathrm{~min}$ & $\begin{array}{l}\beta^{+} \\
\gamma\end{array}$ & $\begin{array}{l}2.91 \\
0.69,0.88,1.13,1.17\end{array}$ \\
\hline${ }^{64} \mathrm{Cu}$ & 12.7 hrs & $\begin{array}{l}\text { e.c. }(42 \%) \\
\beta^{-}(39 \%) \\
\beta^{+}(19 \%) \\
\gamma\end{array}$ & $\begin{array}{l}0.571 \\
0.657 \\
1.34\end{array}$ \\
\hline
\end{tabular}


$29^{\mathrm{Cu}}$ (cont'd.)

$$
\begin{aligned}
& { }^{66} \mathrm{Cu} \quad 5.1 \mathrm{~min} \quad \beta^{-} 2.63,1.5 \\
& \gamma \quad 1.04,0.83 \\
& { }^{67} \mathrm{Cu} \quad 61.7 \text { hrs } \quad B^{-} \quad 0.395,0.484,0.577 \\
& \gamma \quad 0.092,0.182 \\
& \begin{array}{lll}
{ }^{68} \mathrm{Cu} \quad 32 \mathrm{sec} & B^{-} & \sim 3.0 \\
& \gamma & \text { weak }
\end{array}
\end{aligned}
$$


Zinc exists in solution only with a +2 oxidation state, so that oxidation-reduction reactions for carrier exchange need not be considered. Finc is easily electrodeposited and electrolysis methods may be used for preparing counting samples. Insoluble zine compounds suitable for separations and gravimetric determinations include zinc ammonium phosphate, zinc mercurithiocyanate, zinc oxalate, zinc sulfide, as well as many zinc-organic compounds. The wide variety of complex ions and chelate compounds which zine forms may be used to great advantage in the radiochemical determination of this element.

Trace concentrations of zine in the absence of complexing agents may adsorb on filter paper from aqueous solution. Maximum adsorption (90\%) at $2.7 \times 10^{-6} \mathrm{M}$ occurs at $\mathrm{pH} 6.5$. Zinc also adsorbs well on glass and $\mathrm{Fe}(\mathrm{OH})_{3}$ near this $\mathrm{pH}$.

For further details, see H. G. Hicks, "The Radiochemistry of Zinc," USAEC Report NAS-NS-3015 (1960).

\section{Zine - Counting}

Zine-65 decays by electron capture and positron emission with a half-life of 245 days. The maximum positron energy is only $0.326 \mathrm{MeV}$ and occurs in $1.7 \%$ of the disintegrations. A gamma ray of $1.114 \mathrm{MeV}$ is emitted in approximately $49 \%$ of the disintegrations. For these reasons, $65 \mathrm{zn}$ is normally counted by gamma scintillation counting. For special purposes, the $\mathrm{Cu} K \mathrm{~K}$-rays may be used for counting this nuclide.

The nuclear radiations of the zinc isotopes are described in Nuclear Data Sheets(National Academy of Sciences - National Research Council), and ref. 16.

\begin{tabular}{|c|c|c|c|}
\hline $\ln$ & $9.13 \mathrm{~h}$ & $\begin{array}{l}\beta^{+} \\
\gamma\end{array}$ & $\begin{array}{l}0.66 \\
\operatorname{Cu}-\mathrm{X}, 0.042(20 \%), 0.51(47 \%) \\
0.59(22 \%)\end{array}$ \\
\hline & $38.4 \mathrm{~m}$ & $\begin{array}{l}\beta^{+} \\
\gamma\end{array}$ & $\begin{array}{l}2.34 \\
\mathrm{Cu}-\mathrm{X}, 0.511(186 \%), 0.669(8 \%) \\
0.962(6 \%), 1.42(0.9 \%)\end{array}$ \\
\hline $\mathrm{Zn}$ & $245 \mathrm{~d}$ & $\begin{array}{l}\beta^{+} \\
\gamma\end{array}$ & $\begin{array}{l}0.327 \\
\text { Cu-X, } 0.511(3.4 \%), 1.115(49 \%) \\
\text { Shielding: } \\
0-1 \mathrm{mCi} 5 / 8^{\prime \prime} \\
1-10 \mathrm{mCi} 5 / 8^{\prime \prime}+3 / 8^{\prime \prime} \\
10-50 \mathrm{mCi} 5 / 8^{\prime \prime}+1 "\end{array}$ \\
\hline $69 \mathrm{Zn}$ & $57 \mathrm{~m}$ & $\beta^{-}$ & 0.90 \\
\hline $69 m_{\mathrm{Zn}}$ & $13.8 \mathrm{~h}$ & $\gamma$ & $\operatorname{ZnX}, 0.439(95 \%)$ \\
\hline
\end{tabular}


No problem in exchange between carrier and tracer is expected for gallium. It is trivalent in aqueous solutions, and forms $\mathrm{GaCl}^{-}$in dilute $\mathrm{HCl}$. Gallium is amphoteric; near $\mathrm{pH} 7$ it is insoluble at carrier ${ }^{4}$ concentrations and radiocolloidal at tracer concentrations. Sulfates, nitrates, and halides, although soluble, are hydrolized readily at $\mathrm{pH}^{\prime} \mathrm{s}$ above 6 and precipitate basic gallium salts upon boiling.

Gallium trichloride has a boiling point of $215^{\circ} \mathrm{C}$. and will be lost from a solution with a high boiling point or from a deposited sample if this temperature is approached. Metallic gallium can be electrodeposited from an aqueous solution. The metal is liquid above $29.8^{\circ} \mathrm{C}$.

For further details, see J. E. Lewis, "The Radiochemistry of Aluminum and Gallium," USAEC Report NAS-NS-3032 (1961).

$$
\text { Gallium - Counting }
$$

Gallium-67 (half life: 79 hours) decays by electron capture and can be measured by counting zinc X-rays. It decays to an excited state which emits a number of gamma rays-those of $92 \mathrm{keV}$ being the most abundant. The ratio of gamma emission to the disintegration rate does not appear to be accurately known. Gallium-68 (half life: $68 \mathrm{~min}$.) is the daughter of 280-day germanium-68. Of its decay, $88 \%$ is by positron emission, and the remainder by electron capture. Either the positrons or the annihilation radiation are convenientiy counted.

The nuclear radiations of the gallium isotopes are described in Nuclear Data Sheets (National Acadeny of Sciences - National Research Council), and ref. 16.

\begin{tabular}{|c|c|c|c|}
\hline${ }^{66} \mathrm{Ga}$ & $9.45 \mathrm{~h}$ & $\begin{array}{l}\beta^{+} \\
\gamma\end{array}$ & $\begin{array}{l}4.153 \\
\mathrm{Zn}-\mathrm{X}, 0.511(114 \%), 0.828(5 \%) \\
1.039(37 \%), 1.91(3 \%), 2.183(5 \%) \\
2.748(25 \%), 4.30(5 \%)\end{array}$ \\
\hline${ }^{67} \mathrm{Ga}$ & $77.9 \mathrm{~h}$ & $\gamma$ & 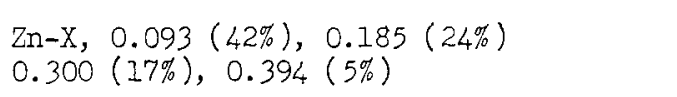 \\
\hline${ }^{68} \mathrm{Ga}$ & $68.3 \mathrm{~m}$ & $\begin{array}{l}\beta^{+} \\
\gamma\end{array}$ & $\begin{array}{l}1.90 \\
\mathrm{Zn}-\mathrm{X} 0.511(176 \%), 0.80(0.4 \%) \\
1.078(3.5 \%), 1.24(0.14 \%), 1.87(0.15 \%)\end{array}$ \\
\hline${ }^{72} \mathrm{Ga}$ & $14.12 \mathrm{~h}$ & $\begin{array}{l}B^{-} \\
\gamma\end{array}$ & $\begin{array}{l}3.15 \\
0.601(8 \%), 0.630(27 \%), 0.835(96 \%) \\
0.894(10 \%), 1.050(7 \%), 1.465(3.5 \%) \\
1.60(5 \%), 1.860(5 \%), 2.201(26 \%) \\
2.50(20 \%)\end{array}$ \\
\hline & $4.9 \mathrm{~h}$ & $\begin{array}{l}\beta^{-} \\
\gamma\end{array}$ & $\begin{array}{l}1.19 \\
0.054(9 \%), 0.295(94 \%), 0.74(6 \%)\end{array}$ \\
\hline
\end{tabular}


Germanium is characterized by chemical properties intermediate to those of silicon and tin. The standard method of separating germanium from other elements is by distillation of $\mathrm{GeCl}_{4}$. Solvent extraction of compounds such as $\mathrm{GeCl}_{4}$ is very helpful in separating germanium for additional purification, and separations based on hydrogen sulfide and the alkaline sulfides are also quite effective. GeS $\mathrm{S}_{2}$ may be mounted for counting, or it and other germanium compounds may be converted to the oxide and ignited to constant weight at $900^{\circ} \mathrm{C}$.

The radiochemical behavior of germanium is summarized in "The Radiochemistry of Germanium" by J. A. Marinsky, USAEC Report NAS-NS-3043 (1961).

\section{Germanium - Counting}

${ }^{68} \mathrm{Ge}$ (287-day) decays entirely by electron capture, and its radioactivity is best measured by first allowing the $68 \mathrm{Ga}$ ( 68.2 minute) daughter to grow to equilibrium. The daughter decays primarily by positron emission ( $87.9 \%$, which is almost entirely due to a $1.90 \mathrm{MeV} B^{+}$-particle), and only $3.6 \%$ of the decays enit a $1.08 \mathrm{MeV} \gamma$-ray. The isotope is therefore best suited to counting by $\mathrm{G}-\mathrm{M}$ or proportional counters.

The positron annihilation radiation $(0.511 \mathrm{MeV})$ can be used for high accuracy measurements with a gamma (scintillation or diode) detector if care is taken to stop all the positrons in a well-defined geometry (e.g., sandwiching between plastic absorbers or counting liquid samples in a well-crystal). $\mathrm{Be}-$ cause of the low branching ratio for the gamma ray emissions and the high percentage of $\mathrm{B}^{+}$-particles emitted, the $1.08 \mathrm{MeV}$ gamma ray is, relatively, not well suited for measuring ${ }^{68} \mathrm{Ge}-68 \mathrm{Ga}$.

The nuclear radiations of $68 \mathrm{Ge}$ are described in Nuclear Data Sheets (National Academy of Sciences - National Research Council), and ref. 16.

$\begin{array}{llll}{ }^{68} \mathrm{Ge} & 287 \mathrm{~d} & \mathrm{EC} & \\ \left.{ }^{68} \mathrm{Ga}\right) & 68.2 \mathrm{~m} & \beta^{+} & 1.90 \mathrm{MeV}(86 \%) \\ & & \beta^{+} & 0.60-1.03 \mathrm{MeV}(1.9 \%) \\ & & \gamma & 1.08 \mathrm{MeV}(3.6 \%) \\ & & \gamma & 0.511 \mathrm{MeV}(87.9 \%) \\ { }^{69} \mathrm{Ge} & 40.4 \mathrm{~h} & \beta^{+} & 1.215 \\ & (36 \mathrm{~h} ?) & & \\ & & \gamma & 0.090,0.388,0.576,0.870 \\ 71_{\mathrm{Ge}} & 11.4 \mathrm{~d} & \mathrm{EC} & 1.12,1.34,1.61 \\ 75 \mathrm{Ge} & 82 \mathrm{~m} & \beta^{-} & 1.19(85 \%), 0.614(15 \%) \\ & & \gamma & 0.066,0.199,0.264,0.427 \\ & & & 0.477,0.628\end{array}$


$32^{\mathrm{Ge}}$ (cont'd.)

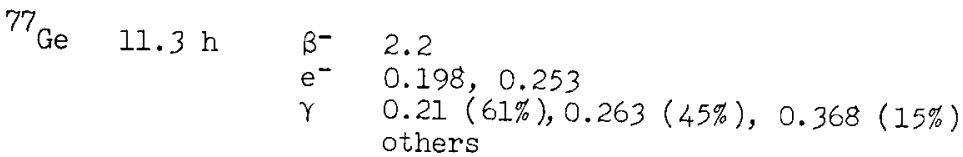


Arsenic in aqueous solution can be either trivalent or pentavalent; hence either oxidation or reduction may be required for exchange between carrier and tracer. In neutral solution, arsenate $\left(\mathrm{AsO}_{4}^{-3}\right)$ ions occur.

The boiling points of arsenous chloride, arsenous bromide, and arsine are 221,130 , and $-55^{\circ} \mathrm{C} .$, respectively; near and above these temperatures, the substances would be lost from solution and from deposited samples. Radioarsenic may be deposited as $\mathrm{As}_{2} \mathrm{~S}_{3}$ or by reducing the halide to the metal (with hypophosphite or by decomposing arsine, for example).

For further details, see H. C. Beard, "The Radiochemistry of Arsenic," USAEC Report NAS-NS-3002 (1960). [Revision 1965]

$$
\text { Arsenic - Counting }
$$

Approximately $32 \%$ of the ${ }^{74}$ As decays occur by beta emission, $30 \%$ by positron emission, and $38 \%$ by electron capture. Although beta particles plus positrons or gamma rays can be measured, the ratios of the individual decay modes to the absolute disintegration rate are not accurately known. Arsenic-76 can be measured by counting the energetic beta particles or the $0.56 \mathrm{MeV}$ gamma ray. Arsenic-77 decays similarly by emitting beta particles and gamna rays, but the energy of the former is below $0.7 \mathrm{MeV}$ and the gamma rays only occur in low intensity. Unless care is taken in depositing the sample for beta counting, selfabsorption will affect the results; the low ratio of gamma rays to disintegrations and the uncertainty in the measured ratio can lead to appreciable errors in computing the disintegration rate from a gamma measurement.

The nuclear radiations of the arsenic isotopes are described in Nuclear Data Sheets (National Academy of Sciences - National Research Council), and ref. 16.

\begin{tabular}{|c|c|c|c|}
\hline${ }^{71} \mathrm{As}$ & $62 h$ & $\begin{array}{l}\beta^{+} \\
\gamma\end{array}$ & $\frac{0.81}{G e-X}, 0.175(90 \%), 0.511(60 \%)$ \\
\hline${ }^{74} \mathrm{As}$ & $17.9 \mathrm{~d}$ & $\begin{array}{l}\beta^{-} \\
\beta^{+} \\
\gamma\end{array}$ & $\begin{array}{l}1.36 \\
1.54(3 \%), 0.95(26 \%), \\
\operatorname{Ge}-\mathrm{X}, 0.511(59 \%), 0.596(61 \%) \\
0.635(14 \%)\end{array}$ \\
\hline 76 As & $26.4 \mathrm{~h}$ & $\begin{array}{l}\beta^{-} \\
\gamma\end{array}$ & $\begin{array}{l}2.97 \\
0.559(43 \%), 0.657(6 \%), 1.22(5 \%) \\
1.44(0.7 \%), 1.789(0.3 \%), 2.10(0.9 \%)\end{array}$ \\
\hline & & & $\begin{array}{l}\text { Shielding: } \\
0-10 \mathrm{mCi} 5 / 8^{\prime \prime} \\
10-50 \mathrm{mCi} 5 / 8^{\prime \prime}+1 "\end{array}$ \\
\hline${ }^{77}$ As & $38.7 \mathrm{~h}$ & $\begin{array}{l}\beta^{-} \\
\gamma\end{array}$ & $\begin{array}{l}0.68 \\
0.086(0.1 \%), 0.239(2.5 \%), 0.522(0.8 \%) \\
{\left[\text { Daughter radiations from } \% 7 \mathrm{~m}_{\mathrm{Se}}\right]:} \\
\text { Se- } \mathrm{X}, 0.161(50 \%)\end{array}$ \\
\hline
\end{tabular}


Selenium in aqueous solution can be either in the IV or the VI state. Selenium is separated from most elements by reduction in acid solutions to precipitate the metal using stannous chloride, $\mathrm{SO}_{2}$ gas, or $\mathrm{Na}_{2} \mathrm{SO}_{3}$ crystals. Selenium may be distilled from $\mathrm{HCl}$ or $\mathrm{HBr}$ for carrier-free separation. If $18 \mathrm{~min} \mathrm{Se}-81$ is measured, traces of 18 -min Br-80 must be removed to avoid interference. For further details see V. J. Molinski and G. W. Leddicotte, "Radiochemistry of Selenium," report NAS-NS-3030 (Rev.) 1965.

\section{Selenium - Counting}

Selenium-75, half-1ife 121 days, emits gamma-rays of $0.365,0.136$, and 0.280 Mev and is a convenient tracer which may be prepared carrier-free by charged particle reactions with arsenic. It is also useful for neutron activation analysis for traces of selenium.

Selenium-77m, half-life $17.5 \mathrm{sec}$, decays by isomeric transition and 0.16 Mev gamma-ray. Selenium-79m, half-life $3.9 \mathrm{~min}$, decays by isomeric transition and $0.096 \mathrm{Mev}$ gamma ray. Both nuclides are useful for rapid neutron activation analysis.

Selenium-81m and 81 , half-lives $56.8 \mathrm{~min}$ and $18.2 \mathrm{~min}$, find some use in activation analysis but suffer from interference by 18 -min $\mathrm{Br}-80$. The nuclear radiations of selenium isotopes are described in Nuclear Data Sheets (NAS-NRC), and ref. 16.

\begin{tabular}{|c|c|c|}
\hline${ }^{75} \mathrm{Se}$ & 120.4 day & $\begin{array}{l}\text { e.c. } \\
\gamma 0.265,0.136,0.280,0.405\end{array}$ \\
\hline $77 \mathrm{~m}_{\mathrm{Se}}$ & $17.5 \mathrm{sec}$ & IT 0.162 \\
\hline${ }^{79} \mathrm{Se}$ & $\leq 6.5 \times 10^{4} \mathrm{y}$ & $\beta^{-} 0.16$ \\
\hline $79 \mathrm{~m}_{\mathrm{Se}}$ & $3.9 \mathrm{~min}$ & IT 0.096 \\
\hline $81 \mathrm{~m}_{\mathrm{Se}}$ & $56.8 \mathrm{~min}$ & $\begin{array}{l}\text { IT } 0.103 \\
\text { [daughter radiations from }{ }^{81} \text { Se] }\end{array}$ \\
\hline${ }^{81} \mathrm{Se}$ & $18.2 \mathrm{~min}$ & $\begin{array}{ll}B^{-} & 1.58 \\
\gamma & 0.28(0.9 \%), 0.56(0.3 \%), 0.83(0.2 \%) \text { others }\end{array}$ \\
\hline $72_{\mathrm{Se}}$ & $8.4 \mathrm{~d}$ & $\begin{array}{l}\text { e. } c . \\
\gamma 0.046(59 \%) \\
\text { [daughter radiations from }{ }^{72} \text { As] }\end{array}$ \\
\hline${ }^{73} \mathrm{Se}$ & $7.1 \mathrm{~h}$ & $\begin{array}{l}\beta^{+}(1.66 \leq 0.7 \%), 1.30 \\
\gamma 0.066(65 \%), 0.359(99 \%), 0.511(130 \%) \\
{\left[\text { daughter radiations from }{ }^{73} \mathrm{As}\right]}\end{array}$ \\
\hline
\end{tabular}


In radioactivity standards, radiobromine usually is prepared as $\mathrm{Br}^{-}$. Molecular bromine and bromate are also common; hence oxidation or reduction may be required for interchange between carrier and tracer. A simple procedure is to add bromate carrier and reduce it to bromide. Organic salts, such as methyl bromide and ethylene dibromide, are also available.

The boiling points of $\mathrm{Br}_{2}$ and $\mathrm{HBr}$ are 59 and $-67^{\circ} \mathrm{C} .\left(126^{\circ} \mathrm{C}\right.$. for the constant-boiling solution of $\mathrm{HBr}^{2}$ in water), respectively; near and above these temperatures, losses would occur from solutions or planchets. A number of metal bromides (antimony tribromide and tin tetrabromide, for instance) also have relatively low boiling points. Radioactive bromine is usually precipitated as $\mathrm{AgBr}$ or interchanged from solution with AgBr.

For further details, see J. Kleinberg and G. A. Cowan, "The Radiochemistry of Fluorine, Chlorine, Bromine, and Iodine," USAEC Report NAS-NS-3005 (1960).

$$
\text { Bromine - Counting }
$$

Bromine-82 decays entirely through beta emission, but the maximum energy of 0.44 $\mathrm{MeV}$ is so low that appreciable self-absorption losses can occur during counting. Measurement by counting its ganma rays, primarily those at 0.55 and $0.77 \mathrm{MeV}$, is convenient, but the number of gamma rays per disintegration is not accurately known.

The nuclear radiations of the bromine isotopes are described in Nuclear Data Sheets (National Academy of Sciences - National Research Council), and ref. 16.

$$
\begin{aligned}
& { }^{75} \mathrm{Br} \quad 1.7 \mathrm{~h} \quad \mathrm{~B}^{+} 1.70 \\
& \gamma 0.285,0.511(180 \%), 0.62 \\
& { }^{76} \mathrm{Br} \quad 16.1 \mathrm{~h} \quad \beta^{+} 3.6 \\
& \gamma \text { Se-X, } 0.511(133 \%), 0.559(63 \%) \\
& 0.65(19 \%), 0.75(6 \%), 0.85(7 \%) \text {, and others } \\
& 77 \mathrm{Br} \quad 57 \mathrm{~h} \quad \mathrm{~B}^{+} 0.34 \\
& \gamma \mathrm{Se}-\mathrm{X}, 0.24(30 \%), 0.300(6 \%), 0.52(24 \%) \text {, } \\
& 0.58(7 \%), 0.75(2 \%), 0.82(3 \%), 1.00(1.3 \%) \\
& \text { [ }{ }^{77} \mathrm{~m}_{\text {Se }} \text { daughter radiations]: } \\
& \gamma \text { As-X, 0.046 (59\%) } \\
& 80 \mathrm{~m}_{\mathrm{Br}} 4.38 \mathrm{~h} \quad \text { Y } \mathrm{Br}-\mathrm{X}, 0.037(36 \%) \\
& {\left[{ }^{80} \mathrm{Br}\right. \text { daughter radiations]: see below }} \\
& { }^{80} \mathrm{Br} \quad 17.6 \mathrm{~m} \quad \beta^{-} 2.00 \\
& \beta^{+} 0.87 \\
& \gamma \operatorname{Se}-\mathrm{X}, 0.511(5 \%), 0.618(7 \%), 0.666(1.0 \%)
\end{aligned}
$$


$\begin{array}{lllll}82 & \mathrm{Br} \quad 35.34 \mathrm{~h} \quad \mathrm{~B}^{-} & 0.444 \\ & \gamma & 0.554(66 \%), & 0.619(41 \%), & 0.698(27 \%) \\ & & 0.777(83 \%), & 0.828(25 \%), & \text { and others }\end{array}$

$35^{\mathrm{Br}}$ (cont'd.) Shielding:

$0-1 \mathrm{mCi} 5 / 8^{\prime \prime}+1 / 4^{\prime \prime}$

$1-10 \mathrm{mCi} \quad 5 / 8^{\prime \prime}+1 "$

$10-50 \mathrm{mCi} 5 / 8^{\prime \prime}+1 \frac{1}{2} "$

${ }^{83} \mathrm{Br} \quad 2.41 \mathrm{~h} \quad \mathrm{~B}^{-} 0.93$

$\gamma 0.530(1.4 \%)$

$\left[{ }^{83 m_{\mathrm{Kr}}}\right.$ daughter radiations]:

Y $\mathrm{Kr}-\mathrm{X}, 0.009(9 \%)$

${ }^{84} \mathrm{Br} \quad 31.8 \mathrm{~m} \quad \beta^{-} 4.68$

$\gamma 0.81(9 \%), 0.88(51 \%), 1.01(10 \%)$, others 
Krypton is almost inert with regard to chemical reactions. Completeness of transfer of krypton from one vessel to another, however, can be affected by the adsorption of krypton on solids (including the walls of the vessels) and by the solubility of krypton in liquids. If transfer is only partially complete, as in simple expansion, transfer loss can be computed from the residual gas pressure and the relative volumes of the vessels. Mixing of carrier and radioactive gas is a physical process and can be performed more rapidly by heating the container.

For further details, see F. F. Momyer, Jr., "The Radiochemistry of the Rare Gasses," USAEC Report NAS-NS-3025 (1960).

$$
\text { Krypton - Counting }
$$

Krypton-85 emits a beta group with $0.67 \mathrm{MeV}$ maximum energy, and, in somewhat less than $1 \%$ of the disintegrations, a $0.51 \mathrm{MeV}$ gamma ray. The radionuclide is usually mixed with the counting gas of a Geiger-Mueller or proportional counter, but can also be counted externally to the counter, in a cell separated from the counter by a thin window. At high concentrations, the radionuclide is measured by counting the ganma ray.

The nuclear radiations of the krypton isotopes are described in Nuclear Data Sheets (National Academy of Sciences - National Research Council), and ref. 16.

\begin{tabular}{|c|c|c|}
\hline $\mathrm{Kr}$ & $34.92 \mathrm{~h}$ & $\begin{array}{ll}\text { e. } & c . \\
B^{i} & 0.60 \\
\gamma & 0.136(0.7 \%), 0.261(9 \%), 0.398(10 \%), \text { others }\end{array}$ \\
\hline $\mathrm{m}_{\mathrm{Kr}}$ & $1.86 \mathrm{~h}$ & $\gamma \mathrm{Kr}-\mathrm{X}, 0.009(9 \%)$ \\
\hline & $10.76 \mathrm{y}$ & $\begin{array}{ll}\beta^{-} & 0.67 \\
\gamma & 0.514(0.41 \%)\end{array}$ \\
\hline $85 m_{K r}$ & $4.4 \mathrm{~h}$ & $\begin{array}{l}\beta^{-} 0.82 \\
\gamma \quad \mathrm{Kr}-\mathrm{X}, 0.150(74 \%), 0.305(13 \%)\end{array}$ \\
\hline${ }^{87} \mathrm{Kr}$ & $76 \mathrm{~m}$ & 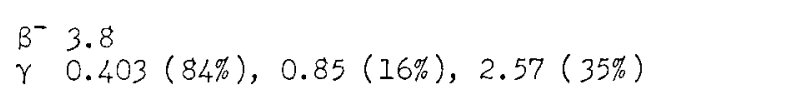 \\
\hline${ }^{88} \mathrm{Kr}$ & $2.80 \mathrm{~h}$ & 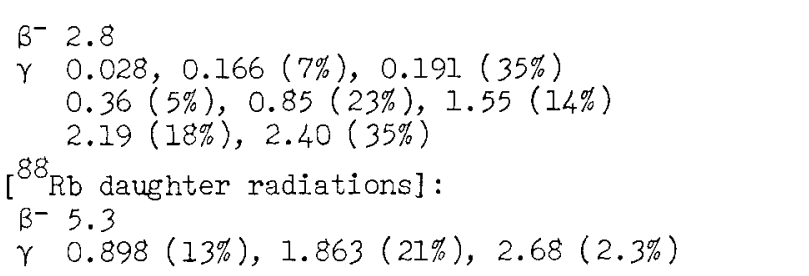 \\
\hline
\end{tabular}


Strontium is usually divalent in aqueous solutions, so no problems arise in exchange between carrier and tracer. The solution should be acid to prevent precipitation or radiocolloid formation in the presence of carbonate from $\mathrm{CO}_{2}$ in the air. Sulfate on glassware (from cleaning solution, for example) or in water may also cause precipitation or radiocolloid formation.

Strontium is precipitated for counting as the carbonate or oxalate. Strontium-90 is accompanied by its radioactive yttrium-90 daughter; any chemical separation may affect the equilibrium between the two.

For further details, see D. N. Sunderman and C. W. Townley, "The Radiochemistry of Barium, Calcium, and Strontium," USAEC Report NAS-NS-3010 (1960).

$$
\text { Strontium - Counting }
$$

Strontium-89 and -90 emit only beta particles. Strontium-89 can be effectively measured by beta counting. Self-absorption losses may occur in counting strontium-90 separated from its yttrium-90 daughter because the beta particles have a maximum energy of only $0.54 \mathrm{MeV}$. Yttrium-90, however, emits beta particles with high maximum energy $(2.27 \mathrm{MeV})$ and this radiation may be counted easily. If the equilibrium between parent and daughter has been disturbed, counting must be delayed for approximately 3 weeks to re-establish equilibrium or the amount of $90 \mathrm{Y}$ present must be determined by calculation.

Strontium-85 decays by electron capture, followed by the emission of a

$0.51 \mathrm{MeV}$ ganma ray. Either the gamma ray or the rubidium X-ray can be counted. The nuclear radiations of the strontium isotopes are described in Nuclear Data Sheets (National Academy of Sciences - National Research Council), and ref. 16.

$$
\begin{aligned}
& { }^{83} \mathrm{Sr} \quad 32.4 \mathrm{~h} \quad \beta^{+} 1.15 \\
& \gamma \mathrm{Rb}-\mathrm{X}, 0.040(24 \%), 0.38(35 \%), 0.511(32 \%), \\
& 0.76(40 \%), 1.16,1.52 \\
& \text { [ } 83 \mathrm{Rb} \text { daughter radiations]: } \\
& \gamma \mathrm{Kr}-\mathrm{X}, 0.53(93 \%), 0.79(0.9 \%) \\
& { }^{85} \mathrm{Sr} \quad 64.0 \mathrm{~d} \quad \gamma \mathrm{Rb}-\mathrm{X}, 0.514(100 \%) \\
& 87 \mathrm{~m}_{\mathrm{Sr}} 2.83 \mathrm{~h} \quad \gamma \mathrm{Sr}-\mathrm{X}, 0.388(80 \%) \\
& { }^{89} \mathrm{Sr} \quad 50.5 \text { d } \quad \beta^{-} 1.463 \\
& \gamma 0.91(0.009 \%) \\
& 90_{\mathrm{Sr}} \quad 27.7 \mathrm{y} \quad \beta^{-} 0.546 \\
& \text { [ } 90 \text { Y daughter radiations]: } \\
& \beta^{-} 2.27
\end{aligned}
$$




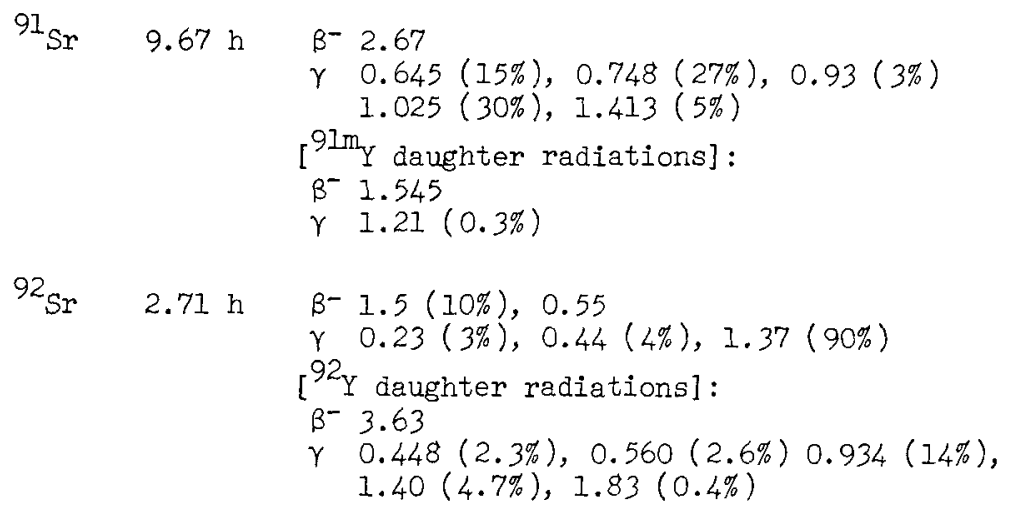


In aqueous solutions, the valence of yttrium is +3 , and exchange between soluble carrier and radionuclide is only a matter of physical mixing. Yttrium hydrolyzes and is adsorbed on glassware, dust particles, and other surfaces above $\mathrm{pH}$ 5. Yttrium precipitates or forms radiocolloids in the presence of oxalates or phosphates in dilute acids, and with fluorides in strong acids.

Yttrium is usually precipitated for counting with oxalic acid. Rare earths, if present, will also precipitate.

For further details, see P. C. Stevenson and W. E. Nervik, "The Radiochemistry of the Rare Earths, Scandium, Yttrium, and Actinium, "USAEC Report NAS-NS-3020 (1961).

$$
\text { Yttrium - Counting }
$$

Yttrium-88 decays almost completely by electron capture (positron emission is approximately $0.5 \%$ of the total), followed by the emission of $0.90 \mathrm{MeV}$ ( $92 \%$ ) and $1.83 \mathrm{MeV}$ (100\%) gamma rays in coincidence. It can be measured by counting these ganna rays or the strontium X-rays.

Yttrium-90 is a pure beta emitter and can be beta counted effectively because of the high maximum energy of the particles. Yttrium-9l emits a beta group with a maximum beta energy of $1.55 \mathrm{MeV}$, and in addition a $1.2 \mathrm{MeV}$ gamma ray in $0.2 \%$ of its disintegrations.

Yttrium carrier, unless especially purified, is generally contaminated with thorium and its radioactive daughters.

The nuclear radiations of the yttrium isotopes are described in Nuclear Data Sheets (National Academy of Sciences - National Research Council), and ref. 16.

$$
\begin{aligned}
& 86_{Y} \quad 14.6 \mathrm{~h} \quad \text { e. c. } \\
& \beta^{+} 3.15,2.34 \\
& \gamma 0.443(14 \%), 0.511,0.63(37 \%), 0.704(14 \%) \text {, others } \\
& 87 \mathrm{Y} \quad 80 \mathrm{~h} \quad \text { e. c. } \\
& \beta^{+} 0.7 \\
& \begin{array}{l}
\gamma \quad 0.483 \\
\text { [daughter radiations from } 87 \mathrm{~m}_{\mathrm{Sr}} \text { ] }
\end{array} \\
& \begin{array}{llll}
87 \mathrm{~m}_{\mathrm{Y}} & 14 \mathrm{~h} & \mathrm{~B}^{+} \\
& \gamma & 0.381(74 \%) & \text { [daughter radiations from }
\end{array}
\end{aligned}
$$

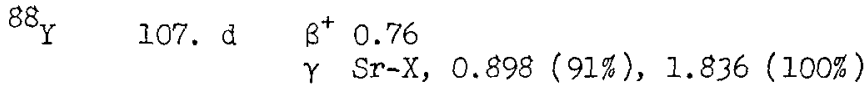

$$
\begin{aligned}
& 90_{\mathrm{Y}} \quad 64.0 \mathrm{~h} \quad \mathrm{~B}^{-} 2.27 \\
& 90 \mathrm{~m}_{\mathrm{Y}} \quad 3.1 \mathrm{~h} \quad \gamma \quad 0.202(97 \%), 0.482(91 \%), 2.315(0.4 \%) \text {, [daughter radiation } \\
& \text { from 90Y] }
\end{aligned}
$$




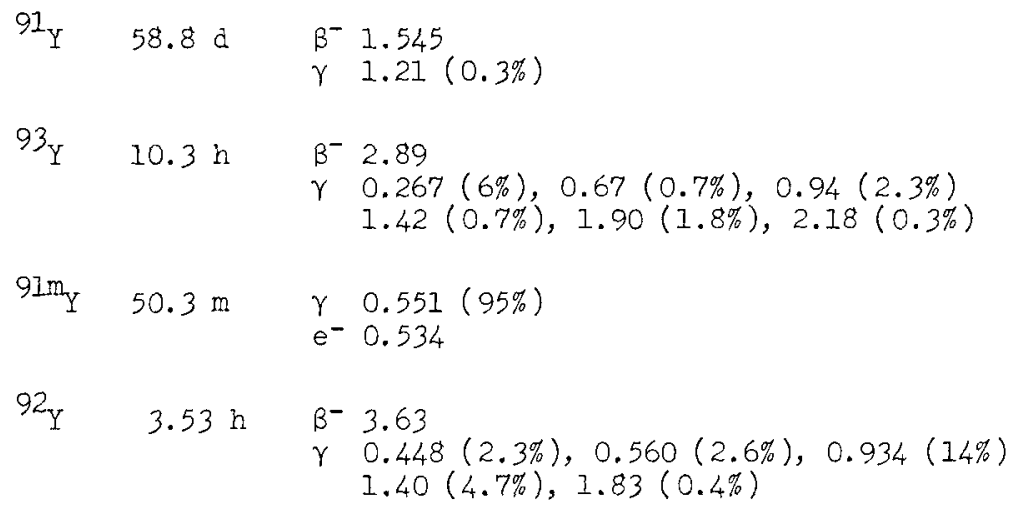


In aqueous solutions, zirconium is normally tetravalent. It hydrolyzes in bases and dilute acids, and either precipitates or forms radiocolloids that absorb on surfaces and settle in solutions. It is maintained soluble by complexing with hydrofluoric acid or oxalic acid. Zirconium is precipitated from acid solutions as zirconyl phosphate, iodate, phenylarsonate, cupferrate, and mandelate, and as barium fluozirconate.

The niobium-95 daughter of zirconium-95 also forms radiocolloids under many conditions; unless the solution contains appropriate complexing agents, such as oxalic acid, transient equilibrium between the two will probably have been disturbed.

For further details, see E. P. Steinberg, "The Radiochemistry of Zirconium and Hafnium," USAEC Report NAS-NS-3011 (1960).

\section{Zirconium - Counting}

Zirconium-95 is readily measured by counting the gamma rays of 0.72 and 0.75 $\mathrm{MeV}$ energy which together occur in $98 \%$ of its disintegrations. The gamma rays are emitted subsequent to beta decay of $0.40 \mathrm{MeV}$ maximum energy. Samples must therefore be prepared carefully for beta counting to minimize self-absorption.

Niobium-95m and -95 , with half lives of 90 hours and 35 days, respectively, are the radioactive daughters of $95 \mathrm{zr}$. Niobium-95m is formed in $2 \%$ of the $95 \mathrm{Zr}$ decays and can be in secular equilibrium with $95 \mathrm{Zr}$; $95 \mathrm{Nb}$ grows into $98 \%$ of $95 \mathrm{Zr}$ and can be in transient equilibrium, at which time there are 2.17 times as many disintegrations of ${ }^{95} \mathrm{Nb}$ as of $95 \mathrm{Zr}$. Most accurate results are achieved by counting freshly separated $95 \mathrm{zr}$ or by maintaining parent and daughter in equilibrium. In intermediate situations, the ratio of $95 \mathrm{Zr}$ to $95 \mathrm{Nb}$ is difficult to compute accurately from decay measurement or beta absorption curves; the gamma rays of the two radionuclides are of almost identical energies, but can be distinguished with $\mathrm{Ge}(\mathrm{Li})$ detectors.

The nuclear radiations of the zirconium isotopes are described in Nuclear Data Sheets (National Acadeny of Sciences - National Research Council), and ref. 16.

\begin{tabular}{|c|c|c|}
\hline${ }^{89} \mathrm{Zr}$ & $78.4 \mathrm{~h}$ & $\begin{array}{l}\beta^{+} 0.90 \\
\gamma \mathrm{Y}-\mathrm{X}, 0.511(44 \%), 0.91(99 \%), 1.71(1 \%)\end{array}$ \\
\hline${ }^{95} \mathrm{Zr}$ & $65.5 \AA$ & $\begin{array}{l}\beta^{-} 0.89(2 \%), 0.396 \\
\gamma \quad 0.724(43.5 \%), 0.757(54.3 \%), \\
\text { Shielding: } \\
0-1 \mathrm{mCi} \quad 5 / 8 "+1 / 4^{\prime \prime} \\
1-10 \mathrm{mCi} \quad 5 / 8^{\prime \prime}+3 / 4^{\prime \prime} \\
10-50 \mathrm{mCi} 5 / 8^{\prime \prime}+1^{\prime \prime} \\
\\
{\left[{ }^{95} \mathrm{Nb} \text { daughter radiations]: }\right.} \\
\beta^{-} 0.160 \\
\gamma \quad 0.765 \text { (100\%) } \\
{[95 \mathrm{mb} \text { daughter radiations]: }} \\
\gamma \mathrm{Nb}-\mathrm{X}\end{array}$ \\
\hline
\end{tabular}


$40^{2 r}$ (cont'd.)
${ }^{97} \mathrm{Zr} \quad 17.0 \mathrm{~h} \quad \beta^{-} 1.91$
$\gamma 0.747(92 \%)$
[ ${ }^{97} \mathrm{Nb}$ daughter radiations] :
$\beta^{-} 1.21$
$\gamma 0.665(98 \%)$


Niobium is found in aqueous solution as pentavalent complexes. In the absence of suitable complexing agents, it forms the insoluble pentoxide or hydrous oxide in both bases and acids, and is radiocolloidal at tracer quantities. Its radiocolloid adsorbs on surfaces of precipitates and containers. Oxalate and fluoride complexes of niobium are soluble.

Niobium fluoride, bromide, and chloride all have boiling points between 229 and $270^{\circ} \mathrm{C}$., and can be lost by heating high-boiling solutions or dry deposits near or above these temperatures. The radionuclide is precipitated for weighing as the oxide by destroying its soluble complex.

For further details, see E. P. Steinberg, "The Radiochemistry of Niobium and Tantalum," USAEC Report NAS-NS-3039 (1961).

Niobium - Counting

Niobium-95 is normally measured by counting its $0.77 \mathrm{MeV}$ gamma ray, which is emitted in $99 \%$ of its disintegrations. The maximum beta energy of niobium-95, $0.17 \mathrm{MeV}$, is too low for accurate beta counting except with liquid scintillation counters. In the latter, $14 \mathrm{C}$ may be used as standard. Niobium may also be standardized by beta-gamma coincidence counting.

The nuclear radiations of the niobium isotopes are described in Nuclear Data Sheets (National Academy of Sciences - National Research Council), and ref. 16.

$$
\begin{aligned}
& 91 \mathrm{~m}_{\mathrm{Nb}} \quad 64 \AA \quad \gamma \mathrm{d} \quad \mathrm{X}, 0.104(0.5 \%), 1.21(3 \%) \\
& 92 \mathrm{~m}_{\mathrm{Nb}} \quad 10.16 \text { d } \quad \gamma \mathrm{Zr}-\mathrm{X}, 0.934(99 \%) \\
& { }^{94} \mathrm{Nb} \quad 2.0 \times 10^{4} \text { y } B^{-} 0.49 \\
& \gamma 0.72(100 \%), 0.871(100 \%) \\
& { }^{95} \mathrm{Nb} \quad 35.0 \mathrm{~d} \quad \mathrm{~B}^{-} 0.160 \\
& \gamma 0.765(100 \%) \\
& \text { Shielding : } \\
& \text { 0-1 mCi } 5 / 8^{\prime \prime}+1 / 4^{\prime \prime} \\
& 1-10 \mathrm{mCi} \quad 5 / 8^{\prime \prime}+3 / 4^{\prime \prime} \\
& 10-50 \mathrm{mCi} 5 / 8^{\prime \prime}+1^{\prime \prime} \\
& { }^{96} \mathrm{Nb} \quad 23.35 \mathrm{~h} \quad \beta^{-} 0.7 \\
& \gamma 0.459(28 \%), 0.569(59 \%), 0.778(97 \%) \\
& 0.811(14 \%), 0.851(22 \%), 1.092(49 \%) \\
& 1.200(21 \%)
\end{aligned}
$$


Molybdenum has known oxidation states of $0,+1,+2,+3,+4,+5$, and +6 . The +6 oxidation state is the one most commonly found in aqueous solution. Molybdenum is generally considered to exist in solution as an oxygenated anion ( MoO ${ }_{4}=$ ) in the +6 state. In acidic solutions, exchange between tracer amounts of molybdenum activity and molybdenum carrier can be assured by heating with bromine water. Water soluble compounds of molybdenum (VI) include ammonium, sodium, potassium, and magnesium salts of normal molybdates.

For further details, see E. M. Scadden and N. E. Ballou, "The Radiochemistry of Molybdenum," USAEC Report NAS-NS-3009 (1960).

$$
\text { Molybdenum - Counting }
$$

The commonly available radioisotope of molydenum is 99 Mo( 66.7 hour) which is inevitably accompanied by its $99 \mathrm{~m} \mathrm{Tc}$ ( 6.0 hour) daughter activity, unless technetium was freshly separated from the molybdenum. Since 99. decays predominantly by the enission of energetic ( $1.2 \mathrm{MeV}$ ) beta particles, it is best counted with a G.M. or beta proportional counter. Samples are normally counted after about 18 hours from the last Mo-Te separation to allow the contribution due to the technetium daughter to reach equilibrium. The amount of this contribution will vary with the sample thickness and beta-counter window thickness. Selective counting of the $0.74-\mathrm{MeV}$ gamma ray with a calibrated $\mathrm{NaI}(\mathrm{Tl})$ scintillation or $\mathrm{Ge}(\mathrm{Li})$ gamma detector and pulse height analyzer system allows direct and immediate counting of the 99 Mo to be done.

The nuclear radiations of the molybdenun isotopes are described in Nuclear Data Sheets (National Academy of Sciences - National Research Council), and refs. 15 and 16 .

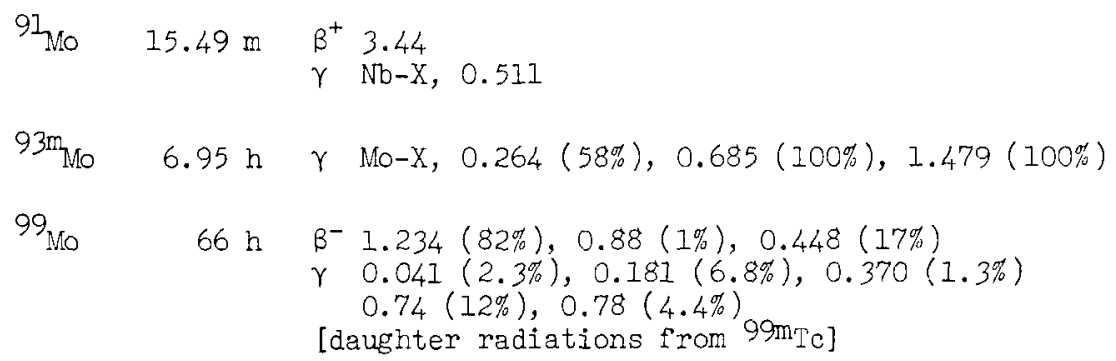


There are no known stable isotopes of this element, but there are three long lived isotopes $97_{\mathrm{TC}}, 98_{\mathrm{TC}}$, and $99 \mathrm{Tc}$. Gram amounts of $99 \mathrm{Tc}$ are available as a separated fission product. Technetium exists as the metal, and in solution the common oxidation states are $+4,+5$, and +7 . The +7 oxidation state as the pertechnetate $\mathrm{TeO}_{4}^{-}$ion is stable in either acid or basic solution.

Technetium heptasulfide $\mathrm{Tc}_{2} \mathrm{~S}_{7}$ may be precipitated from an acid solution of $\mathrm{TeO}_{4}^{-}$with hydrogen sulfide. Technetium can be removed from pertechnetate solutions as $\mathrm{TCO}_{2}$ by a strong reducing agent like stannous chloride. Pertechnetate is extracted from basic solutions ( $1-5 \mathrm{~N} \mathrm{NaOH}$ ) with methyl ethyl ketone and this can be used as a separation from Mo and Ru. Technetium as $\mathrm{TcO}$ - when reduced in the presence of strong chelating agents as EDTA or DTPA form stable complexes. For further details on the chemical properties of technetium see "The Radiochemistry of Technetium" by E. Anders, NAS-NS 3021 (1960). Technetium isotopes are usually available as an aqueous solution of ammonium, sodjum or potassium pertechnetate. The isotope $99 \mathrm{~m}_{\mathrm{Tc}}$ (half-life 6.0 hours) is very widely used in nuclear medicine as a diagnostic tracer. It is readily available commercially in the form of a $99 \mathrm{~m}_{\mathrm{Te}}$ generator from which $99 \mathrm{~m} \mathrm{Te}$ is readily milked from its parent 99Mo. This isotope is also available in solution separated from its parent $99 \mathrm{MO}$.

\section{Technetium - Counting}

The $140 \mathrm{keV} \gamma$ from $99 \mathrm{~m}_{\mathrm{TC}}$ is easily counted with NaI(TI) scintillation detectors or $\mathrm{Ge}(\mathrm{Ii})$ solid state detectors. These detectors can be standardized for $99 \mathrm{~m}_{\mathrm{Tc}}$ radiation by comparison to $57 \mathrm{Co}$ standards (half-life 270 days, $122 \mathrm{keV}$ ( $87 \%$ ) $136(11 \%)$. A variety of precalibrated ionization chambers are available commercially for assaying high level $99 \mathrm{~m}$ Tc samples commonly used in medical applications. The nuclear radiations of the technetium isotopes are discussed in ref. 16.

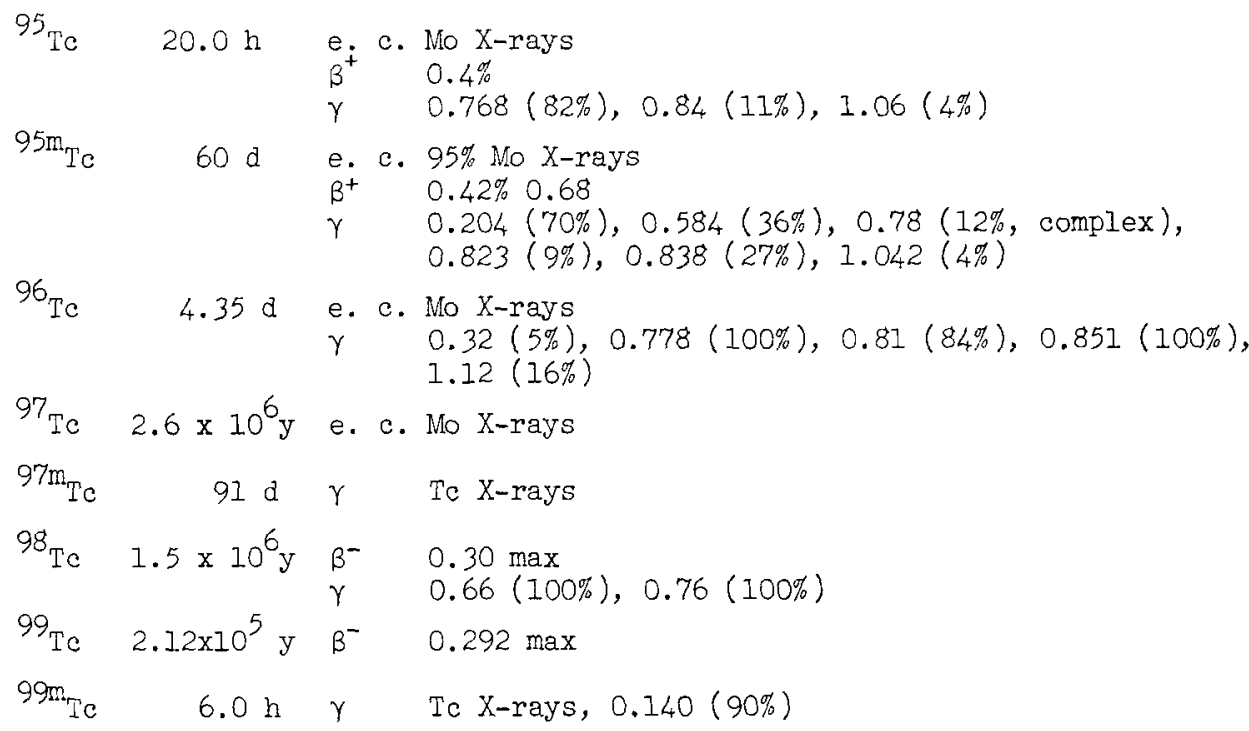


In standardized solutions, radioactive ruthenium is usually trivalent; it can, however, take all oxidation states between zero and eight. In addition to metallic and cationic ruthenium, oxyanions and coordination compounds such as nitrosylruthenium commonly occur. Attaining or maintaining a desired oxidation state, or achieving exchange between the radionuclide and stable ruthenium, may be difficult.

Ruthenium tetroxide is volatile and is easily lost. The tetroxide can be formed from some lower oxidation states by use of a strong oxidant in acid solution. At very low concentrations, trivalent ruthenium does not remain stable in either neutral or basic solution. Ruthenium trioxide and dioxide are reduced to the metal by more electropositive metals such as magnesium. Metallic ruthenium readily precipitates from solution.

The most common radioisotopes of ruthenium are the fission products 40-day ${ }_{103} \mathrm{Ru}$ and 1.0-year 106Ru. Ruthenium-106 decays completely to 30-second 106 Rh, and approximately $3 \%$ of $103 \mathrm{Ru}$ decays to 57 -minute $103 \mathrm{~m} \mathrm{Rh}$. When undisturbed for several daughter half lives, these daughters will be in secular equilibrium with their ruthenium parents. In preparing samples to measure these daughters, the chemical behavior of the daughters must be considered.

For further details, see E. I. Wyatt and R. R. Rickard, "The Radiochemistry of Ruthenium," USAEC Report NAS-NS-3029 (1961).

Ruthenium - Counting

Ruthenium-106 emits beta particles with a maximum energy of $39 \mathrm{keV}$, and can be counted by itself only with a detector sensitive to very low-energy beta particles. Its rhodium-106 daughter, however, emits energetic beta particles and gamma rays that can be measured with most beta or gamma detectors. The 513 and $624 \mathrm{keV}$ gamma rays are emitted in 20 and $10 \%$, respectively, of the disintegrations of rhodium-106. The low-energy beta particles of ruthenium-106 can be eliminated with a thin absorber when rhodium-106 beta particles are counted.

Approximately 96\% of the beta particles emitted by ruthenium-106 are below $212 \mathrm{keV}$; self-absorption of these particles in the sample and absorption between sample and detector cause problems in beta counting. A $498 \mathrm{keV}$ gamma ray following $88 \%$ of the beta particles can be measured conveniently with gamma detectors. Ruthenium-103 decays to 57-minute rhodium-103m, which emits a highly converted ganma ray.

Both rhodium-106 and ruthenium-103 can be measured by coincidence counting. In mixtures of the two radioisotopes, one may be distinguished from the other because the intensity of the $0.5 \mathrm{MeV}$ gamma ray relative to the $0.6 \mathrm{MeV}$ garma ray is much greater in ruthenium-103 than in ruthenium-106.

The nuclear radiations of the ruthenium isotopes and their radioactive rhodium daughters are described in Nuclear Data Sheets (National Academy of Sciences - National Research Council), and ref. 16.

\begin{tabular}{|c|c|c|c|}
\hline${ }^{97} \mathrm{Ru}$ & $2.88 \mathrm{~d}$ & $\gamma$ & Tc-X, $0.215(91 \%), 0.324(8 \%$ \\
\hline${ }^{0} 3_{R u}$ & $39.5 \mathrm{~d}$ & $\begin{array}{l}\beta^{-} \\
\gamma\end{array}$ & $\begin{array}{l}0.70,0.21 \\
0.497(88 \%), 0.610(6 \%)\end{array}$ \\
\hline & & & $\begin{array}{l}\text { Shielding: } \\
0-1 \mathrm{mCi} 5 / 8^{\prime \prime} \\
1-10 \mathrm{mCi} 5 / 8^{\prime \prime}+1 / 8^{\prime \prime} \\
10-50 \mathrm{mCi} 5 / 8^{\prime \prime}+1 "\end{array}$ \\
\hline
\end{tabular}


${ }_{44}^{\mathrm{Ru}}$ (cont'd.)

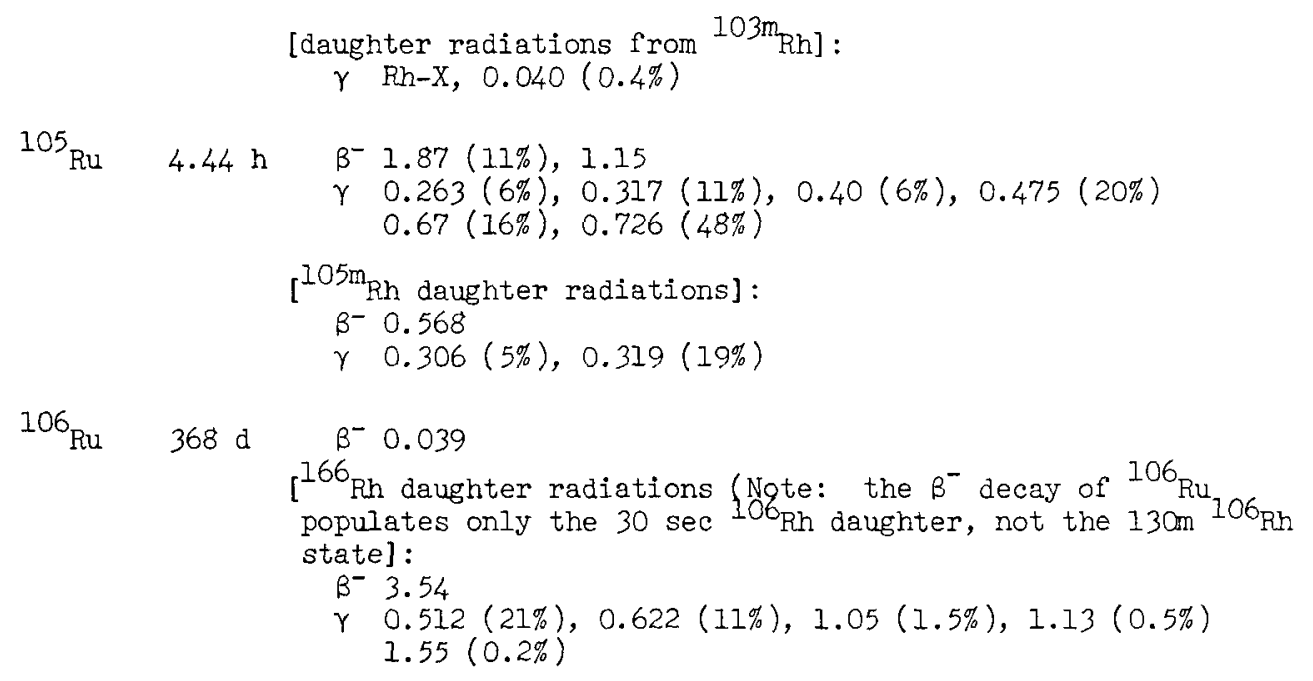


Rhodium is commonly trivalent, and forms many of the complexes typical of group VIII and especially of Co (III). Exchange is difficult to achieve among these species. The uncomplexed ion hydrolyzes at pH 6 and above, forming a precipitate at higher concentrations and a radiocolloid in tracer quantities.

Rhodium can be prepared for counting by reduction to the metal with magnesium or $\mathrm{TiCl}_{3}$, or by electrodeposition.

For further details, see J. C. Armstrong, Jr. and G. R. Choppin, "The Radiochemistry of Rhodium," USAEC Report NAS-NS-3008 (Rev.) (1965).

\section{Rhodium - Counting}

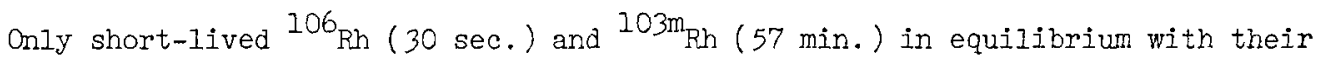
ruthenium parents are available.

The nuclear radiations of the rhodium isotopes are described in Nuclear Data Sheets (National Academy of Sciences - National Research Council), and ref. 16.

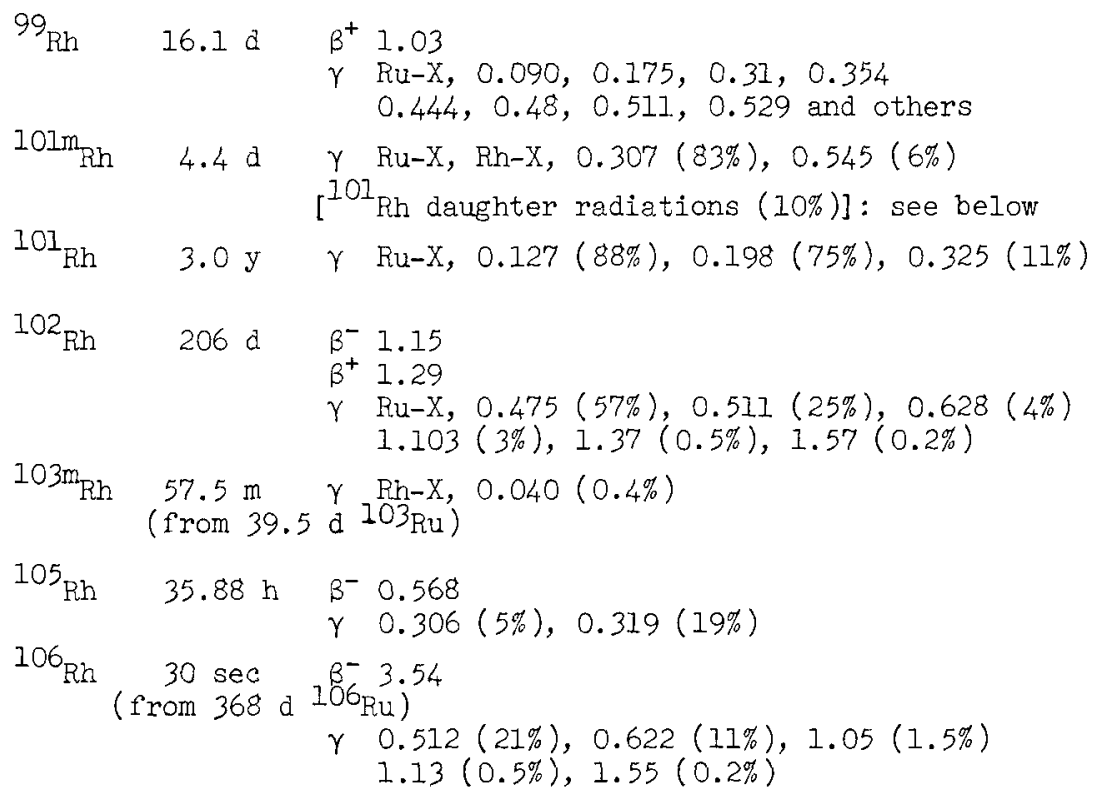


Silver is monovalent in aqueous solution, hence carrier and radionuclide exchange rapidly. It forms insoluble chlorides, bromides, iodides, oxides, and sulfides, and soluble complexes with a number of inorganic salts, such as ammonia, iodate, and chloride. At high $\mathrm{pH}$, trace amounts become radiocolloidal. Formation of a radiocolloid may be caused by traces of chloride or bromides either in solution (e.g., from solution of $\mathrm{HCl}$ or $\mathrm{HBr}$ vapor) or on container walls.

Metallic silver is formed electrolytically or by reducing $\mathrm{Ag}^{+}$with formic acid, ascorbic acid, or zinc. Ionic silver exchanges readily with silver halide precipitates.

For further details, see D. N. Sunderman and C. W. Townley, "The Radiochemistry of Silver," USAEC Report NAS-NS-3047 (1961).

Silver - Counting

Silver-105 decays by electron capture and can be measured by counting the Pd Xray or its major gamma rays at 64,280 , and $344 \mathrm{keV}$. Nany other gamma rays are emitted in low intensity, but accurate gamma abundances are not available.

Silver-110m decays by beta and gamma emission. Beta decay is through two groups of approximately equal intensity with maximum beta decay energies of 0.08 and $0.53 \mathrm{MeV}$; hence beta counting is not a suitable means of standardization. The gamma decay is complex, with the highest intensity gamma ray having approximately $0.68 \mathrm{MeV}$. The $24-\mathrm{sec}$. $110 \mathrm{Ag}$ daughter is formed in $5 \%$ of the decays of $110 \mathrm{~m}_{\mathrm{Ag}}$.

The nuclear radiations of the silver isotopes are described in Nuclear Data Sheets (National Academy of Sciences - National Research Council), and ref. 16.

$$
\begin{aligned}
& { }^{105} \mathrm{Ag} \quad 40 \mathrm{~d} \quad \gamma \quad \mathrm{Pd}-\mathrm{X}, 0.064(10 \%), 0.280(32 \%), 0.344(42 \%) \\
& 0.443(10 \%), \quad 0.65(12 \%), 1.088(2 \%) \\
& 106 \mathrm{~m}_{\mathrm{Ag}} 8.5 \mathrm{~d} \quad Y \quad \mathrm{Pd}-\mathrm{X}, 0.221(9 \%), 0.512(86 \%), 0.717(31 \%) \\
& 1.528(15 \%) \text {, and others } \\
& 110 \mathrm{~m} A g \quad 250 \mathrm{~d} \quad B^{-} 1.5(0.6 \%), 0.53(31 \%), 0.087 \\
& \gamma 0.658(96 \%), 0.68(16 \%), 0.706(19 \%), 0.764(23 \%) \\
& 0.818(8 \%) \text {, and others } \\
& \text { Shielding: } \\
& 0-1 \mathrm{mCi} 5 / 8^{\prime \prime}+1 / 8^{\prime \prime} \\
& 1-10 \mathrm{mCi} 5 / 8^{\prime \prime}+1 " \\
& 10-50 \mathrm{mCi} 5 / 8^{\prime \prime}+2^{\prime \prime} \\
& {\left[{ }^{110} \mathrm{Ag}\right. \text { daughter radiations] : }} \\
& B^{-} 2.87 \\
& \gamma 0.658(4.5 \%) \\
& \begin{array}{lll}
{ }^{111} \mathrm{Ag} \quad 7.5 \mathrm{~d} \quad \beta^{-} & 1.05 \\
& \quad \gamma \quad 0.247(1 \%), 0.342(6 \%)
\end{array} \\
& \begin{array}{lll}
112 \mathrm{Ag} \quad 3.14 \mathrm{~h} \quad B^{-} 3.94 \\
& \gamma \quad 0.617(41 \%), 1.40(5 \%), 1.63(3 \%), 2.11(3 \%)
\end{array} \\
& 2.55(2 \%) \text {, and others }
\end{aligned}
$$


Cadmium has only one valence, +2 , which is stable in aqueous solution. All of the common salts of cadmium are soluble in water, with the exception of the sulfide, carbonate, oxalate, phosphate, cyanide, ferrocyanide, ferricyanide, and hydroxide. Cadmium is precipitated with $\mathrm{H}_{2} \mathrm{~S}$ in dilute acid or basic solution and is insoluble in $\left(\mathrm{NH}_{4}\right)_{2} \mathrm{~S}_{\mathrm{x}}$. The sulfide formed between $218^{\circ} \mathrm{C}$. and $420^{\circ} \mathrm{C}$. is suitable for weighing. Cadmium hydrolyzes at $\mathrm{pH}>5$ in aqueous solution. It is possible to coprecipitate cadmium onto many substances: Any precipitate which allows chemical interaction with cadmium which is comparable to hydrolysis on a hydrous oxide will carry cadmium. Cadmium coprecipitates on $\mathrm{AgCl}$.

For further details, see J. R. DeVoe, "The Radiochemistry of Cadmium," USAEC Report NAS-NS-3001 (1960).

\section{Cadmium - Counting}

Cadmium-109 is produced by proton bombardment of ${ }^{109} \mathrm{Ag}$ via a $(\mathrm{p}, \mathrm{n})$ reaction, which yields a carrier-free product with a radiochemical purity greater than 99.9\%. In addition, reactor production from silver targets is an important production method. The reactions are:

$$
{ }^{107} \mathrm{Ag}(\mathrm{n}, \mathrm{\gamma}){ }^{108} \mathrm{Ag} \frac{\mathrm{B}^{-}}{2.4 \mathrm{~m}}{ }^{108} \mathrm{Cd}(\mathrm{n}, \mathrm{\gamma}){ }^{109} \mathrm{Cd}
$$

The reactor-produced products available commercially usually have a specified purity of $98 \%$ or greater. Common impurities are $115 \mathrm{~m}_{\mathrm{Cd}}$ and $110 \mathrm{~m} \mathrm{Ag}$. Both the accelerator-produced and reactor-produced products are supplied in $20.5 \mathrm{~N} \mathrm{HCl}$. The accelerator material is carrier-free, and the reactor material has a specific activity of $1-5 \mathrm{Ci} / \mathrm{g}$.

$109 \mathrm{Cd}$ decays by electron capture (100\%) with a half-life of 1.26 years. It decays to an isomeric level $(40 \mathrm{~s} \mathrm{Tl} / 2$ ) at $88.04 \mathrm{keV}$ in $109 \mathrm{Ag}$. The isomeric transition in $109 \mathrm{~m} \mathrm{Ag}$ has $\mathrm{eK} / \mathrm{\gamma}$ of 11.2 and $\mathrm{K} / \mathrm{L}+\mathrm{M}=0.87$ yielding a total conversion coefficient of 0.96 . Therefore, a source of $109 \mathrm{Cd}$ decays by the emission of $88.04 \mathrm{keV}$ gamma-rays (from $109 \mathrm{~m} \mathrm{Ag}$ ) in $4 \%$ of the $109 \mathrm{Cd}$ decays. $\mathrm{K}$ and $\mathrm{L}$ $\mathrm{X}$-rays from the $\mathrm{EC}$ and $\mathrm{IT}$ rearrangements in the $\mathrm{Ag}$ daughter nucleus are also important for spectroscopy applications. In certain rapid separations with ${ }_{109} \mathrm{Cd}$, care should be exercised to ensure equilibrium of the $109 \mathrm{~m}_{\mathrm{Ag}}$ daughter before counting the $88.04 \mathrm{keV}$ gamma-ray (wait $6-8$ minutes).

Cadmium-115m is produced commercially by neutron irradiation of cadmium with a usual specific activity of $0.1-2 \mathrm{Ci} / \mathrm{g}$ and a radiochemical purity of $98 \%$ or greater (exclusive of daughters). It is routinely supplied in $0.5 \mathrm{~N} \mathrm{HCl}$ solution. Common impurities are $1.3 \mathrm{yr} 109 \mathrm{Cd}$ and $240 \mathrm{~d} 110 \mathrm{~m}_{\mathrm{Ag}}$, especially in older preparations. Cadmium-115m has a half-life of 43 days with a beta emission of $1.6 \mathrm{MeV}$ in $97 \%$ of its decays. Camma-rays of $0.49,0.94$ and $1.29 \mathrm{MeV}$ are emitted in $0.3,1.9$, and 0.9 percent of the decays respectively. Fresh preparations of $115 \mathrm{~m}_{\mathrm{Cd}}$ are accompanied by $115 \mathrm{~g}_{\mathrm{Cd}}$, a $\left(\beta^{-}, \gamma\right)$ emitter with a $55-\mathrm{h}$ half-life, and the $4.5-\mathrm{h} 115 \mathrm{~m}$ In daughter. The $55-\mathrm{h} 115 \mathrm{Cd}$ has gamma rays of 0.49 and $0.52 \mathrm{MeV}$ in $\sim 10$ and $26 \%$ respectively, of its decays. Therefore, the $55-\mathrm{h}$ isomer may be a serious interference in $115 \mathrm{~m}_{\mathrm{Cd}}$ gamma measurement. In addition, $62 \%$ of the decays of $115 \mathrm{Cd}$ are associated with a $\beta^{-}$emission of $1.11 \mathrm{MeV}$, which will interfere in beta-particle measurements of the $1.6 \mathrm{MeV} \beta^{-}$from $115 \mathrm{~m}$ Cd. As an unsealed source, $10 \mu \mathrm{Ci}$ of ${ }^{109} \mathrm{Cd}$ or $115 \mathrm{~m} \mathrm{Cd}$ may be Generally Licensed. 
${ }_{48} \mathrm{Cd}$ (cont'd.)

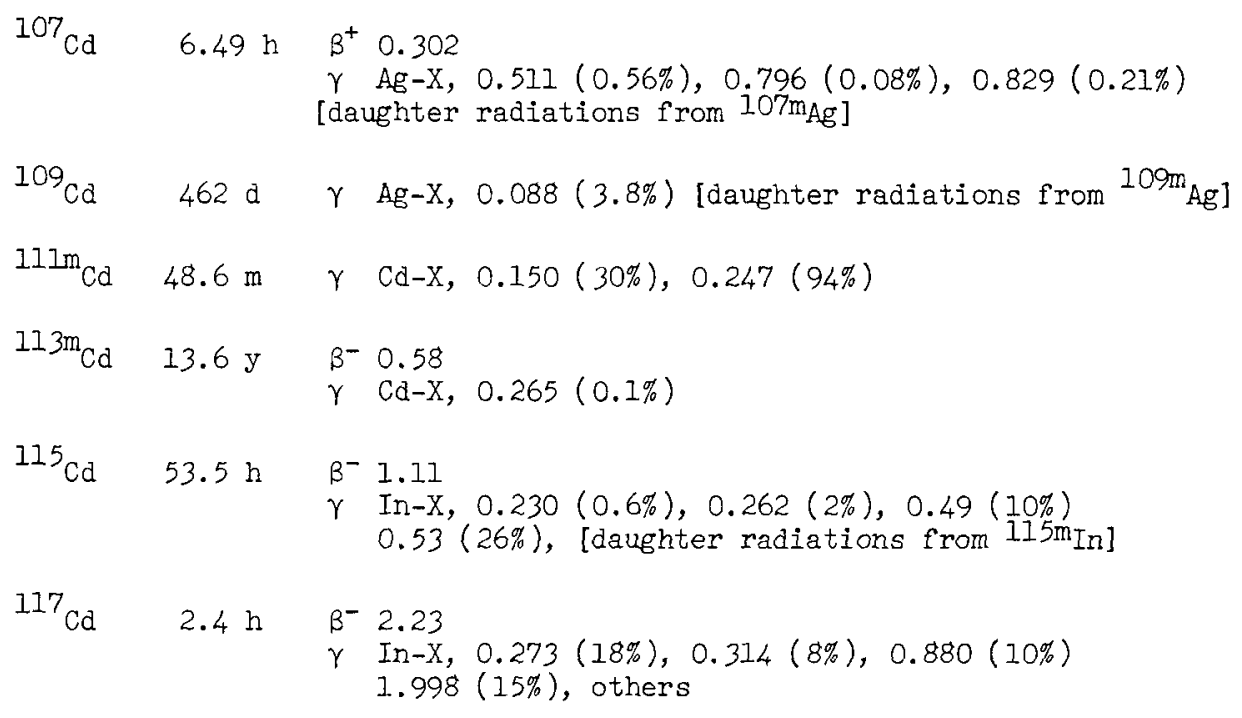


Tin, in aqueous solution, is either divalent or tetravalent, the latter forming upon exposure to air. It can be easily reduced, hence exchange between carrier and radionuclide is no problem. Tin hydrolyzes near $\mathrm{pH} 7$, and forms radiocolloids at tracer concentrations; the radionuclide is therefore usually kept in 1 M hydrochloric acid as chiorostannate, $\mathrm{SnCl}_{6}{ }^{-2}$.

A number of tin compounds have relatively low boiling points, especially stannic chloride, bromide, and iodide. These could be lost from solutions with high boiling points and from planchets if the boiling points were approached or exceeded. To prevent loss during evaporation of a counting sample in hydrochloric acid, some phosphoric acid is added. Stannane, $\mathrm{SnH}_{4}$, is an unstable gas. Metallic tin is prepared by electrodeposition.

Radioactive $113 \mathrm{~m}$ In occurs in secular equilibrium with its $113 \mathrm{Sn}$ parent, and could be separated during preparation.

For further details, see W. E. Nervik, "The Radiochemistry of Tin," USAEC Report NAS-NS-3023 (1960).

$$
\text { Tin - Counting }
$$

Tin-113 decays by electron capture and can be measured by counting the ${ }^{113}$ In $X-$ ray. A $0.25 \mathrm{MeV}$ gamma ray is emitted only as a small fraction of the decay. The $113 m^{2}$ In daughter of $113 \mathrm{Sn}$ decays with a $104-\min$. half life; hence, at least 10 hours should elapse between sample preparation and counting if fractionation of the tin parent and indium daughter may have occurred. The $113 \mathrm{~m}$ In daughter emits a $0.39 \mathrm{MeV}$ gamma ray by means of which $113 \mathrm{Sn}$ can be counted.

The nuclear radiations of the tin isotopes are described in Nuclear Data Sheets (National Academy of Seiences - National Research Council), and ref. 16.

\begin{tabular}{|c|c|c|}
\hline${ }^{11} 3_{\mathrm{Sn}}$ & $115 \mathrm{~d}$ & $\begin{array}{l}\gamma \quad \operatorname{In}-\mathrm{X}, 0.255(1.8 \%) \\
{\left[{ }^{113 \mathrm{~m}} \text { In daughter radiations }\right]:} \\
\gamma \quad \text { In-X, } 0.393(64 \%)\end{array}$ \\
\hline $117 \mathrm{~m}_{\mathrm{Sn}}$ & $14.0 \mathrm{~d}$ & $\gamma \quad \mathrm{Sn}-\mathrm{X}, 0.158(87 \%)$ \\
\hline $119 m_{S n}$ & $254 d$ & $\gamma$ Sn-X, $0.0238(16 \%)$ \\
\hline${ }^{121} \mathrm{Sn}$ & $27.5 \mathrm{~h}$ & $\beta^{-} 0.383$ \\
\hline $121 m_{\mathrm{Sn}}$ & $76 \mathrm{y}$ & $\begin{array}{ll}B^{-} & 0.42 \\
\gamma & S b-X, 0.037\end{array}$ \\
\hline $123 \mathrm{Sn}$ & $125 \mathrm{~d}$ & $\begin{array}{ll}\beta^{-} & 2.42 \\
\gamma & 1.08 ? \text { (weak) }\end{array}$ \\
\hline $125 \mathrm{Sn}$ & $9.4 d$ & $\begin{array}{ll}B^{-} & 2.34 \\
\gamma & 0.342(0.3 \%), 0.468(0.4 \%), 0.811(1.5 \%), 0.904(1.4 \%) \\
& 1.068(4 \%), 1.17(0.14 \%), 1.41(0.14 \%), 1.97(0.6 \%) \\
& 2.23(0.05 \%)\end{array}$ \\
\hline
\end{tabular}


$\left[{ }^{125} \mathrm{Sb}\right.$ daughter radiations]:

$B^{-} 0.61$

$\gamma \mathrm{Te}-\mathrm{X}, 0.176(6 \%), 0.427(31 \%), 0.463(10 \%)$

$0.599(24 \%), 0.634(11 \%), 0.66(3 \%)$

$+125 \mathrm{~m}$ Te daughter radiations ( $\gamma$ only)

${ }^{127} \mathrm{Sn} \quad 2.05 \mathrm{~h} \quad \mathrm{~B}^{-} \mathrm{I.45}$

$\gamma 0.44,0.49,0.82,1.10,2.00,2.32$

$2.58,2.68,2.82$

$\left[{ }^{127} \mathrm{Sb}\right.$ daughter radiations]:

$\beta-1.5$

$\gamma 0.060,0.25,0.41$, others 
Antimony in water can be either in the III or V state; hence either oxidation or reduction may be necessary to exchange carrier and radionuclide. Antimony salts hydrolyze in weak acids and bases, and behave as radiocolloids under these conditions at tracer levels.

The halides of antimony are relatively volatile, and stibene, $\mathrm{SbH}_{3}$, is a gas. Antimony is reduced to the metal by metals such as iron, magnesium, and zinc, and can be electrodeposited.

A number of long-lived antimony isotopes decay to radioactive tellurium; in preparing antimony for counting, the possible separation of its daughter inust be considered.

For further details, see W. J. Maeck, "The Radiochemistry of Antimony," USAEC Report NAS-NS-3033 (1961).

$$
\text { Antimony - Counting }
$$

Antimony-122 emits energetic beta particles and is readily measured by beta counting. Several gamma rays are also emitted, primarily one of $0.56 \mathrm{MeV}$.

Approximately $2 \%$ of the beta particles emitted by 124 Sb have a maximum energy of $0.05 \mathrm{MeV}$, and $11 \%, 0.22 \mathrm{MeV}$; hence, beta counting of solid samples would not be expected to provide an accurate disintegration rate. The gamma ray of highest intensity has an energy of $0.60 \mathrm{MeV}$.

Most of the beta particles emitted by ${ }^{125} \mathrm{Sb}$ are of low energies, leading to difficulties in beta counting solid samples. The most intense gamma rays of the many emitted by $125 \mathrm{Sb}$ are at $0.18,0.43,0.46,0.60$, and $0.63 \mathrm{MeV}$. The 2.7year ${ }^{125} \mathrm{Sb}$ decays to 58 -day $125 \mathrm{~m}_{\mathrm{Te}}$, which emits highly converted gamma rays at 35 and $109 \mathrm{keV}$, as well as the Te X-rays that arise as a consequence of internal conversion.

The nuclear radiations of the antimony isotopes are described in Nuclear Data Sheets (National Academy of Sciences - National Research Council), and ref. 16.

$$
\begin{aligned}
& { }^{119} \mathrm{Sb} \quad 38.0 \mathrm{~h} \quad \gamma \mathrm{SnX}, 0.024 \\
& { }^{120} \mathrm{Sb} \quad 5.8 \mathrm{~d} \quad \gamma \operatorname{SnX}, 0.090(81 \%), 0.200(88 \%), 1.03(99 \%) \\
& 1.171(100 \%) \\
& \text { Shielding: } \\
& \text { 0-10mCi 5/8" } \\
& 10-5 \mathrm{mCi} 5 / 8^{\prime \prime}+1 / 2^{\prime \prime} \\
& 122 \mathrm{Sb} \quad 2.7 \mathrm{~d} \quad \beta^{-}-1.97 \\
& \beta^{+} 0.56 \\
& \gamma \mathrm{Sn}-\mathrm{X}, 0.564(66 \%), 0.686(3.4 \%), 1.140(0.7 \%) \\
& 1.26(0.7 \%)
\end{aligned}
$$




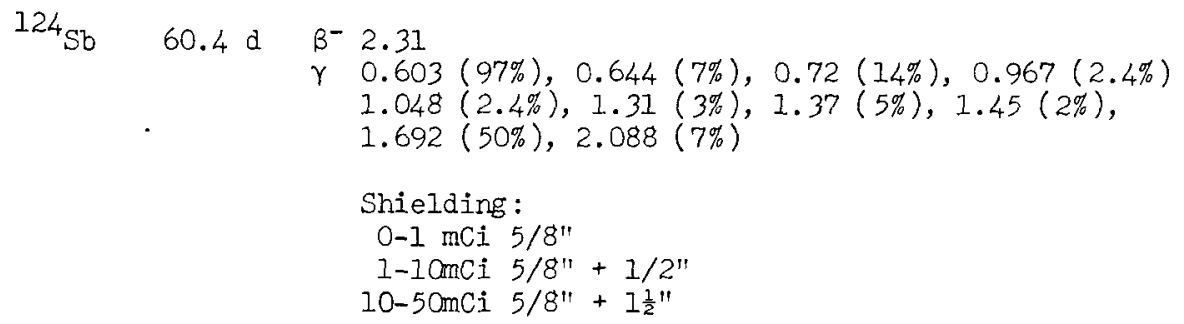

${ }^{125} \mathrm{Sb}$

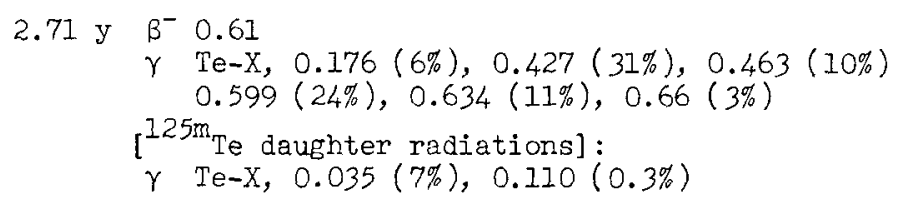


Tellurium in aqueous solutions has valences of II, IV, and VI, so that exchange between carrier and radionuclide may have to be achieved by oxidation or reduction. In neutral solutions, tellurium hydrolyzes and probably forms radiocolloids at tracer concentrations. At these low concentrations, it is carried on ferric hydroxide and on insoluble acid sulfides.

Tetravalent tellurium forms volatile oxychlorides and oxybromides in strong $\mathrm{HCl}$ and $\mathrm{HBr}$, respectively, and $\mathrm{H}_{2} \mathrm{Te}$ is volatile and unstable. Metallic tellurium can be electrodeposited, or prepared by reduction with $\mathrm{SO}_{2}$ or $\mathrm{H}_{2} \mathrm{~S}$ in hydrochloric acid, although $\mathrm{NO}_{3}^{-}, \mathrm{Cu}^{+2}$, and $\mathrm{Au}^{+}+3$ interfere.

A number of long-lived tellurium isotopes decay to radioactive antimony or iodine daughters. One must consider the possibility that equilibrium between parent and daughter has been disturbed in preparation of counting samples.

For further details, see G. W. Leddicotte, "The Radiochemistry of Tellurium," USAEC Report NAS-NS-3038 (1961).

Tellurium - Counting

Only the 58 -day $125 \mathrm{~m}_{\mathrm{Te}}$ daughter of ${ }^{125} \mathrm{Sb}$ is currently issued as a radioactivity standard. Decaying by isomeric transition, it can be counted by the characteristic Te $\mathrm{X}$-ray or the $110 \mathrm{keV}$ gamma ray.

The nuclear radiations of the tellurium isotopes are described in Nuclear Data Sheets (National Acaderny of Sciences - National Research Council), and ref. 16.

\begin{tabular}{|c|c|c|}
\hline${ }^{19} \mathrm{Te}$ & $15.9 \mathrm{~h}$ & $\begin{array}{l}\beta^{+} 0.627 \\
\gamma \quad S b-X, 0.645(85 \%), 0.70(11 \%), 1.76(3.6 \%) \\
{\left[{ }^{119} \mathrm{Sb} \text { daughter radiations] }:\right.} \\
\gamma \quad S n-X, 0.024(16 \%)\end{array}$ \\
\hline $119 \mathrm{~m}_{\mathrm{Te}}$ & $4.68 \mathrm{~d}$ & $\begin{array}{l}\gamma \mathrm{Sb}-\mathrm{X}, 0.153(62 \%), 0.270(25 \%), 0.92-1.14(36 \%) \\
1.221(67 \%), 2.09(4 \%) \\
{[119 \mathrm{Sb} \text { daughter radiations, see above }]}\end{array}$ \\
\hline $121_{\mathrm{Te}}$ & $17 \mathrm{~d}$ & $\gamma \mathrm{Sb}-\mathrm{X}, 0.508(18 \%), 0.573(80 \%)$ \\
\hline $121 \mathrm{~m}_{\mathrm{Te}}$ & $154 \mathrm{~d}$ & $\begin{array}{l}\gamma \mathrm{Te}-\mathrm{X}, \mathrm{Sb}-\mathrm{X}, 0.212(82 \%), 1.10(3 \%) \\
{\left[{ }^{12 I_{\text {Te }}} \mathrm{Taughter} \text { radiations, see above] }\right.}\end{array}$ \\
\hline $123 \mathrm{~m}_{\mathrm{Te}}$ & $117 \mathrm{~d}$ & $\gamma \mathrm{Te}-\mathrm{X}, 0.159(84 \%)$ \\
\hline $125 \mathrm{~m}_{\mathrm{Te}}$ & $58 \mathrm{~d}$ & $\gamma \mathrm{Te}-\mathrm{X}, 0.035(7 \%), 0.110(0.3 \%)$ \\
\hline $127 \mathrm{~m}_{\mathrm{Te}}$ & 109 d & $\begin{array}{l}\gamma \mathrm{Te}-\mathrm{X}, 0.059(0.19 \%), 0.089(0.08 \%), 0.67(0.004 \%) \\
{\left[{ }^{127} \mathrm{Te} \text { daughter radiations }\right]:} \\
\beta^{-} 0.70\end{array}$ \\
\hline
\end{tabular}


$127_{\mathrm{Te}}$

$\gamma \operatorname{I-X}, 0.058(0.010 \%), 0.21(0.03 \%), 0.360$ $(0.05 \%), 0.417(0.3 \%)$

$1.29 \mathrm{~m}_{\mathrm{Te}}$

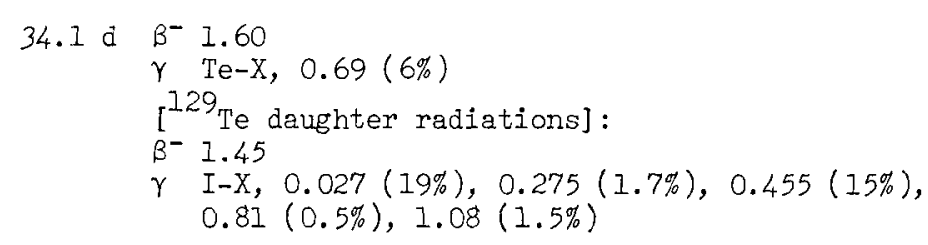


As a radioactivity standard, radioiodide is usually prepared with bisulfite added to the aqueous solution to maintain the reduced state. Small fractions of the radioiodine exist in forms that do not behave as predicted when the radioiodine is oxidized, distilled, or extracted into organic solvents. Because iodine is also chemically stable as iodate, periodate, and molecular iodine, interchange between carrier and radionuclide is assured by oxidizing to periodate and then reducing to iodide. In aqueous solutions, $\mathrm{I}^{-}, \mathrm{I}_{3}^{-}$, and $\mathrm{I}_{2}$ are in equilibrium. Interhalogen compounds and organic compounds of iodine such as $\mathrm{CH}_{3} \mathrm{I}$ are common.

Because of the appreciable vapor pressure of $I_{2}$ and $H I$, these compounds can be lost from aqueous solutions during evaporation; hence, solutions should be basic to retain radioiodine as $I^{-}$. Molecular iodine is readily absorbed by organic material from solution or during distillation. Radioiodine is precipitated as $\mathrm{AgI}$ from dilute $\mathrm{HNO}_{3}$ or as $\mathrm{PdI}_{2}$ from dilute $\mathrm{HCl}$.

For further details, see J. Kleinberg and G. A. Cowan, "The Radiochemistry of Fluorine, Chlorine, Bromine, and Iodine," USAEC Report NAS-NS-3005 (1960). See also M. Kahn in "Inorganic Isotopic Syntheses," Benjamin, New York 1962.

Iodine - Counting

The energies of almost all the beta particles of ${ }^{13}{ }^{1} \mathrm{I}$ are below $0.61 \mathrm{MeV}$; hence care must be taken to minimize self-absorption in beta counting. For gamma counting, $81 \%$ of the disintegrations occur via the $0.36 \mathrm{MeV}$ gamm ray. Approximately $0.7 \%$ of the disintegrations form 12-day I3ImXe, which decays with a highly converted $164 \mathrm{keV}$ ganma ray.

Iodine-125 decays by electron capture and can be measured by counting the characteristic $T e X$-rays together with the $35 \mathrm{keV}$ gamma rays. The two radiations are usually not resolved and total approximately 1.44 gamma plus X-rays per disintegration.

The nuclear radiations of the iodine isotopes are described in Nuclear Data Sheets (National Academy of Sciences - National Research Council), and ref. 16.

$$
\begin{aligned}
& { }^{124} \mathrm{I} \quad 4.15 \mathrm{~d} \quad \beta^{+} 2.14 \\
& \gamma \mathrm{Te}-\mathrm{X}, 0.511(50 \%), 0.605(67 \%), 0.644(12 \%) \text {, } \\
& 0.73(14 \%), 1.37(3 \%), 1.51(4 \%), 1.69(14 \%) \text {, } \\
& 2.09(2.0 \%), 2.26(1.5 \%) \\
& { }^{125} \text { I } 60.2 \mathrm{~d} \quad \gamma \mathrm{Te}-\mathrm{X}, 0.035(7 \%) \\
& { }^{126} \mathrm{I} \quad 12.8 \mathrm{~d} \quad B^{-1.25} \\
& B^{+} 1.13 \\
& \gamma \mathrm{Te}-\mathrm{X}, 0.386(34 \%), 0.667(33 \%) \\
& \begin{aligned}
{ }^{129} \mathrm{I} 1.6 \times 10^{7} \mathrm{y} \quad B^{-} 0.150 \\
\gamma \text { Xe-X, } 0.040(9 \%)
\end{aligned} \\
& { }^{13 I_{I}} \quad 8.05 \mathrm{~d} \quad \beta^{-} 0.806(0.6 \%), 0.606 \\
& \gamma \text { Xe-X, } 0.080(2.6 \%), 0.284(5.4 \%), 0.364(82 \%) \text {, } \\
& 0.637(6.8 \%), 0.723(1.6 \%)
\end{aligned}
$$




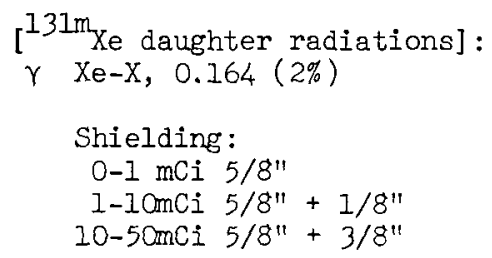

$132 \mathrm{I} \quad 2.26 \mathrm{~h}$
$B^{-} 2.12$
Y $0.24(1 \%), 0.52(20 \%), 0.67(144 \%), 0.773(89 \%)$ $0.955(22 \%), 1.14(6 \%), 1.28(7 \%), 1.40(14 \%)$, $1.45(1 \%), 1.91(1.3 \%), 1.99(1.3 \%)$

133 I $20.3 \mathrm{~h}$

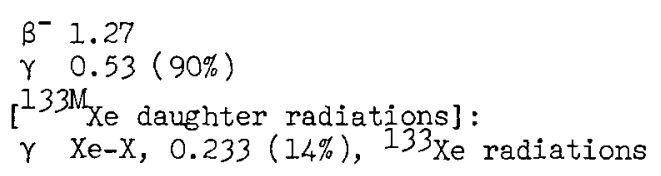


For the large majority of radiochemical problems, xenon may be considered an inert, permanent gas. Radio-xenon is usually collected as mixed fission product off gas from dissolution of spent reactor elements or of fissile targets irradiated in a nuclear reactor. Pure samples of radio-xenon are most conveniently obtained by preparative gas chromatographic techniques utilizing activated charcoal as the adsorbent material. Xenon can be recovered carrier-free by these techniques, but a small quantity of inactive xenon carrier is normally added prior to purification to facilitate subsequent handling. The nearly quantitative condensation of xenon at liquid nitrogen temperatures facilitates its manipulation in the vacuum systems normally used for containment, purification and counter filling.

The separation processes applicable to radioactive xenon are discussed in "The Radiochemistry of the Rare Gases," by F. F. Momyer, USAEC Report, NAS-NS3025 (1960).

Xenon - Counting

The most efficient means of counting gaseous $\beta$ emitters is by their incorporation in the filling of a Geiger-Miiller or gas proportional counter. Sample preparation and counting problems are considerably reduced, at some sacrifice in sensitivity, by arranging a thin window gas and thin window $B$ counter in reproducible geometry. Both procedures suffer in that extended counting periods are required in order to resolve mixtures of the radio-xenons. Properly aged fission product xenon samples consist principally of $133 \mathrm{Xe}$ with lesser quantities of $131 \mathrm{mXe}$ and $133 \mathrm{mXe}$. For many applications a source of $133 \mathrm{Xe}$ which is sufficiently free of these interferences can be obtained by aging for one week, the xenon separated from a fissile target at one to two days following irradiation.

The availability of non-converted photons in the decay of the xenon isotopes permits application of gamma spectroscopic techniques to their measurement in gas samples. $133 \mathrm{Xe}$ can be determined by observation of the $36.4 \%$ abundant, $81 \mathrm{keV}$ gamma. Similarly, 131mXe exhibits a 1.85\% abundant, $164 \mathrm{keV}$ gamma while $133 \mathrm{~m}$ Xe can be measured using the $10.1 \%$ abundant gamma at $233 \mathrm{keV}$. Appropriately calibrated glass or aluminum gas containers which can be reproducibly located in relation to the detector can be used as a source container. Alternatively, suitable sources can be prepared by ion-implantation on metal foils utilizing cathode glow discharge or isotopic separator beams.

The nuclear radiations of the xenon isotopes are described in Nuclear Data Sheets (National Academy of Science - National Research Council), and ref. 16.

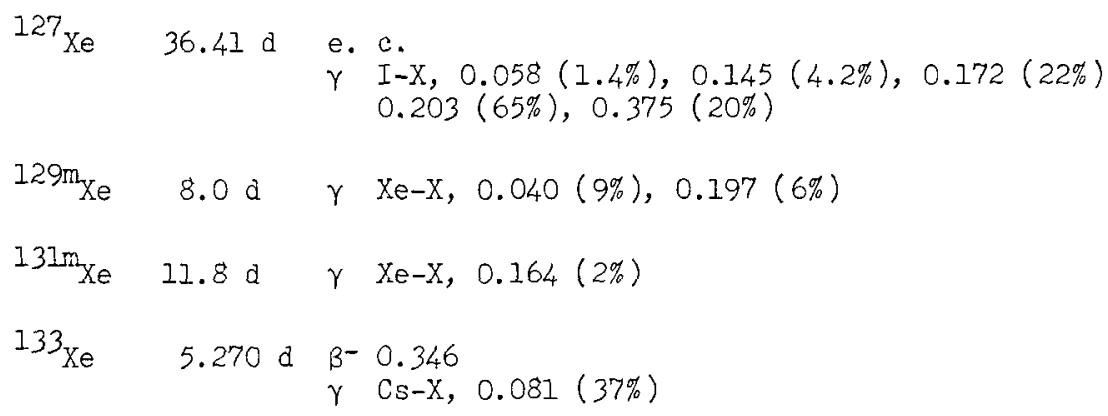


$54^{\mathrm{Xe}}($ cont'd.)

${ }^{133 \mathrm{~m}_{\mathrm{Xe}}} 2.26 \mathrm{~d} \quad \gamma \quad \mathrm{Xe}-\mathrm{X}, 0.233(14 \%$ )

[daughter radiations from $133 \mathrm{Xe}$

${ }^{135} \mathrm{Xe} \quad 9.14 \mathrm{~h} \quad \beta^{-} 0.92$

$\gamma 0.250(91 \%), 0.61(3 \%)$ 
The chemical behavior of radiocesium in aqueous solutions is relatively simple: it is a monovalent cation, is not readily complexed, and forms soluble salts with most simple anions. Tracer quantities may be retained from solution on glass and paper, possible by ion exchange with sodium or potassium.

Cesium nitrate decomposes when heated to form the oxide, and $\mathrm{Cs}_{2} \mathrm{O}$ is volatile at $250^{\circ} \mathrm{C}$. These salts can therefore be lost if a dry sample is heated. Cesium perchlorate is precipitated from alcohol solutions. The insolubility of a number of complex ions, such as cesium silicotungstate and phosphomolybdate, is also used to prepare radiocesium deposits.

For further details, see H. L. Finston and M. T. Kinsley, "The Radiochemistry of Cesium," USAEC Report NAS-NS-3035 (1961).

$$
\text { Cesium - Counting }
$$

Cesium-131 and -132 decay by electron capture and can be measured by counting Xe $\mathrm{X}$-rays. Cesium-132 also emits positrons in approximately $1 \%$ of its disintegrations, and a $0.66 \mathrm{MeV}$ gamma ray.

Cesium-134 emits a large fraction of weak beta particles; approximately $27 \%$ of its decay is through a beta group with a maximum energy of $0.09 \mathrm{MeV}$. Results obtained by beta counting would therefore be questionable. Approximately $98 \%$ of its disintegrations are accompanied by a $0.60 \mathrm{MeV}$ gamma ray, which can be used to measure $134 \mathrm{Cs}$. The conversion coefficient of this gamma ray is only 0.005 . The gamma ray is in coincidence with a number of others. With NaI( $T I$ ) detectors, it would not be resolvable from 2 other gamma rays with energies of 0.56 and $0.57 \mathrm{MeV}$.

Cesium-137 decays by beta particles of intermediate energy; hence, care must be taken to minimize self-absorption in beta counting. The beta count rate includes conversion electrons from the $0.66 \mathrm{MeV}$ gamma ray. The number of 0.66 $\mathrm{MeV}$ gamma rays per disintegration is 0.86 , and the number of conversion electrons is 0.095 . This gamma ray is suitable for measuring ${ }^{137} \mathrm{Cs}$. It is, however, emitted by the 2.6 -min. daughter $137 \mathrm{~m} \mathrm{Ba}$; hence, a 15 -minute interval between preparation and counting is necessary if barium could have been separated during preparation. Although $134 \mathrm{Cs}$ is not a fission product, it contaminates most $137 \mathrm{Cs}$ samples prepared from fission products because of the neutron activation of stable $133 \mathrm{Cs}$, which is also formed in fission.

The nuclear radiations of the cesium isotopes are described in Nuclear Data Sheets (National Academy of Sciences - National Research Council), and ref. 16.

$$
\begin{aligned}
& { }^{131} \mathrm{Cs} \quad 9.70 \mathrm{~d} \quad \gamma \quad \mathrm{Xe}-\mathrm{X} \\
& { }^{132} \mathrm{Cs} \quad 6.59 \mathrm{~d} \quad B^{+} 0.40 \\
& \gamma \mathrm{Xe}-\mathrm{X}, 0.48(4 \%), 0.668(99 \%), 1.138(0.5 \%), 1.320(0.6 \%) \\
& { }^{134} \mathrm{Cs} \quad 2.046 \mathrm{y} \quad \mathrm{B}^{-} 0.662
\end{aligned}
$$

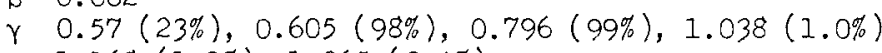

$$
\begin{aligned}
& 1.168(1.9 \%), 1.365(3.4 \%) \\
& \text { Shielding: } \\
& \text { 0-1 } \mathrm{mCi} 5 / 8^{\prime \prime} \\
& 1-10 \mathrm{mCi} 5 / 8^{\prime \prime}+5 / 8^{\prime \prime} \\
& 10-50 \mathrm{mCi} 5 / 8^{\prime \prime}+1 \frac{1}{2} "
\end{aligned}
$$




$$
55^{\mathrm{Cs}} \text { (cont'd.) }
$$

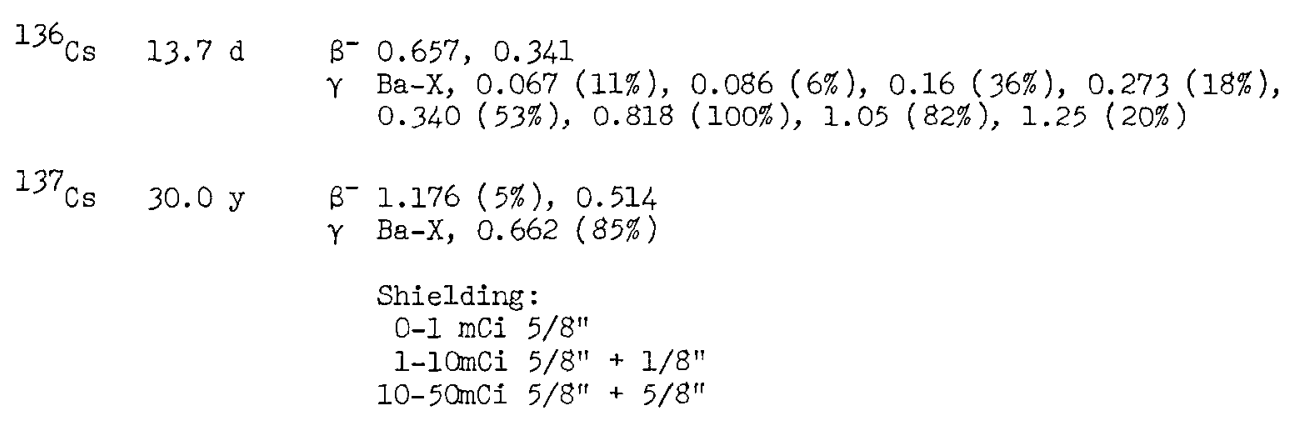


Barium is usually divalent in aqueous solutions. The hydroxide of barium is relatively solutle ( $30 \mathrm{~g} / 1$ ), but barium is precipitated by $\mathrm{CO}_{2}$ in basie solution. $\mathrm{BaCl}_{2}$ precipitates in strong hydrochloric acid and $\mathrm{Ba}\left(\mathrm{NO}_{3}\right)_{2}$ in fuming nitric acid. Both $\mathrm{BaCl}_{2}$ and $\mathrm{Ba}\left(\mathrm{NO}_{3}\right)_{2}$ dissolve readily in water or dilute acid. $\mathrm{BaSO}_{4}$ forms an insoluble precipitate in dilute sulfuric acid. This precipitation is used to prepare the sample for counting, but is avoided generally as a step in a separation scheme because of the difficulty in dissolving barium sulfate; it may be dissolved in ethylenediamine tetraacetic acid (EDTA), however. Tracer amounts of barium are sometimes coprecipitated on $\mathrm{PbSO}_{4}$ and $\mathrm{PbCrO}_{4}$.

Lanthanum-140 can be separated from its $140_{\mathrm{Ba}}$ parent by solvent extraction using $0.05 \mathrm{M} \mathrm{HCl}$ aqueous phase and $1.5 \mathrm{M}$ di(2-ethyl hexyl) orthophosphoric acid in toluene. The $14 \mathrm{O}_{\mathrm{Ba}}$ remains in the aqueous phase. Elution from both cation exchange resin (using citrate solutions) and anion exchange resin (using dilute $\mathrm{HCl}$ ) has been used to purify $140 \mathrm{Ba}$ from its radioactive daughter, $140 \mathrm{La}$. Barium $-137 \mathrm{~m}$ can be separated from its parent $137 \mathrm{Cs}$ by precipitation of $\mathrm{BaSO}_{4}$ using carrier barium.

For further details, see "The Radiochemistry of Barium, Calcium, and Strontium," by D. N. Sunderman and C. W. Townley, USAEC Report NAS-NS-3010 (1960).

$$
\text { Barium - Counting }
$$

Barium-133 and ${ }^{137 m} \mathrm{Ba}$ are gamma-ray emitters and may be counted by conventional scintillation techniques. When $137 \mathrm{mBa}$ is counted while in secular equilibrium with the $137 \mathrm{Cs}$ parent, the decay rate can be used to ascertain the amount of $137^{\mathrm{C}} \mathrm{s}$ present.

Barium-140 ( $t_{1 / 2}=12.8$ days ) may be measured by beta or gamma counting. For the former, care must be taken to minimize self-absorption because approximately $35 \%$ of the decay is by beta groups with maximum energies of $0.6 \mathrm{MeV}$ or less. The 40.2-hour daughter of $140 \mathrm{Ba}$, 140 La, grows in a barium fraction after separation from lanthanum; consequently, gross beta or gamma counting may include contribution from $140 \mathrm{La}$. The ratio of $14 \mathrm{O}_{\mathrm{La}}$ to $140 \mathrm{Ba}$ activity is 1.15 at equilibrium. Gamma-ray spectroscopy can be used to determine the amount of 140Ia in the mixture.

The nuclear radiations of the barium isotopes are described in Nuclear Data Sheets (National Academy of Sciences - National Research Council), and ref. 16.

$$
\begin{aligned}
& 133 \mathrm{Ba} \quad 10.5 \mathrm{y} \quad \gamma(\mathrm{S}-\mathrm{X}, 0.080(36 \%), 0.276(7 \%), 0.302(14 \%), \\
& 0.356(69 \%), 0.382(8 \%) \\
& 133 \mathrm{~m}_{\mathrm{Ba}} \quad 38.9 \mathrm{~h} \quad \gamma \mathrm{Ba}-\mathrm{X}, 0.276(17 \%) \\
& 135 m_{\mathrm{Ba}} \quad 28.7 \mathrm{~h} \quad \gamma \mathrm{Ba}-\mathrm{X}, 0.268(16 \%) \\
& 137 \mathrm{~m}_{\mathrm{Ba}} \quad 2.554 \mathrm{~m} \quad \gamma \mathrm{Ba}-\mathrm{X}, 0.662(89 \%) \\
& { }^{139} \mathrm{Ba} \quad 82.9 \mathrm{~m} \quad \beta^{-2.3} \\
& \gamma \operatorname{La}-X, 0.166(23 \%), 1.43(0.4 \%)
\end{aligned}
$$


$56^{\mathrm{Ba}}$ (cont'd.)

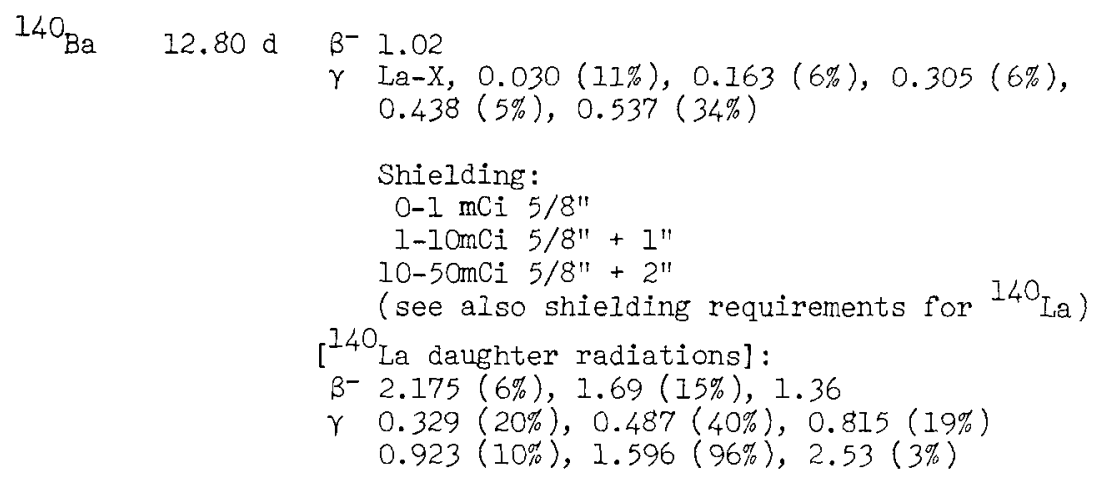


The rare earth (lanthanide) elements exhibit close similarity in their chemical properties. The tripositive oxidation state is the common and most stable for all these elements in aqueous solutions although solutions of $\mathrm{Ce}$ (III) can be oxidized easily to $\mathrm{Ce}$ (IV) by such strong oxidizing agents as $\mathrm{S}_{2} \mathrm{O}_{8}^{-2}, \mathrm{Co}^{+3}$, and $\mathrm{BrO}_{3}$ - (acid solution). The lanthanide ions hydrolyze readily in solutions above pH 6 unless complexing agents are present. Solutions below pH 5 are stable to hydrolysis. Fluorides and oxalates are quite insoluble and precipitation from solution is most frequently achieved via these compounds. Hydroxides are also insoluble but their gelatinous nature results in coprecipitation of relatively large amounts of impurities. Tracer quantities of lanthanide ions can be coprecipitated in very high yield with lanthanum fluoride, oxalate, or hydroxide or with ferric hydroxide.

The lanthanide elements are separated from each other by ion exchange or by solvent extraction techniques. Weightless samples for $4 \pi$ beta counting may be prepared after using these techniques.

In preparing solid samples for counting with milligram quantities of carrier, precipitation with oxalate is the most common procedure. In dilute acid, oxalate precipitation is almost specific for the rare earths, and the precipitate has a crystalline structure which permits easy filtering and washing. For accurate gravimetric determinations, the oxalate is ignited to the oxide. The hydrated oxalate solubilities range from $0.4 \mathrm{mg} / 1$ for $\mathrm{Ce}^{+3}$ to $4 \mathrm{mg} / 1$ for $\mathrm{Lu}^{+3}$.

Samples may be prepared by anodic electrodeposition of the hydroxide, but yields are not quantitative.

For further details, see "The Radiochemistry of the Rare Earths, Scandium, Yttrium, and Actinium," by P. C. Stevenson and W. E. Nervik, USAEC Report NASNS-3020 (1961).

Lanthanum - Counting

Lanthanum-140 is the radioactive daughter of ${ }^{140} \mathrm{Ba}$. Its decay scheme is complex as six beta groups are emitted. The maximum end point energy is $2.20 \mathrm{MeV}$ and the average energy is $0.49 \mathrm{MeV}$; consequently, ordinary methods of beta counting may be used. A total of seven gamma rays with energies between 0.329 and $2.20 \mathrm{MeV}$ are emitted in reasonable abundance, and several are in coincidence with each other. The $1.60 \mathrm{MeV}$ gamma ray is most intense; it occurs in approximately $95 \%$ of the disintegrations and can be used to determine $140 \mathrm{La}$ activity if the effect of coincidences with weaker gamma rays are taken into account.

The nuclear radiations of the lanthanum isotopes are described in Nuclear Data Sheets (National Academy of Sciences - National Research Council), and ref. 16.

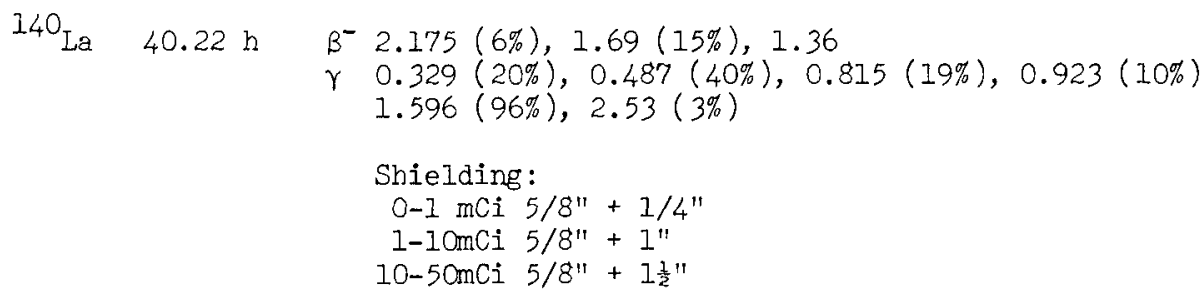


Cerium is the only rare earth with a useful +4 oxidation state. The $\mathrm{Ce}^{+3}-\mathrm{Ce}^{+4}$ couple has a potential of -1.61 volts in acid solution and $\mathrm{Ce}^{+3}$ is easily oxidized by strong oxidizing agents such as $\mathrm{S}_{2} \mathrm{O}_{8}^{-2}, \mathrm{CO}^{+3}$, or $\mathrm{BrO}_{3}$ (in strong acid). Exchange between carrier and sample may be effected by a $\mathrm{Ce}^{+3}-\mathrm{Ce}^{+4}$ oxidation-reduction cycle.

Cerium may be separated from the other rare earths by oxidation to the +4 state and precipitation as the iodate. Ion exchange and solvent extraction techniques may also be used.

The fluoride, hydroxide and oxalate of $\mathrm{Ce}^{+3}$ are quite insoluble and precipitation from solution is usually achieved by these methods. In preparing solid samples of milligram quantities, precipitation as the oxalate is the most common procedure. The crystalline structure of the precipitate permits easy filtering and washing. The solubility of the hydrated $\mathrm{Ce}^{+3}$ oxalate is $0.4 \mathrm{mg} / \mathrm{l}$. For accurate gravimetric determinations, the oxalate is ignited to the oxide.

For further details see "The Radiochemistry of the Rare Earths, Scandium, Ytterium and Actinium," by P. C. Stevenson and W. E. Nervik, USAEC Report NASNS-3020 (1961).

$$
\text { Cerium - Counting }
$$

Cerium-139 can be measured by counting the single gamma emission of $166 \mathrm{keV}$. The K-internal conversion factor is $0.22\left(e_{K} / \gamma\right)$ and the total internal conversion factor is $0.25(\mathrm{e} / \gamma)$.

Due to the low beta end points of ${ }^{141} \mathrm{Ce}$, self-absorption must be kept to a minimum in beta counting. A single ganma ray of $145 \mathrm{keV}$ is conducive to gamma counting. The rate of gamma ray emission is related to the absolute rate of beta decay $(\gamma / \beta)$ by 0.5 when the branching ratio and internal conversion factors are considered.

The nuclear radiations of cerium isotopes are described in Nuclear Data Sheets (National Academy of Sciences - National Research Council), and ref 16. and $14 \mathrm{C} \mathrm{Ce}$.

The low energy of the gamma rays make shielding a minor problem for ${ }^{139} \mathrm{Ce}$

$$
\begin{aligned}
& { }^{139} \mathrm{Ce} \quad 140 \mathrm{~d} \text { e. c. } \\
& \text { y La-X, } 0.165(80 \%) \\
& \begin{array}{rlll}
{ }^{141} \mathrm{Ce} \quad 32.5 \text { d } \quad \beta^{-} & 0.581 \\
& & \gamma & \operatorname{Pr}-\mathrm{X}, 0.145(48 \%)
\end{array} \\
& { }^{143} \mathrm{Ce} \quad 33 \mathrm{~h} \quad \beta^{-} 1.39 \\
& \gamma \text { Pr-X, } 0.057(11 \%), 0.293(46 \%), 0.493(2.4 \%) \\
& 0.668(7 \%), 0.725(8 \%), 0.88(1.4 \%), 1.10(0.6 \%) \\
& \text { [ }{ }^{143} \mathrm{Pr} \text { daughter radiations] } \\
& \begin{aligned}
{ }^{144} \mathrm{Ce} \quad 284 \mathrm{~d} \quad & \beta^{-} 0.31 \\
& \gamma \mathrm{Pr}-\mathrm{X}, 0.080(2 \%), 0.134(11 \%) \\
& {\left[{ }^{144} \operatorname{Pr} \text { daughter radiations }\right] }
\end{aligned}
\end{aligned}
$$


The ${ }^{139} \mathrm{Ce}$ daughter of ${ }^{139} \mathrm{Pr}$ decays by electron capture. It may be measured by counting the single gamma emission of $166 \mathrm{keV}$. The K-internal conversion factor is $\left.0.22 \mathrm{e}_{\mathrm{K}} / \gamma\right)$, and the total internal conversion factor is 0.25 .

Cerium-141 emits beta groups of two end point energies. $442 \mathrm{KeV}$ and 581

$\mathrm{KeV}$, hence self-absorption must be kept to a minimum in beta counting. A single gamma ray of $145 \mathrm{keV}$ in the decay of $14 \mathrm{I}_{\mathrm{Ce}}$ is conductive to gamma counting. The rate of gamma-ray emission is related to the absolute rate of beta decay $(Y / \beta)$ by 0.5 when the branching ratio and internal conversion factors are considered.

Cerium-144 is the parent of radioactive 17 -minute $144 \mathrm{Pr}$. While $144 \mathrm{Ce}$ is an emitter of low energy beta particles (maximum end point energy $0.320 \mathrm{MeV}$, average energy $0.081 \mathrm{MeV}$ ), $144 \mathrm{Pr}$ emits energetic beta particles (maximum end point energy $2.98 \mathrm{MeV}$, average energy, $1.20 \mathrm{MeV}$ ). The activity of $144 \mathrm{Pr}$ may be measured by removing the $144 \mathrm{Ce}$ beta particles in aluminum absorbers; however, $a b-$ sorption of $144 \mathrm{Pr}$ beta particles must be considered. The $144 \mathrm{Pr}$ daughter attains secular equilibrium with its $144 \mathrm{Ce}$ parent within two hours.

Cerium-144 may also be counted by its $134 \mathrm{keV}$ gamma ray. However, this gamma ray is enitted only in low abundance, and bremsstrahlung from $144 \mathrm{Pr}$ may interfere in this energy region.

The nuclear radiations of the cerium-praseodymium isotopes are described in Nuclear Data Sheets (National Academy of Sciences - National Research Council).

Promethium - Counting

Promethium-147 is a low-energy beta emitter with a maximum end point energy of $0.225 \mathrm{MeV}$ and an average energy of only $0.062 \mathrm{MeV}$. The gamma emission from $147 \mathrm{Fm}$ is extremely weak. It is necessary to use special techniques applicable to low energy beta counting, including windowless proportional counting and weightless deposits of the sample. Problems of absorption and self-absorption make counting of $147 \mathrm{Pm}$ a challenge. Liquid scintillation counting in dioxare and water is a convenient method.

The nuclear radiations of the promethium isotopes are described in Nuclear Data Sheets (National Academy of Sciences - National Research Council), and ref. 16.

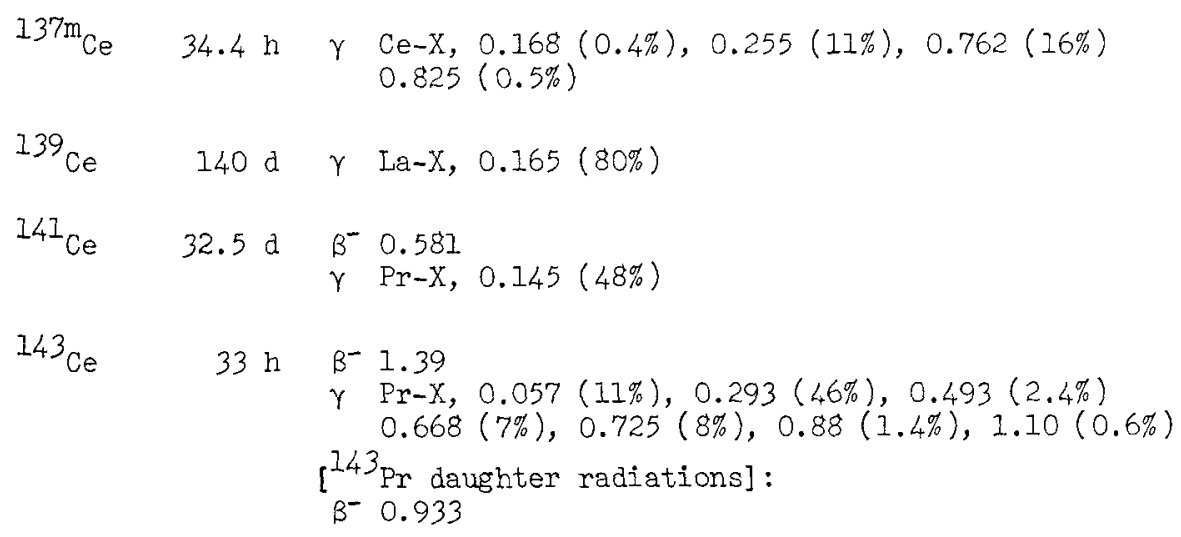


${ }^{144} \mathrm{Ce} \quad 284 \mathrm{~d}$

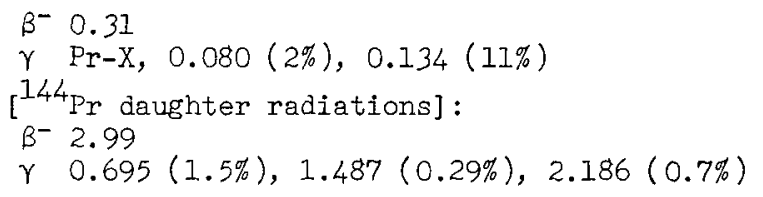


Iridium exhibits the $0,+1,+2,+3,+4$, and +6 oxidation states. Ir(III) and $\operatorname{Ir}$ (IV) are the most common states; in both, iridium frequently exists as anionic complexes in aqueous solutions. The chemistry of iridiun coordination complexes is complicated by the fact that a number of species such as $\operatorname{IrX}_{6}^{-3}$, $\operatorname{IrX}_{5}\left(\mathrm{H}_{2} \mathrm{O}\right)^{-2}$, and $\operatorname{IrX} \mathrm{X}_{4}\left(\mathrm{H}_{2} \mathrm{O}\right)^{-1}$ can coexist in solution. The simultaneous presence of several species in a solution also can cause difficulties in chromatographic separations. Iridium can, however, be separated from the other platinum-group elements on cation and anion exchange resins, and by solvent extraction.

Iridium can be precipitated by reduction to the metal with formic acid, sodium formate, powdered zinc, aluminum, or magnesium. In common with other platinum group metals, iridium metal is not attacked by mineral acids. Treatment with aqua regia, concentrated $\mathrm{H}_{2} \mathrm{SO}_{4}$ and sulfur, and alkaline fusion have been used successfully.

For further details, see G. W. Leddicotte, "The Radiochemistry of Iridium," USAEC Report NAS-NS-3045 (1961).

\section{Iridium - Counting}

Iridium-192 decays by beta-particle emission (96\%) and electron capture ( $4 \%$ ). Three main groups of beta particles have energies below $0.670 \mathrm{MeV}$ and an average energy of $0.175 \mathrm{MeV}$. Care must be paid to minimize self-absorption when beta counting is used. The decay of ${ }^{192} \mathrm{Ir}$ is accompanied by emission of gamma rays of a number of different energies, so that scintillation counting is a useful method for this nuclide. The most intense gamma-ray photopeak, at 0.3 $\mathrm{MeV}$, is caused by gamma rays of $0.296,0.308$, and $0.316 \mathrm{MeV}$ with respective $\gamma / \beta$ ratios of approximately $0.30,0.32$, and 0.82 . Coincidences occur among several gamma rays, transferring a fraction of the radiation detected in gamma spectrometers from the characteristic peaks to sum peaks.

Iridium-194 also decays by emission of several beta-particle groups. The maximum beta energy is $2.23 \mathrm{MeV}$ while the average energy is $0.75 \mathrm{MeV}$, hence beta-counting is suitable. Of the number of gamma rays emitted in the decay of $194 \mathrm{Ir}$, the most intense is the one of $0.328 \mathrm{MeV}$. Most beta particles go to the ground state of $194 \mathrm{Pt}$, but scintillation counting of the 0.294 and $0.328 \mathrm{MeV}$ gamma rays is useful.

The nuclear radiations of the iridium isotopes are described in Nuclear Data Sheets (National Academy of Sciences - National Research Council), and ref. 16.

$$
\begin{aligned}
& { }^{189} \text { Ir } 13.3 \mathrm{~d} \quad \gamma \quad \text { Os-X, } 0.245(18 \%) \\
& { }^{190} \text { Ir } 11 \text { d } \quad \gamma \text { Os-X, } 0.187(51 \%), 0.37(39 \%), 0.40(39 \%) \\
& 0.518(39 \%), 0.56(72 \%), 0.604(47 \%) \text { plus others } \\
& { }^{192} \operatorname{Ir} \quad 74.2 \text { d } \quad \beta^{-} 0.67 \\
& \gamma \text { Os-X, Pt-X, } 0.296(29 \%), 0.308(30 \%), 0.317(81) \\
& 0.468(49 \%), 0.589(4 \%), 0.604(9 \%), 0.612(6 \%) \\
& \text { Shielding: } \\
& 0-1 \mathrm{mCi} 5 / 8 " \\
& 1-10 \mathrm{mCi} 5 / 8^{\prime \prime}+1 / 8^{\prime \prime} \\
& 10-50 \mathrm{mCi} 5 / 8^{\prime \prime}+1 / 2^{\prime \prime}
\end{aligned}
$$


$77^{\operatorname{Ir}}\left(\operatorname{cont}^{\prime} \mathrm{d}.\right)$

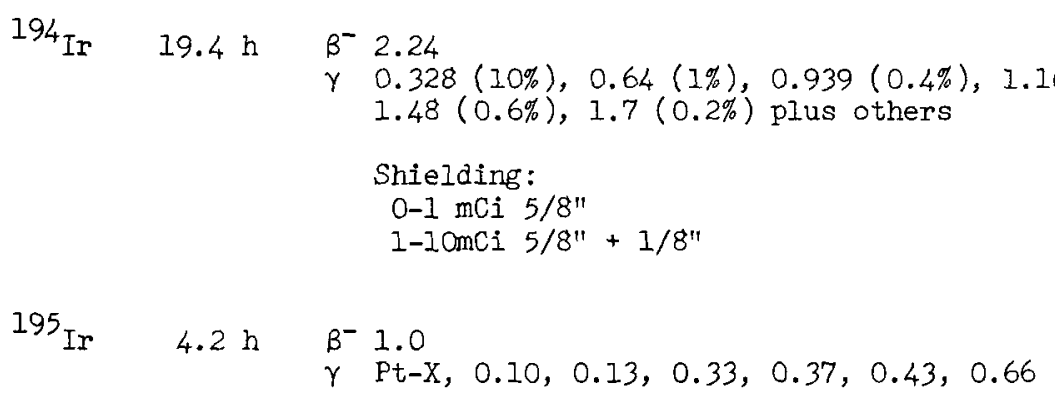


Dissolution of gold samples in aqua regia must be carried out with some caution as loss by volatilization can occur during rapid evaporation to dryness. Losses up to $3 \%$ from solutions containing $0.1 \mathrm{gm}$ gold have been reported. Addition of $70 \%$ perchloric acid during the evaporation prevents this loss.

Gold exists in both the +1 and +3 oxidation states in compounds. The $\mathrm{Au}$ (III) compounds are generally more soluble and more stable in aqueous solutions. It is necessary to avoid even mild reducing conditions if standard solutions of gold compounds are to be stable. Gold can be displaced from solutions by almost all other metals unless it is present in a very stable complex. Ions such as $\mathrm{Fe}(\mathrm{II}), \mathrm{Sn}(\mathrm{II}), \mathrm{SO}_{3}{ }^{-2}$, and $\mathrm{NO}_{2}^{-}$also reduce gold to the metallic state, as will many organic compounds such as oxalic, acetic, citric, and tartaric acids. Hydroquinone is considered to be the best reducing agent for gold.

Both $A u(I)$ and $A u(I I I)$ compounds may be extracted quantitatively from aqueous solutions by a variety of organic solvents. Precipitation of metallic gold should not be performed in a test tube that previously contained ethyl acetate, because a residual film of ethyl acetate on the tube walls tends to retain a portion of the finely divided precipitate.

The chemical behavior of radioactive gold is more fully discussed in "The Radiochemistry of Gold" by J. F. Fmery and G. W. Leddicotte, USAEC Report NASNS-3036 (1961).

$$
\text { Gold - Counting }
$$

Gold-198 is a negatron emitter with a half-life of 2.7 days. The average energy of the beta particles is $315 \mathrm{keV}$. Consequently, $198 \mathrm{Au}$ may be beta counted in thin samples. Gold-198 also emits a gamma of $412 \mathrm{keV}$ in $96 \%$ abundance so it may be counted conveniently by normal techniques for gamma rays such as scintillation counting.

The average energy of the beta particles from 3.2-day ${ }^{199} \mathrm{Au}$ is only $84 \mathrm{keV}$, so that the loss in count rate is significant for even thin samples. A 0.16 $\mathrm{MeV}$ ganma ray is emitted with approximately $37 \%$ yield, and characteristic Pt Xrays and a $0.21 \mathrm{MeV}$ gamma ray can also be detected. In mixtures of $198 \mathrm{Au}$ and $199 \mathrm{Au}$, it is best to use gamma-ray spectrometry to ascertain the amount of each nuclide.

The nuclear radiations of the gold isotopes are described in Nuclear Data Sheets (National Academy of Sciences - National Research Council), and ref. 16.

$$
\begin{aligned}
& { }^{194} \mathrm{Au} \quad 39.5 \mathrm{~h} \quad \mathrm{~B}^{+} 1.49 \\
& \gamma \text { Pt-X, 0.294 (12\%), } 0.328(68 \%), 1.469(8 \%) \\
& 1.596(3 \%), 1.887(4 \%), 2.044(4 \%) \text { plus others } \\
& { }^{195} \mathrm{Au} \quad 183 \text { a } \quad \text { y Pt-X, } 0.099(10 \%), 0.129(1 \%) \\
& { }^{196} \mathrm{Au} \quad 6.18 \mathrm{~d} \quad \beta^{-} 0.259 \\
& \gamma \text { Pt-X, } 0.333(25 \%), 0.356(94 \%), 0.426(6 \%), 1.091(0.2 \%) \\
& 196 \mathrm{~m}_{\mathrm{Au}} \quad 9.7 \mathrm{~h} \quad \gamma \mathrm{Au}-\mathrm{X}, 0.148(42 \%), 0.188(32 \%), 0.285(5 \%), 0.316(5 \%) \\
& \text { [196 Au daughter radiations, above] }
\end{aligned}
$$


$79^{\mathrm{Au}}$ (cont'd.)

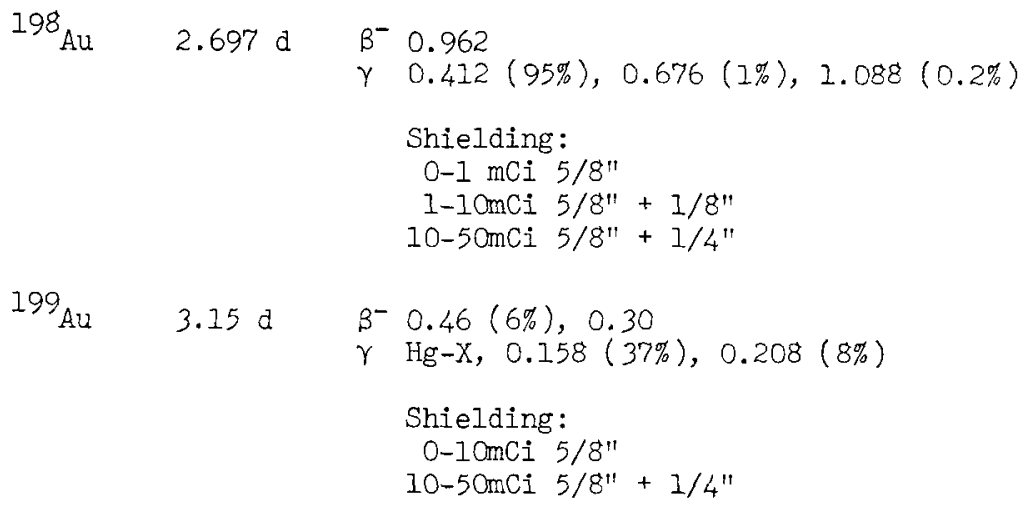


$80^{\mathrm{Hg}}$ (cont'd.)

${ }^{197} \mathrm{Hg} \quad 65 \mathrm{~h} \quad \gamma \quad$ Au-X, $0.077(18 \%), 0.191(2 \%), 0.268(0.15 \%)$

Shielding:

$0-10 \mathrm{mCi} 5 / 8^{\prime \prime}$

$10-50 \mathrm{mCi} 5 / 8 "+1 / 8 "$

$197 \mathrm{~m}_{\mathrm{Hg}} \quad 24 \mathrm{~h} \quad \mathrm{Y} \mathrm{Hg}-\mathrm{X}, 0.134(42 \%), 0.279(7 \%)$

$\left[{ }^{197} \mathrm{Hg}\right.$ daughter radiations, see above]

${ }^{203} \mathrm{Hg} \quad 46.9$ d $\quad B^{-} 0.214$

$\gamma 0.279(81.6 \%)$

Shielding:

$0-10 m \mathrm{mci} 5 / 8^{\prime \prime}$

10-50mCi $5 / 8^{\prime \prime}+1 / 4^{\prime \prime}$ 
Many of the salts of mercury are either insoluble in water or require the presence of free acid to prevent hydrolysis. A dilute nitric acid solution is probably the most convenient and stable form for solution standards of mercury. Excess nitric acid is required to prevent reduction through the possible presence of reducing agents or photochemical reactions. A large excess of acid should be avoided since source preparation may then become difficult. Mercuric solutions 0.01 normal in nitric acid appear to have long-term stability and concentrations higher than 0.1 normal in acid are not recommended for source preparation.

Problems in source preparation arise out of the volatility of many mercury compounds. Volatilization occurs from boiling solutions. Mercuric compounds are more stable than mercurous ones, but these are also reduced fairly easily to mercurous compounds and then to metallic mercury. The vapor pressure of the metal is about 2 microns at room temperature, so activity loss from thin sources in which reduction has occurred can be severe.

Among metals, mercury has the greatest affinity for sulfur, and samples prepared as mercuric sulfide (HgS) appear to be the only stable form for sources of mercury. Thin sources may be prepared from the nitrate solution by drying the aliquot in an atmosphere of hydrogen sulfide. When large amounts of carrier are present it may be necessary to add the sulfide ion as a soluble sulfide or thiosulfate to ensure complete precipitation, although this adds mass to the source. Excess nitric acid in the mercuric solution will oxidize $\mathrm{H}_{2} \mathrm{~S}$ to elemental sulfur and even with a normal acid solution large masses of sulfur may be deposited on the source. In the last stages of drying, the concentrated acid may also result in some more volatile $\mathrm{Hg}\left(\mathrm{NO}_{3}\right)_{2}$ being formed from the original $\mathrm{H} . \mathrm{S}$. The chemical behavior of radioactive mercury is more fully described by J. Roesmer in USAEC Report NAS-NS-3026 [Revision 1970].

Mercury - Counting

Mercury-203 is widely used in gamma-ray spectrometry as both an energy and intensity standard. Its simple decay scheme, consisting of a single gamma ray of $279 \mathrm{keV}$ make it ideal for this purpose. The internal conversion coefficients of the $279 \mathrm{keV}$ transition are well established. When using disintegration rate standards for spectrometer calibrations, the following ratios are useful: $\gamma / \beta=$ $0.816 \pm 0.002 ; X_{K} / \beta=0.127 ; X_{K} / \gamma=0.156 \pm 0.002$. The latter ratio is useful for checking the relative response of the spectrometer at 74 and $279 \mathrm{keV}$.

Because of the low energy of the beta spectrum ( $\left.\sim 214 \mathrm{keV} \mathrm{F}_{\max }\right)$, self-absorption seriously affects beta counting. The electron count rate and correction for coincidences between conversion electron and $\beta$ - particles must also be considered.

The decay schemes of $24-\mathrm{hr} 197 \mathrm{~m} \mathrm{Hg}$ and the electron-capture nuclide ${ }^{197} \mathrm{Hg}$ $\left(t_{1 / 2}=65 \mathrm{hr}\right.$ ) are neither simple nor well known. Mercury-197 activities are usually specified by emission rate of the $70 \mathrm{keV} \mathrm{K} \mathrm{X-ray} \mathrm{plus} \mathrm{the} 77 \mathrm{keV} \gamma$-ray, and these radiations are not resolved in a $\mathrm{NaI}$ scintillation spectrometer. Taking the best available values for branching ratios, capture ratios, conversion coefficient and fluorescence yields leads to an estimate of $70 \% \mathrm{~K}$ X-rays plus $20 \% 77 \mathrm{keV} \gamma$-rays per disintegration. Care must be taken to minimize or correct for coincidence suming of these radiations.

The nuclear radiations of the mercury isotopes are described in Nuclear Data Sheets (National Academy of Sciences - National Research Council), see also ref. 16. 
Thallium can exist in +3 and +1 oxidation states in solution. $\mathrm{Tl}$ (III) is a strong oxidizing agent and readily reduces to TI(I). Compounds of thallic ion, TI(III), tend to decompose upon heating to the corresponding thallous compounds. Even hot water serves to reduce $\mathrm{Tl}$ (III) to $\mathrm{TI}(\mathrm{I})$. Reduction of $\mathrm{Tl}$ (I) to the metallic state requires a strong reducing agent.

The thallous ion behaves somewhat like potassium and somewhat like the plumbous ion. Thus, the oxide readily absorbs water to form a soluble hydroxide exhibiting the properties of a strong base. The chloride, bromide, iodide, sulfide, and chromate are sparingly soluble. The chloride, like plumbous chloride, is soluble in hot water, but thallous iodide frequently serves as a quantitative precipitate.

The NAS-NS series publication on the "Radiochemistry of Thallium" has not yet been issued.

$$
\text { Thalium - Counting }
$$

Thallium-204 decays by negatron emission (98\%) and by electron capture ( $2 \%$ ). The maximum beta energy is $0.765 \mathrm{MeV}$, hence attention must be paid to selfadsorption in counting solid samples. No gamma rays are emitted in association with the beta decay. The electron capture decay leads to X-ray emission of low intensity.

The nuclear radiations of the thallium isotopes are described in Nuclear Data Sheets (National Academy of Sciences - National Research Council), and ref. 16.

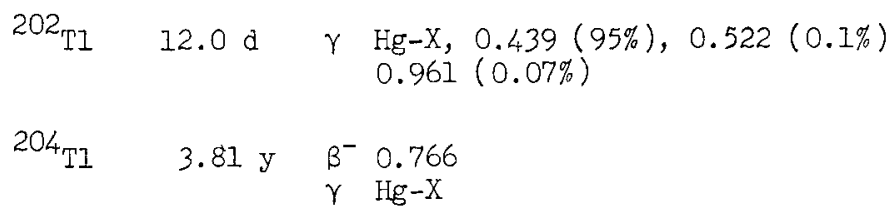


The most stable oxidation state in aqueous solution for polonium is +4 . In alkaline, neutral, and weakly acid solutions, polonium forms radiocolloids. Careful purification of reagents can diminish this radiocolloidal formation. Polonium hydrolyzes even in dilute acid $(<0.1 \mathrm{~N}$ ) and is adsorbed on glass walls from which it is difficult to remove even with acid washing. Solutions containing polonium should be at least $1 \mathrm{~N}$ in acidity; when this is not feasible, glass vessels with paraffin coatings may be used. Polyethylene may prevent losses of polonium, but there are indications that, over long periods of time, the walls of polyethylene containers act as semi-permeable membranes.

Care must be exercised with halide solutions as polonium halides are rather volatile. When milligram amounts of polonium are involved, the high specific activity ( 4.5 curies per $\mathrm{mg}$ ) of the alpha particle emission causes radiation effects. For example, the crystal structure of solid compounds of polonium may be destroyed or altered and organic complexing agents and solvents may undergo radiation decomposition.

Polonium is spontaneously deposited on silver from dilute $\mathrm{HNO}_{3}$ or $\mathrm{HCl}$, on nickel from dilute $\mathrm{HCl}$, on bismuth from $\mathrm{HCl}$ or $\mathrm{H}_{2} \mathrm{SO}_{4}$, and on platinum and palladium from dilute HCl. However, since the deposition potential for bismuth is close to that of polonium, $210_{B i}$ ( $R a E$ ) is also deposited in many cases. Electrodeposition with controlled potential can avoid codeposition of $210 \mathrm{Bi}$.

Care must be exercised in preparing solid counting samples of polonium to prevent volatilization. Since the nitrate and the oxide of polonium are much less volatile than the halides, evaporation of $\mathrm{FNO}_{3}$ solutions is recommended. The solid samples should not be flamed nor heated excessively. Spreading of dried sources is a common problem.

While handling polonium, safety precautions must be rigorously observed since the maximum permissible body burden for ingested 210po is only $0.02 \mu \mathrm{Ci}$. Therefore, all work should be done in good glove boxes.

For further details, see P. E. Figgins, "The Radiochemistry of Polonium," USAEC Report NAS-NS-3037 (1961).

$$
\text { Polonium - Counting }
$$

The counting of 210 o presents no special problems. It decays by emission of a 5. $31 \mathrm{MeV}$ alpha particle which is counted readily by ionization chambers, proportional counters, zinc sulfide crystals, and solid state detectors. The ratio of decay by the $0.80 \mathrm{MeV}$ gamma ray to the alpha decay is $1.2 \times 10^{-5}$, hence large amounts of 210 Po can be measured by counting the gamma ray.

The nuclear radiations of the polonium isotopes are described in Nuclear Data Sheets (National Academy of Sciences - National Research Council), and ref. 16.

$$
\begin{array}{rll}
210_{\text {Po }} 138.40 \mathrm{~d} \quad & \alpha 5.305 \\
& \gamma 0.803(0.0011 \%)
\end{array}
$$


Radon is the heaviest of the inert gasses. It condenses at $-62^{\circ} \mathrm{C}$. Radon is much more soluble in oils, greases, and most organic solvents than in water; greased stoppers, for example, may therefore become heavily contaminated. Twothirds of the a-activity and most of the gamma activity associated with radon are due to its short-lived daughters which are not gaseous and hence deposit on container walls.

Environmental radon $\left(22 \mathrm{Fn}_{\mathrm{n}}\right.$ ) is usually collected on charcoal in a dry iceether bath $\left(-73^{\circ} \mathrm{C}\right.$ ), and released by heating the charcoal to $450^{\circ} \mathrm{C}$. It may be purified of other inert gasses as well as oxygen and nitrogen by pumping from a liquid oxygen trap. Thoron $\left(22 \mathrm{Rn}_{\mathrm{Rn}}\right.$ ) and actinon ( $\left.219_{\mathrm{Rn}}\right)$ are too short-lived $(<1 \mathrm{~m})$ to affect radon measurements.

For radon handling techniques, a book such as "Radon, Its Technique and Use," by Jennings and Russ (John Murray, London, 1948) should be consulted. For further details, see "The Radiochemistry of the Rare Gasses," by F. F. Momyer, Jr., USAEC Report NAS-NS-3025 (1960).

Radon - Counting

\section{(1) Low Level}

The most sensitive method for assaying radon at the nanocurie level or lower is by counting in the a proportional region or with $\mathrm{ZnS}$ scintillator. The counter may be calibrated with radium standards prepared specifically for radon analysis. These are solution standards containing $10^{-9}$ or $10^{-11} \mathrm{~g}$ of radium from which the radon is removed by gas sweeping. The standards may be reused after equilibrium is restored ( $\sim$ month) or sooner if the appropriate correction is applied. Since it takes about 3 hours for the $214 \mathrm{~Pb}$ and $214 \mathrm{Bi}$ daughters to grow to equilibrium, the alpha count rate must be corrected for non-equilibrium of the 164- sec 214 Po daughter of $214 \mathrm{Bi}$, unless there is a delay of 3 hours between filling the counter with radon and counting it. Alpha particles from 3.8-day $222 \mathrm{Rn}$, 3-min $218 \mathrm{Po}$, and $214 \mathrm{Po}$ contribute to the count rate. Those from $222 \mathrm{Rn}$ are usually uniformly distributed throughout the gas volume while the others are usually deposited on surfaces, hence the counter efficiency is difficult to compute from the geometry and must be obtained by counting a standard.

\section{(2) Higher Levels}

Radon is usually used in the form of sealed "seeds" which may be compared directly with $226_{\mathrm{Ra}}$ standards by gamma-ray spectroscopy or ion chamber measurements, since nearly all the gamma radiation from $226 \mathrm{Ra}$ standards follows the decay of RaB and RaC. Radon is essentially in equilibrium with 27 -min RaB about 3 hours after preparation of the source. In solutions of ${ }^{226} \mathrm{Ra}$, the ${ }^{222} \mathrm{Rn}$ and daughters are usually unevenly distributed between aqueous and gas phases.

The nuclear radiations of the radon isotopes are described in Nuclear Data Sheets (National Academy of Sciences - National Research Council), and ref. 16.

$$
\begin{aligned}
& 222_{R n} \quad 3.82 \text { d } \quad \alpha 5.49 \\
& \text { y } 0.510(0.07 \%) \\
& \text { [ }{ }^{218} \text { Po daughter radiations] }
\end{aligned}
$$


The chemical behavior of radium is similar to that of barium, which is commonly used as a carrier for separation procedures. Sulfate and carbonate form insoluble radium salts and must be excluded from standard solutions; for example, if glassware contains sulfate or $\mathrm{CO}_{2}$ enters a basic radium solution, radium will behave radiocolloidally, settling in solution and depositing on container walls. Since the first daughter product of $226 \mathrm{Ra}$ decay is the inert gas radon $\left({ }^{222} \mathrm{Rn}\right)$ with its own $\alpha$-half-life of 3.8 days, and subsequent radioactive decay products include lead, bismuth, and polonium, source preparation requires careful consideration of radioactive equilibrium conditions and chemical behavior of these daughters. Salts of radium as solid sources will always emanate radon to some extent. Heating the source to a high temperature will not necessarily remove all the radon but may well remove a large fraction of polonium. Radon contamination of counters due to emanation of strong radium sources can be a severe problem.

In sealed sources of radium, the container can develop leaks because of the pressure build up from the formation of helium (i.e., alpha particles) and radiation damage.

For further details, see "The Radiochemistry of Radium," by H. W. Kirby and M. L. Salutsky, USAEC Report NAS-NS-3057 (1964).

Radium - Counting

Because of the difficulties arising from the emanation of radon, gross alpha, beta or gamma counting of open radium sources is often not practicable. With thin sources, alpha pulse analysis permits direct determination of radium in the presence of the daughter activities. With strong sources, the emanation may seriously contaminate the detector.

The emanation method for determining radium involves the removal of the radon from the radium solution by sweeping radon from a radium solution and counting the collected radon. Errors may arise if insoluble salts (e.g., sulfate, carbonate) are accidentally precipitated in the radium solution since the radon can then not be quantitatively removed.

Larger quantities of radium can best be determined by comparison of the gamma-ray emission from sealed samples with that from a known radium standard. The equilibrium conditions must be known and it is usually necessary to filter out the beta radiation.

Gamma ray $226_{\mathrm{Ra}}$ standards are sealed to prevent escape of radon gas $\left(222_{\mathrm{Rn}}\right)$. When aliquoting Ra solutions for comparison, most of the Rn usually escapes so it is necessary to seal the aliquot and let it reach equilibrium ( $\sim$ month) since most of the gamma ray emission follows the decay of $\mathrm{RaB}$ $(214 \mathrm{~Pb})$ and $\operatorname{RaC}(214 \mathrm{Bi})$. (Alternatively the growth of activity may be followed and extrapolated to equilibrium.) Within the sealed ampoule, radium and its daughters are not uniformly or identically distributed if aqueous and gas phases exist: radium is usually in solution, radon is in both gas and liquid, and radon daughters are on the container walls. Radium-226 solutions do not normally contain 22-year $\mathrm{RaD}(21 \mathrm{OPb})$ and its daughters in equilibrium with $226_{\mathrm{Ra}}$, but this is unimportant for gamma ray spectrometry or for ion chamber measurements which discriminate against the beta rays and $46 \mathrm{keV}$ gamma rays from RaE $\left(21 \mathrm{OBi}^{\mathrm{B}}\right.$.

The nuclear radiations of the radium isotopes are described in Nuclear Data Sheets (National Academy of Sciences - National Research Council), and ref. 16. 
$88^{\operatorname{Ra}}$ (cont'd.)

${ }^{224} \mathrm{Ra} \quad 3.64 \mathrm{~d} \quad \alpha \quad 5.68(94 \%), 5.45(6 \%)$

$\gamma \mathrm{Rn}-\mathrm{X}, 0.241(3.7 \%)$, others

$\left[{ }^{220} \mathrm{Rn},{ }^{216} \mathrm{Po},{ }^{212} \mathrm{~Pb}\right.$ daughter radiations]

${ }^{226} \mathrm{Ra} \quad 1602$ y $\quad \alpha \quad 4.78(95 \%), 4.60(6 \%)$

$\gamma \mathrm{Rn}-\mathrm{X}, 0.186(4 \%)$, others

[222 $\mathrm{Pn},{ }^{218} \mathrm{Po},{ }^{214} \mathrm{~Pb},{ }^{214} \mathrm{Bi},{ }^{214} \mathrm{Po}$ daughter radiations]

${ }^{228} \mathrm{Ra} \quad 5.75$ y $\quad$ B 0.05

B 0.05
[daughter radiations from ${ }^{228} \mathrm{Ac},{ }^{228} \mathrm{Th},{ }^{224} \mathrm{Ra}$ etc.] 
Thorium exists exclusively as Th(IV) in aqueous solutions so redox problems need not be considered. In the solubility of its compounds, Th(IV) resembles tetravalent cerium: halides, nitrate, and perchlorate are soluble whereas the fluoride, iodate, hydroxide, and oxalate are insoluble. Hydrolysis of thorium in solutions is negligible below pH 3 but becomes serious as the pH increased.

Very insoluble thorium peroxide precipitates when $\mathrm{H}_{2} \mathrm{O}_{2}$ is added to a dilute mineral acid solution of thorium. This precipitation provides a clean separation of thorium from most other elements. Solvent extraction with TTA and TBP and ion exchange also provide excellent separations of thorium.

Thorium-232 is the longest-lived member of the $4 \mathrm{n}$ radioactive family. The older the sample, the greater the need to consider the possibility of contributions to the observed count rate by daughter activities.

For further details, see "The Radiochemistry of Thorium," by E. K. Hyde, USAEC Report NAS-NS-3004 (1960).

$$
\text { Thorium - Counting }
$$

Thorium-232 is measured by counting its alpha particles. The usual precautions concerning preparation of very thin and uniform samples for alpha counting must be observed. Freshly separated thorium usually consists of two alpha-particle emitters, $1.39 \times 10^{10}$-year $232 \mathrm{Th}$ and 1.90 -year $228 \mathrm{Th}$. The two do not necessarily occur in equal amounts because $232 \mathrm{Th}$ decays to $228 \mathrm{Th}$ through $5.75-y e a r$ $228 \mathrm{Ra}$ and 6.1 -hour $228 \mathrm{Ac}$, and removal of $228 \mathrm{Ra}$ can decrease the amount of $228 \mathrm{Th}$. The ingrowth of 3.64-day 224Ra and its daughters adds 5 alpha emitters; if all of these were in equilibrium with $228 \mathrm{Th}, 5$ alpha particles would be emitted per disintegration of $228 \mathrm{Th}$.

The continuous emanation of $54-\mathrm{sec} 220 \mathrm{Rn}$ can lead to the deposition of 10.6-hour $212 \mathrm{~Pb}, 60-\mathrm{min} 212 \mathrm{Bi}, 3.0 \times 10^{-7}-\mathrm{sec} 212 \mathrm{Po}$, and $3.1-\mathrm{min} 208 \mathrm{Tl}$ in counters and on other surfaces.

The nuclear radiations of the thorium isotopes are described in Nuclear Data Sheets (National Academy of Sciences - National Research Council), and ref. 16.

$$
\begin{aligned}
& 226 \text { Th } 30.9 \mathrm{~m}\left({ }^{238} \mathrm{U} \text { daughter }\right) \propto 6.34(79 \%), 6.22(19 \%) \\
& \gamma \operatorname{Ra}-\mathrm{X}, 0.111(3.4 \%), 0.131(0.34 \%) \\
& 0.20,0.242(1.2 \%)
\end{aligned}
$$

$$
\begin{aligned}
227 \mathrm{Th} 18.2 \mathrm{~d}\left({ }^{235} \mathrm{U} \text { daughter }\right) & \alpha 6.04(23 \%), 5.98(24 \%), 5.76(21 \%), 5.72 \text { (14\%, } \\
& \mathrm{d}) \\
& \gamma \mathrm{Ra}-\mathrm{X}, 0.050(8 \%), 0.237(15 \% \text { complex), } \\
& 0.31(8 \% \text { comp })
\end{aligned}
$$

$$
\begin{aligned}
& 228_{\mathrm{Th}} \quad 1.910 \mathrm{y}\left({ }^{232} \mathrm{U} \text { daughter }\right) \propto 5.43(71 \%), 5.34(28 \%) \text {, } \\
& \text { Y Ra-L-X, } 0.084(1.6 \%), 0.132(0.2 \%) \text {, } \\
& 0.167(0.1 \%), 0.214(0.3 \%)
\end{aligned}
$$

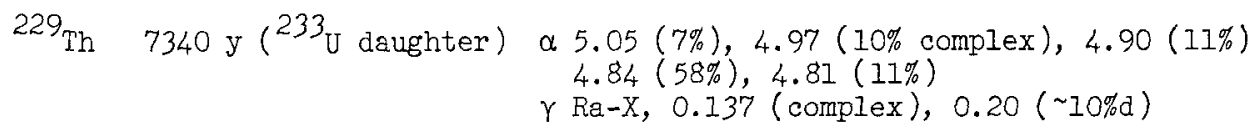


$90^{\mathrm{Th}}$ (cont'd.)

230 Th $8.0 \times 10^{4} \mathrm{y}(238 \mathrm{U}$ daughter) $\propto 4.68(76 \%), 4.62(24 \%)$

$\gamma \operatorname{Ra}-\mathrm{L}-\mathrm{X}, 0.068(0.6 \%), 0.142(0.07 \%), 0.184$ $(0.014 \%), 0.253(0.017 \%)$

${ }^{231_{T h}} 25.52 \mathrm{~h}\left({ }^{235} \mathrm{U}\right.$ daighter $) \quad B^{-} 0.30$

$\gamma \mathrm{Pa}-\mathrm{X}, 0.026(2 \%), 0.084(10 \%$, complex $)$

$232 \mathrm{Th} \quad 1.41 \times 10^{10} \mathrm{y}$

$\begin{array}{ll}\alpha & 4.01(76 \%), 3.95(24 \%) \\ \gamma & \operatorname{Ra}-\mathrm{L}-\mathrm{X}\end{array}$

${ }^{234}$ Th $24.10 \mathrm{~d}\left({ }^{238} \mathrm{U}\right.$ daughter $) \quad B^{-} 0.191$

$\gamma$ Pa-L-X, $0.063(3.5 \%), 0.093(4 \%)$

[ ${ }^{234 \mathrm{~m}} \mathrm{~Pa}$ daughter radiations] 
Uranium can exist in aqueous solutions in the tri-, tetra-, penta-, and hexavalent states. In the latter two cases, the cationic species is represented as $\mathrm{UO}_{2}{ }^{+1}$ and $\mathrm{UO}_{2}{ }^{+2}$. U(III) is unstable with respect to oxidation to U(IV). $\mathrm{U}(\mathrm{IV})^{2}$ solutions are stable in the absence of air but undergo hydrolysis as the $\mathrm{pH}$ increases above $3 . \mathrm{UO}_{2}^{+}$is unstable in solution to disproportionation to $\mathrm{U}(\mathrm{VI})$ and $\mathrm{U}(\mathrm{IV})$. The uranyl ion, $\mathrm{UO}_{2}^{+2}$, is the most stable in aqueous solution. The nitrate, halides (including fluoride), sulfate, many organic acid salts, and such double salts as sodium uranyl carbonate are soluble. Uranyl nitrate hexahydrate is also soluble in a number of organic solvents such as ethers, esters, and ketones.

Uranyl solutions can be treated with $\mathrm{NH}_{4} \mathrm{OH}$, acid solutions of peroxides, or phosphates to precipitate the uranium. Alternately, the uranyl ion can be reduced with $\mathrm{Zn}+\mathrm{HCl}$ for subsequent precipitation of UF,. Many separation techniques utilizing ion exchange or solvent extraction are described in the literature. Electrodeposition, vacuum sublimation, painting solutions in organic solvents, electrospraying and direct evaporation of an aliquot of aqueous solutions using a spreading agent such as tetraethyleneglycol (TEG) are used in sample preparation.

For further details, see "The Radiochemistry of Uranium," by J. E. Gindler, USAEC Report NAS-NS-3050 (1952).

Uranium - Counting

Uranium-234, -235, and -238 all decay by alpha emission. The energies of their alpha particle groups are resolvable easily by alpha-particle spectrometry using a solid state detector or a Frisch grid chamber. Uranium-235 can be detected by gamma counting. For alpha counting, thin and uniform samples are necessary. In "pure" samples of $235 \mathrm{U}$ and $238 \mathrm{U}$, the growth of the alpha-decaying members of the decay chains $(231 \mathrm{~Pa}$ and $234 \mathrm{U})$ is sufficiently rapid to affect the gross alpha count rate. Since $234 \mathrm{U}, 235 \mathrm{U}$, and $238_{\mathrm{U}}$ are isotopic, chemical separation is impossible and alpha spectrometry is necessary to obtain accurate measurements of the decay rate of specific nuclides. On the basis of genetic relations, $234 \mathrm{U}$ would be expected to occur in a sample with the same decay rate as $238 \mathrm{U}$; however, differences occur because of the different chemical states (and hence, solubilities) of the two isotopes in nature, or because of physical separation by man.

The nuclear radiations of the uranium isotopes are described in Nuclear Data Sheets (National Academy of Sciences - National Research Council), and ref. 16.
$232 \mathrm{U} \quad 72 \mathrm{y}$
( ${ }^{232} \mathrm{~Pa}$ daughter)
a $5.32(68 \%), 5.27(32 \%)$
$\gamma$ Th-L-X, $0.058(0.21 \%), 0.129(0.082 \%)$, $0.270(0.004 \%), 0.328(0.003 \%)$
$233 \mathrm{U} \quad 1.62 \times 10^{5} \mathrm{y}$
$\alpha 4.82(83 \%), 4.78(15 \%)$
$\gamma$ Th-X, complex
${ }^{234} \mathrm{U} \quad 2.47 \times 10^{5} \mathrm{y}\left({ }^{238} \mathrm{U}\right.$ daughter $)$
$\alpha 4.77(72 \%), 4.72(28 \%)$
$\gamma \mathrm{Th}-\mathrm{L}-\mathrm{X}, 0.053(0.2 \%)$, others, complex 


$$
92^{\mathrm{U}}(\text { cont'd. })
$$

$235 \mathrm{U} \quad 7.04 \times 10^{8} \mathrm{y}$

$236 \mathrm{U} 2.39 \times 10^{7} \mathrm{y}$

$238 \mathrm{U} \quad 4.47 \times 10^{9} \mathrm{y}$ $\alpha 4.58(8 \%, \mathrm{~d}), 4.40(57 \%), 4.37(18 \%)$

$\gamma \mathrm{Th}-\mathrm{X}, 0.143(11 \%), 0.185(54 \%)$, $0.204(5 \%)$

$\alpha 4.49(76 \%), 4.44(24 \%)$

$\gamma$ Th-L-X

$\alpha 4.20(75 \%), 4.15(25 \%)$

$\gamma$ Th-L-X 
Neptunium can occur in the III, IV, V, and VI oxidation states in aqueous solution. $\mathrm{Np}(\mathrm{V})$ and $\mathrm{Np}(\mathrm{VI})$ exist as $\mathrm{NpO}_{2}^{+1}$ and $\mathrm{NpO}_{2}^{+2}$, respectively. Solutions of $\mathrm{Np}$ (III) and $\mathrm{Np}$ (IV) are unstable with respect to oxidation to $\mathrm{NpO}_{2}{ }^{+1}$ in the presence of nitrate or atmospheric oxygen. $\mathrm{Np}(\mathrm{IV})$ is quite stable in sulfuric acid as a result of complex formation. $\mathrm{NpO}_{2}+1$ is stable in non-complexing acid media unless the solution is very acid. $\mathrm{NpO}_{2}^{2}+2$ is reduced to $\mathrm{NpO}_{2}+1$ by hydrazine, iodide, oxalate, sulfite, and $\operatorname{Sn}(I I)$.

Like uranium and plutonium, neptunium forms an insoluble, flocculent peroxide. Insoluble di-neptunates form on addition of $\mathrm{NaOH}$ or $\mathrm{NH}, \mathrm{OH}$ to $\mathrm{NpO}_{2}^{+2} \mathrm{sol}_{-}$ utions. Trace concentrations of neptunium can be coprecipitated from aqueous solutions with certain carrier compounds. $\mathrm{LaF}_{3}$ is an excellent carrier of $\mathrm{Np}$ (IV) and $\mathrm{Np}(\mathrm{V})$ but not $\mathrm{Np}(\mathrm{VI})$. $\quad \mathrm{Zr}_{3}\left(\mathrm{PO}_{4}\right)$, carries $\mathrm{Np}(\mathrm{IV})$ but not $\mathrm{Np}$ (III) or $\mathrm{Np}$ (VI). Sodium uranyl acetate is the preferred carrier for $\mathrm{Np}$ (VI). Neptunium may also be isolated and purified from other elements by a variety of ion exchange and solvent extraction techniques.

For further details, see "The Actinide Elements," by J. J. Katz and G. T. Seaborg, Wiley (1957).

Neptunium - Counting

Neptunium-237 can be counted by either alpha or gamma detection techniques. Samples must be thin and uniform for alpha counting. Older samples of $237 \mathrm{~Np}$ may have $233 \mathrm{U}$ present which would add to the gross alpha count rate. Chemical purification or alpha spectrometry can overcome this difficulty.

The nuclear radiations of the neptunium isotopes are described in Nuclear Data Sheets (National Academy of Sciences - National Research Council), and ref. 16.

$\begin{aligned}{ }^{235} \mathrm{~Np} \quad 410 \mathrm{~d} & \text { e. c. }(99+\%) \\ & \alpha(1.6 \times 10-3 \%) 5.02 \\ & \gamma \mathrm{U}-\mathrm{L}-\mathrm{X}, \mathrm{U}-\mathrm{K}-\mathrm{X} \text { (weak) }\end{aligned}$

${ }^{237} \mathrm{~Np} 2.14 \times 10^{6}$ y a $4.78(75 \%$, complex $), 4.65(12 \%, \mathrm{~d})$

$\gamma \mathrm{Pa}-\mathrm{L}-\mathrm{X}, 0.030(14 \%), 0.086(14 \%), 0.145(1 \%)$

$\begin{array}{rlll}239 \mathrm{~Np} \quad 2.346 \mathrm{~d} \quad B^{-} & 0.713(11 \%), 0.437 \\ & \gamma & P u-X, 0.106(23 \%), 0.209(4 \%), 0.228(12 \%), 0.278(14 \%)\end{array}$ 
Plutonium may be prepared in any of several positive oxidation states, the most common of which is the +4 state. This oxidation state is usually strongly complexed in solution, of ten forming an anionic species. Plutonium is commonly commercially available as the nitrate complex in a solution 3-4 M in nitric acid. Care must be taken to maintain plutonium in acid solution or, if precipitation in basic solution is desired, to use excess reagent. This avoids the formation of a plutonium-oxygen (hydroxide) polymer which is often quite difficult to break up and exhibits properties decidedly dissimilar to true solutions of plutonium. Among the undesirable properties of this polymer are a strong tendency to adsorb on glass, quartz, or paper, and non-adsorptivity on cationexchange resins. The chemistry of plutonium is very extensive and much research is detailed in the literature. For further details, see "The Radiochemistry of Plutonium" by G. H. Coleman, NAS-NS-3058 (1965).

\section{Plutonium - Counting}

Solutions of plutonium which are to be mounted as count-rate standards need only be evaporated or precipitated with as little mass as possible onto a suitable counting planchet. However, even solution evaporation of ten results in sources too thick to be used as alpha-decay energy standards, sinee very little mass is required to degrade the energy of the alpha particles. For this reason, energy standards are best prepared as very thin sources by either vacuum flash-volatilization of plutonium or electroceposition of plutonium onto a counting plate from a suitable electrolyte such as a solution of $\mathrm{NH}_{4} \mathrm{Cl}$. Samples of $\mathrm{Pu}-239$ usually contain a small percentage by weight of Pu-240. These two isotopes are indistinguishable by ordinary alpha pulse-height analysis, because their main alpha-decay groups are so similar in energy.

The radiation of the plutonium isotopes are described in ref. 16.

$\begin{array}{ccccc}{ }^{236} \mathrm{Pu} & 2.85 \mathrm{y} & \alpha & 5.767(69 \%), 5.720(31 \%) \\ { }^{238} \mathrm{Pu} & 87.8 \mathrm{y} & \alpha & 5.499(71 \%), 5.455(29 \%) \\ 239 \mathrm{Pu} & 2.439 \times 10^{4} \mathrm{y} & \alpha & 5.155(73 \%), 5.143(15 \%), 5.110(11.5 \%) \\ 240 \mathrm{Pu} & 6500 \mathrm{y} & \alpha & 5.168(76 \%), 5.123(24 \%) \\ 241 \mathrm{Pu} & 14.8 \mathrm{y} & \begin{array}{l}\mathrm{B}^{-}(99+\%) 0.021 \\ \end{array} & \alpha & 4.90(83 \%), 4.86(12 \%) \\ 242 \mathrm{Pu} & 3.87 \times 10^{5} \mathrm{y} & \alpha & 4.900(79 \%), 4.856(21 \%)\end{array}$


Americium, except under strong oxidizing conditions, occurs only in tripositive form in aqueous media. Its properties are very similar to those of trivalent rare earths. The nitrate, halides, sulfate, sulfide, and perchlorate are soluble while the fluoride, oxalate, and hydroxide are insoluble. $\mathrm{La}$ (III) serves as an excellent carrier for Am(III). If alpha counting is used, the La(III) must be separated, usually by elution with a solution of saturated $\mathrm{HCl}$ from cation exchange resin. Fe(III) serves as a good carrier in precipitating the hydroxide. Subsequently, the $\mathrm{Fe}$ (III) is easily separated in $6 \mathrm{~N}$ HCl solution by solvent extraction with ethyl ether or elution from anion exchange resin.

Thin sources for alpha counting may be prepared by evaporation of pure samples in mineral acid solution or by anodic deposition of the hydrous oxide although the yield in the latter method is not quantitative. Very thin sources can be prepared by vacuum volatilization with relatively low yields.

For further details, see "The Radiochemistry of Americium and Curium," by R. A. Penneman and T. K. Keenan, USAEC Report NAS-NS-3006 (1960).

$$
\text { Americium - Counting }
$$

If americium-241 is to be counted for its alpha decay, massless samples are necessary to avoid self-absorption. Backscattering adds several percent to the counting efficiency. Americium-241 can also be counted by the $59.6 \mathrm{keV}$ gamma ray. Coincidence counting of the alpha emission of $5.477 \mathrm{MeV}$ and the $59.6 \mathrm{keV}$ gamma ray will yield the total disintegration rate.

The nuclear radiations of the americium isotopes are described in Nuclear Data Sheets (National Academy of Sciences - National Research Council), and ref. 16.

$$
\begin{aligned}
& { }^{241} \mathrm{Am} \quad 433 \mathrm{y} \quad \alpha \quad 5.49(85 \%), 5.44(13 \%) \\
& \gamma \text { Np-L-X, } 0.060(36 \%), 0.101(0.04 \% \text {, complex), others } \\
& \begin{array}{rlll}
242 \mathrm{Am} \quad 16.01 \mathrm{~h} & B^{-} & 0.67 \\
& & \gamma & \text { Pu-X, Cm-L-X }
\end{array} \\
& 242 \mathrm{~m}_{\mathrm{Am}} \quad 152 \mathrm{y} \quad \alpha \quad 5.21(0.41 \%) \\
& \gamma \text { Am-L-X, Np-X, } 0.049(0.20 \%) \text {, others } \\
& { }^{243} \text { Am } 7.95 \times 10^{3} \text { y } \alpha 5.28(87 \%), 5.23(11.5 \%) \\
& \gamma \mathrm{Np}-\mathrm{L}-\mathrm{X}, 0.044(4 \%), 0.075(50 \%)
\end{aligned}
$$




\section{NUCLEAR SCIENCE ABSTRACTS}

Nuclear Science Abstracts is a semimonthly publication of the USAEC Office of Information Services and is published by the USAEC Technical Information Center. Nuclear Science Abstracts provides the only comprehensive abstracting and indexing coverage of the international nuclear science literature. It covers scientific and technical reports of the U.S. Atomic Energy Commission and its contractors, other U. S. Government agencies, other governments, universities, and industrial and research organizations. In addition, books, conference proceedings, individual conference papers, patents, and journal literature on a worldwide basis are abstracted and indexed. Each issue of Nuclear Science Abstracts includes four indexes: subject, personal author, corporate author, and report number.

\section{Availability}

Nuclear Science Abstracts is available on subscription from the Superintendent of Documents, U.S. Government Printing Office, Washington, D.C. 20402. For the two 12 -issue volumes per calendar year, the annual subscription rate is $\$ 75.50$ for domestic subscribers and $\$ 94.50$ for foreign subscribers. A single issue costs $\$ 3.25$ domestic rates or $\$ 4.07$ foreign rates. Domestic rates apply to the United States, Canada, Mexico, and Central and South American countries except Argentina, Brazil, Guyana, French Guiana, Surinam, and British Honduras.

Indexes are cumulated only for each 12 -issue volume, i.e., for each six-month volume. The price of each volume index is $\$ 35.70$ for domestic subscribers and $\$ 45.10$ for foreign subscribers.

Nuclear Science Abstracts is available on an exchange basis to universities, research institutions, industrial firms, and publishers of scientific information. Government agencies may obtain NSA free of charge. Inquiries should be directed to the USAEC Technical Information Center, P. O. Box 62, Oak Ridge, Tennessee 37830.

Nuclear Science Abstracts is also available on $16-\mathrm{mm}$ and $35-\mathrm{mm}$ microfilm in reel or cartridge from Princeton Microfilm Corporation, Alexander Road, Princeton, New Jersey 08540. The cost of each volume (six months) of NSA and its indexes is $\$ 45.00$. The cost of Vols. 1-26 (1948-1972) including Abstracts of Declassified Documents (1947-1948) is $\$ 730.00$. The indexes for $N S A$ volumes $1-26(1948-1972)$ can be bought for $\$ 385.00$. 


\section{NUCLEAR SCIENCE SERIES: MONOGRAPHS ON RADIOCHEMISTRY AND RADIOCHEMICAL TECHNIQUES}

See the back of the title page for availability information

\section{ELEMENTS}

Recent Radiochemical Separation Procedures for As, At, Be, Mg, Ni, Ru, and Se, NAS.NS: 3059 [1974]

Aluminum and Gallium, NAS-NS-3032 [1961]

Americium and Curium, NAS-NS-3006 [1960]

Antimony, NAS-NS-3033 [1961]

Arsenic, NAS-NS-3002 (Rev.) [1965)

Astatine, NAS-NS-3012 [1960]

Barium, Calcium, and Strontium, NAS-NS-3010 [1960]

Beryilium, NAS-NS-3013 [1960]

Cadmium, NAS-NS-3001 [1960]

Carbon, Nitrogen, and $\mathrm{O} x y$ gen, NAS-NS-3019 [1960]

Cesium, NAS.NS-3035 [1961]

Chromium, NAS-NS-3007 (Bev.) [1963]

Cobait, NAS-NS-3041 [1961]

Copper, NAS-NS-3027 [1961]

Fluorine, Chlorine, Bromine, and lodine, NAS-NS-3005 [1960]

Francium, NAS-NS-3003 [1960]

Germanium, NAS-NS-3043 [1961]

Gold, NAS.NS.3036 [1961]

Indium, NAS-NS-3014 [1960]

Iridium, NAS-NS-3045 [1961]

Iron, NAS-NS-3017 [1960]

Lead, NAS-NS-3040 [1961]

Magnesium, NAS-NS-3024 [1961]

Manganese, NAS-NS-3018 (Rav.) [1971]

Mercury. NAS-NS-3026 (Rev.) [1970]

Molybdenum, NAS-NS-3009 [1960]

Nickel, NAS-NS-3051 [1961]

Niobium and Tantalum, NAS-NS-3039 [1961]

Osmium, NAS.NS-3046 [1961]

Palladium, NAS-NS-3052 [1961]

Phosphorus, NAS-NS-3056 [1962]

Platinum, NAS-NS-3044 [1961]

Plutanium, NAS-NS-3058 [1965]

Polonium, NAS-NS-3037 [1961]

Potassium, NAS-NS-3048 [1961]

Protactinium, NAS-NS-3016 [1959]

Radium, NAS-NS-3057 [1964]

Rare Earths - Scandium, Yttrium, and

Actinium, NAS-NS-3020 [1961]

Rare Gases, NAS-NS-3025 [1960]

Rhenium, NAS-NS-3028 [1961]

Rhodium, NAS-NS-3008 (Rev.) [1965]

Rubidium, NAS-NS-3053 [1962]

Ruthenium, NAS-NS-3029 [1961]

Selenium, NAS-NS.3030 (Rev.) [1965]

Silicon, NAS-NS.3049 (Rev.) [1968]
Silver, NAS-NS-3047 [1961]

Sodium, NAS-NS-3055 [1962]

Sulfur, NAS-NS-3054 [1961]

Technetium, NAS-NS-3021 [1960]

Tellurium, NAS-NS-3038 [1960]

Thorium, NAS-NS.3004 [1960]

Tin, NAS-NS-3023 [1960]

Titanium, NAS-NS-3034 (Rev.) [1971]

Transcurium Elements, NAS-NS-3031 [1960]

Tungsten, NAS.NS-3042 [1961]

Uranium. NAS-NS-3050 [1961]

Vanadium, NAS-NS-3022 [1960]

Zinc, NAS-NS-3015 [1960]

Zirconium and Hafnium, NAS-NS-307] [1960]

\section{TECHNIQUES}

Absolute Measurement of Alpha Emission and Spantaneous Fission, NAS-NS-3112 [1968]

Activation Analysis with Charged Particles, NAS-NS-31 10 [1966]

Applications of Computers to Nuclear and Radiochemistry, NAS.NS-3107 [1962]

Application of Distillation Techniques to Radiochemical Separations, NAS-NS-3108 [1962]

Cation-Exchange Techniques in Radiochemistry. NAS-NS-3113 [1971]

Chemical Yield Determinations in Radiochemistry. NAS.NS-3111 [1967]

Detection and Measurement of Nuclear Radiation, NAS.NS-3105 [1961]

Liquid-Liquid Extraction with HighMolecular-Weight Amines, NAS-NS.3101 [1960]

Low-Level Radiochemical Separations, NAS.NS-3103 [1961]

Neutron Activation Techniques for the Measurement of Trace Metals in Environmental Samples, NAS-NS-3114 [1974]

Paper Chromatographic and Electromigration Techniques in Radiochemistry, NAS.NS3106 [1962]

Processing of Counting Data, NAS-NS-3t09 [1965]

Rapid Radiochemical Separations, NAS-NS. 3104 [1961]

Separations by Solvent Extraction with Tri-n-octyiphosphine Oxide, NAS-NS-3102 [1961]

Users' Guides for Radioactivity Standards, NAS.NS-3115 [1974] 
